\title{
Cranial anatomy of Paleogene Micromomyidae and implications for early primate evolution
}

Jonathan I. Bloch ${ }^{\mathrm{a}}$ (Corresponding author)

${ }^{\mathrm{a}}$ Florida Museum of Natural History, University of Florida, P. O. Box 117800, Gainesville, FL 32611-7800, USA. e-mail: jbloch@flmnh.ufl.edu. phone: 352-273-1938. fax: 352- 846-0287.

Stephen G. B. Chester ${ }^{\text {b,c,d }}$

${ }^{\mathrm{b}}$ Department of Anthropology and Archaeology, Brooklyn College, City University of New York, 2900 Bedford Avenue, Brooklyn, NY 11210, USA.

${ }^{c}$ Department of Anthropology, Graduate Center, City University of New York, 365 Fifth Avenue, New York, NY 10016, USA.

${ }^{\mathrm{d}}$ New York Consortium in Evolutionary Primatology, New York, NY, USA.

e-mail: stephenchester@brooklyn.cuny.edu

Mary T. Silcox ${ }^{\mathrm{e}}$

e Department of Anthropology, University of Toronto Scarborough, 1265 Military Trail, Scarborough, Ontario, M1C 1A4, Canada. e-mail: msilcox@utsc.utoronto.ca

Key Words: Primates; Plesiadapiformes, cranial anatomy

Running Title: micromomyid cranial anatomy 


\begin{abstract}
Paleogene micromomyids are small $(\sim 10-40 \mathrm{~g})$ euarchontan mammals with primate-like molars and postcrania suggestive of committed claw-climbing positional behaviors, similar to those of the extant arboreal treeshrew, Ptilocercus. Based primarily on evidence derived from dental and postcranial morphology, micromomyids have alternately been allied with plesiadapiforms, Dermoptera (colugos), or Primatomorpha (Primates + Dermoptera) within Euarchonta. Partial crania described here of Paleocene Dryomomys szalayi and Eocene Tinimomys graybulliensis from the Clarks Fork Basin of Wyoming are the first known for the family Micromomyidae. The cranium of $D$. szalayi exhibits a distinct, small groove near the lateral extreme of the promontorium, just medial to the fenestra vestibuli, the size of which suggests that the internal carotid artery was non-functional, as has been inferred for paromomyid and plesiadapid plesiadapiforms, but not for Eocene euprimates, carpolestids, and microsyopids. On the other hand, D. szalayi is similar to fossil euprimates and plesiadapoids in having a bullar morphology consistent with an origin that is at least partially petrosal, unlike that of paromomyids and microsyopids, although this interpretation will always be tentative in fossils that lack exhaustive ontogenetic data. Micromomyids differ from all other known plesiadapiforms in having an inflated cochlear part of the bony labyrinth and a highly pneumatized squamosal and mastoid region with associated septa. Cladistic analyses that include new cranial data, regardless of how bullar composition is coded in plesiadapiforms, fail to support either Primatomorpha or a close relationship between micromomyids and dermopterans, instead suggesting that micromomyids are among the most primitive known primates.
\end{abstract}




\section{Introduction}

Despite many exciting new fossil discoveries and increasingly rigorous morphological analyses, in part driven by the advent of new imaging technologies and analytical tools, questions surrounding primate origins are still hotly debated. A few aspects of early primate history are less controversial, however. With the possible exception of the poorly-known Altiatlasius from the late Paleocene of Africa (Sigé et al., 1990; Gheerbrant et al., 1998), the first "unambiguous primates" appear abruptly in the fossil record of Europe, Asia, and North America at the beginning of the Eocene Epoch about 55.8 million years ago (Ni et al., 2004; Smith et al., 2006; Beard, 2008; Rose et al., 2011, 2012), when global temperatures increased by 5-10 degrees Celsius (Zachos et al., 2003). While these early primates (omomyoids Teilhardina brandti, Teilhardina gingerichi, and Teilhardina magnoliana, and adapoid Cantius torresi in North America; omomyoid Teilhardina asiatica in Asia; and omomyoid Teilhardina belgica in Europe) are known mostly from fragmentary dentitions and a few isolated postcrania (e.g., Rose et al., 2011, 2012; Gebo et al., 2012, 2015; but see Ni et al., 2004, 2013), it is still widely accepted, based in large part on the morphology of their better-known descendants (e.g., Gregory, 1920; Beard et al., 1991), that they are "unambiguous primates" by virtue of sharing a common ancestor that presumably had a relatively large brain, enhanced vision related to optical convergence and postorbital bars, leaping specializations as reflected in the ankle morphology, nails instead of claws, and grasping hands and feet. It is also accepted by many (e.g., Gregory, 1920; Gingerich, 1980; Kay et al., 1997; Ni et al., 2004, 2013; Seiffert et al., 2009) that these "unambiguous primates" gave rise to extant haplorhines (Tarsius and Anthropoidea) and strepsirrhines (lemurs, lorises, and galagos), and thus are considered crown-clade primates, or "euprimates." 
But where did euprimates come from so abruptly 55.8 million years ago? To address that question we must look deeper in time, into the Paleocene. It is also understood that the closest living relatives of primates are treeshrews (Scandentia) and colugos (Dermoptera), together classified as Euarchonta (e.g., O'Leary et al., 2013), and that the Paleocene euarchontan fossil record is well-represented by a diversity of fossil taxa traditionally classified in the "Plesiadapiformes" (see Silcox and Gunnell, 2008). What is controversial is whether some or all plesiadapiforms represent an early fossil record of Dermoptera (e.g., Beard, 1990, 1993a; Kay et al., 1992; Ni et al., 2009), Primates (Bloch and Boyer, 2002; Bloch et al., 2007), stem Primatomorpha (Ni et al., 2013), or are perhaps more distantly related to these modern orders (e.g., Wible et al., 2009; but see Chester et al., 2015). While the controversy is largely driven by an understanding that some plesiadapiforms lack certain diagnostic characteristics of crown Primates (see Martin 1968, 1972; Cartmill, 1972, 1974), until relatively recently most of the diversity for this group has been represented by only fragmentary dentitions with very few associated crania or postcrania.

In the last twenty-five years, descriptions of a few fairly complete plesiadapiform skulls and postcranial skeletons have allowed for some reassessment of this question (e.g., Kay et al., 1990, 1992; Beard, 1990, 1993a, b; Bloch and Boyer, 2002; Bloch and Silcox, 2006; Bloch et al., 2007; Boyer and Bloch, 2008; Boyer, 2009; Boyer et al., 2012; Chester, 2013). Cladistic analyses of postcranial (Bloch and Boyer, 2002) and cranial (Bloch and Silcox, 2006) data supported a paraphyletic Plesiadapiformes, with some taxa more closely related to euprimates than others. Results from more comprehensive cladistic analyses that include cranial, postcranial, and dental data provide two competing hypotheses. The first supports Plesiadapiformes as a paraphyletic series of stem primate taxa (e.g., Silcox, 2001, 2008), with 
plesiadapoids as the sister taxon to Euprimates (Euprimateformes; Bloch et al., 2007; Boyer, 2009; Silcox et al., 2010b; Chester et al., 2015). These results have been questioned by some (e.g., Godinot, 2007; Soligo and Martin, 2007; Gebo, 2009), but are supported by cladistic methodology and take into account morphology from all areas of the skeleton in a broad sampling of fossil euarchontans. In this context, it is also worth noting that the dental morphology of Altiatlasius from the late Paleocene of North Africa seems to blur the distinction between certain proposed stem- and crown-primates, with some analyses supporting it as a plesiadapoid (Hooker et al., 1999), others as an omomyoid (Sigé et al., 1990), and still others a stem anthropoid (Seiffert et al., 2005; Beard, 2006; Bajpai et al., 2008; Ni et al., 2013). Results from another analysis with broad character sampling (Ni et al., 2013) also suggest a paraphyletic Plesiadapiformes, but with some microsyopids, together with species often classified in "Plagiomenidae" and "Mixodectidae," in a clade with Dermoptera, and still other microsyopids, together with Mixodectes and plesiadapiforms as a clade that is sister to a Primatomorpha (sensu lato) clade. These two hypotheses are, therefore, in general agreement with regards to inclusion of plesiadapiforms in Euarchonta, but differ on their exact significance to primate origins.

Late Paleocene to early Eocene micromomyids from North America have long been recognized as being among the most primitive plesiadapiforms, with molar morphology similar to those of early Paleocene palaechthonids (Szalay, 1974; Bown and Rose, 1976) and Purgatorius (Fox, 1984; Beard and Houde, 1989). Beard (1989, 1990, 1991, 1993a,b) described the first postcrania attributed to Micromomyidae and suggested that they, together with Paromomyidae, were capable of mitten-gliding behaviors that suggested a shared common ancestor with extant colugos (Dermoptera). The mitten-gliding hypothesis has been challenged based on analyses of new and more complete fossils (Bloch et al., 2007; Boyer and Bloch, 2008), 
and neither of the recent, comprehensively sampled cladistic analyses recovered a special relationship between micromomyids (or paromomyids) and dermopterans (Bloch et al., 2007; Ni et al., 2013). Instead, it has been suggested that the postcranial skeleton of micromomyids is more similar to that of the most plesiomorphic extant treeshrew, Ptilocercus (Bloch and Boyer, 2007; Bloch et al., 2007; Boyer and Bloch, 2008). Therefore, it is perhaps not surprising that micromomyid plesiadapiforms were supported in the Bloch et al. (2007) cladistic analysis as one of the most primitive stem-primate clades. Ni et al. (2013) included only a single micromomyid in their analysis, but it also fell out as a relatively primitive taxon, near the base of Primatomorpha. Recently discovered tarsals of the oldest known euarchontan, Purgatorius, are uniquely similar to those of micromomyids in several ways, which suggests that partial skeletons of micromomyids (Bloch et al., 2007; Chester, 2013) might represent the best current evidence for understanding the skeletal morphology of ancestral primates close to their divergence from other euarchontan mammals (Chester et al., 2015). As such, Micromomyidae is a key taxon to deciphering relationships near the base of the primate tree.

The current paper provides the first detailed description of the best-preserved skull for a micromomyid, which is part of a skeleton of the Paleocene species Dryomomys szalayi (UM 41870; Bloch et al., 2007). Prior to the recovery of this skull only two cranial fragments had been described for the Micromomyidae, both tentatively attributed to Eocene Tinimomys graybulliensis (Gunnell, 1989; MacPhee et al., 1995). While these specimens (UM 85176 and USNM 461202) were recovered with partial dentitions correctly identified as those of $T$. graybulliensis, significant differences in basicranial morphology between the two led to controversy regarding their associations. Specifically, it was suggested that one or the other might pertain to a different, unidentified, taxon (MacPhee et al., 1995; Silcox, 2001). The partial 
cranium of D. szalayi with unambiguously associated dentitions described here provides a context for re-consideration of these identifications. Additionally, the discovery of basicrania that are directly associated with dentitions of another clade of small early Paleogene mammals, the insectivorous Nyctitheriidae (Manz et al., 2015), provides data relevant to a reassessment of the affinities of the UM 85176 and USNM 461202. These discoveries allow for an initial characterization of the cranial morphology of Micromomyidae and permit a consideration of these data with respect to the phylogenetic position of the family within Euarchonta.

\section{Institutional abbreviations}

AMNH, American Museum of Natural History (New York); CM, Carnegie Museum of Natural History (Pittsburgh); FMNH, Field Museum of Natural History (Chicago); MNHN Museum nationale d'Histoire naturelle (Paris); PSU, Pennsylvania State University Museum of Anthropology (State College); UF, Division of Vertebrate Paleontology, Florida Museum of Natural History (Gainesville); UKMNH, University of Kansas Museum of Natural History (Lawrence); UM, University of Michigan Museum of Paleontology (Ann Arbor); UMMZ, University of Michigan Museum of Zoology (Ann Arbor); USNM, United States National Museum Department of Paleobiology (Smithsonian Institutions, Washington, D.C.); USNM(MA), United States National Museum Department of Mammalogy (Smithsonian

Institutions, Washington, D.C.); YPM, Yale Peabody Museum of Natural History (New Haven).

\section{Materials and methods}

Materials 
Micromomyid cranial anatomy is documented from two partial crania from the Willwood Formation in the Clarks Fork Basin, Park County, Wyoming. The cranium of Dryomomys szalayi (UM 41870, holotype and only known specimen; Fig. 1) is from UM locality SC-327 of latest Paleocene age (Cf-3 faunal zone of the Clarkforkian North American Land Mammal Age [NALMA]; 1385 meters above the K-Pg boundary; 56-57 Ma). The specimen of Tinimomys graybulliensis (USNM 461202) is from UM locality SC-26 of early Eocene age (Wa-1 faunal zone of the Wasatchian NALMA; $1555 \mathrm{~m}$ above the K-Pg boundary; 55-56 Ma). Detailed locality information is archived at the University of Michigan Museum of Paleontology (see also Rose, 1981; Gingerich, 2001).

Comparisons were made to fossil specimens of nyctitheriids (UM 85176, UF 274601, UF 274600), Tinimomys graybulliensis (USNM 461201), Ignacius graybullianus (USNM 421608, 482353; UM 65569, 68006, 108210), Phenacolemur jepseni (AMNH 48005), Carpolestes simpsoni (UM 82670, 82688, 85177, 86273, 101923, 101963; USNM 482354), Plesiadapis tricuspidens (MNHN CR-125), Plesiadapis cookei (UM 87990), Microsyops knightensis (AMNH 55286), Megadelphus lundeliusi (AMNH 55284), Palaechthon nacimienti (UKMNH 9557), Cantius abditus (USNM 494881), Smilodectes gracilis (UM 32773 [MPM 2612], and Shoshonius cooperi (CM 31366, 31367, and 60494). Modern taxa examined include Tupaia glis (USNM[MA] 114553, 154599, 242241), Ptilocercus lowii (USNM[MA] 291272, 488061; YPM 10179), Pteropus poliocephalus (USNM[MA] 395262), Tarsius syrichta (PSU specimen), Galeopterus variegatus (AMNH 106628; USNM[MA] 83276, 84421, and 307553) and Cynocephalus volans (AMNH 203255; FMNH 1392, 56442; UMMZ 117122).

\section{Limestone preparation}


Cranial specimens of Dryomomys, Tinimomys, and the nyctitheriids discussed here were recovered from freshwater limestone deposits that likely represent accumulations in low-energy, ponded water on the ancient floodplain (see Bloch and Bowen, 2001; Bowen and Bloch, 2002). Specimens cataloged at the University of Michigan Museum of Paleontology (e.g., UM 41870, 85176) were prepared by D. Boyer and JIB and specimens cataloged at the University of Florida, Florida Museum of Natural History (UF 274601, UF 274600) were prepared by J. Bourque and C. Manz by submersion of limestone in $7 \%$ formic acid buffered with calcium phosphate tribasic for one to three hours at a time. To protect fossils from acid etching, a thin coating of polyvinyl acetate (PVA) was applied to the surface of all exposed bones. Bloch and Boyer (2001) provided a more detailed description of preparation methods and Bloch and Boyer (2007) provided detailed documentation of preparation for the Dryomomys szalayi specimen (UM 41870). The Tinimomys graybulliensis (USNM 461202) specimen was initially similarly prepared at New Mexico State University by P. Houde from freshwater limestone using 7\% buffered acetic acid for two days at a time, and later further prepared by J. Bourque at the Florida Museum of Natural History using $7 \%$ formic acid buffered with calcium phosphate tribasic for one to three hours at a time.

High-resolution X-ray computed tomography $(\mu \mathrm{CT})$

UM 41870 and UM 85176 were each embedded in a cylinder of floral foam. Floral foam, also known as "oasis," is a light, porous, and yet stiff substance used by florists in preparing arrangements of cut flowers. It provides a very good substrate for safely encapsulating fragile specimens for CT analysis, as it is not dense enough to interfere with the scan, and yet it is stiff enough that once a "pocket" in the foam has been carved out to house the specimen, it will not 
move. The floral foam was then placed in a plastic vial, and mounted on the OMNI-X Industrial Scanner at the Center for Quantitative Imaging (CQI), Pennsylvania State University. The threedimensional $\mu \mathrm{CT}$ data set was acquired in volume mode in which 21 individual two-dimensional slices were created for each rotation. The axial fan angle was small enough to assume parallel beam reconstructions. Each rotation consisted of 2400 views of the object spanning 360 degrees. The post-acquisition reconstruction process included all 2400 views, and each individual slice was stored as a $1024 \times 1024$ matrix of 16 bit integers in tiff format. For UM 41870 the reconstructed pixel size is $0.02728 \mathrm{~mm}$, and the interslice distance is $0.02976 \mathrm{~mm}$. For UM 85176 the reconstructed pixel size is $0.0267005 \mathrm{~mm}$ and the interslice distance is $0.0247006 \mathrm{~mm}$. USNM 461202 was scanned at 10 microns on a Scanco $\mu$ CT 35 machine at the Department of Internal Medicine, Yale University.

Images were studied using Scion Image Beta 4.02 (Scion Corporation, 2002) and ImageJ 1.27w-1.47e (Rasband, 2002). 3D reconstructions were built in Avizo 6.1.1 and 7.0

(Visualization Sciences Group; www.vsg3D.com). The three-dimensional $\mu$ CT data presented here, including shape files and the original tiff stacks, will be made publicly available on Morphosource (Boyer et al., 2014; www.morphosource.org) upon publication of the study.

\section{Terminology}

Anatomical terminology follows McDowell (1958), Miller, (1964), MacPhee (1981), Rowe et al. (1995), Bloch and Silcox (2001, 2006), and Wible (2008). 


\section{Description of the cranial anatomy of Dryomomys szalayi}

\section{Dentition}

The type and only known specimen of Dryomomys szalayi preserves crown morphology of all upper and lower tooth positions (Bloch et al., 2007). Detailed descriptions and measurements of these teeth were published in a recent systematic revision of Micromomyidae (Chester and Bloch, 2013). This specimen is recognized as a micromomyid plesiadapiform based on its small size and distinct morphology of $\mathrm{P}_{4}$ (with a trenchant paracristid). It is the type species of the genus Dryomomys, which is distinct from other micromomyids in having relatively enlarged and inflated upper and lower premolars. At the species level, Dryomomys szalayi is distinguished in its upper dentition by its large $\mathrm{P}^{2-4}$ relative to the upper molars; wide $\mathrm{P}^{3}$ relative to its length with a large protocone, a larger and more lingually positioned protocone lobe, and larger distolingual basin; and $\mathrm{P}^{4}$ that is wide compared to the molars with a more lingually extensive protocone lobe. In its lower dentition it is further distinguished in having a narrower $\mathrm{P}_{3}$ relative to length with a better developed talonid basin, $\mathbf{M}_{1}$ that lacks a distinct paraconid, and $\mathrm{M}_{2}$ with a relatively small paraconid (Chester and Beard, 2012; Chester and Bloch, 2013).

\section{Face and braincase}

While the face and braincase of Dryomomys szalayi are crushed and poorly preserved, certain aspects of the anatomy are nevertheless evident. Both premaxillae and nasals, while disarticulated, were recovered in association with the rest of the cranium. The snout of $D$. szalayi was elongate with a tapering rostrum (Fig. 1). This observation is supported by the acute 
angle formed by the articulated right and left dentaries, which also bear elongate lower central incisors that are anteriorly inclined (Fig. 2)

The left nasal (Fig. 3) is nearly complete apart from a small fragment missing from the rostral end and ventral surface. The right nasal (not illustrated) is essentially identical in morphology to that of the left, although less complete with only the caudal one-third preserved. The nasals clearly contacted each other medially and the premaxilla and maxilla laterally, but preservation is not adequate to determine whether there was a caudal contact with the frontal. Likewise, because the nasals are not preserved in articulation with the premaxilla, it is not clear whether they would have overhung the external nasal aperture. The nasal is long rostrocaudally and thin mediolaterally. Most of the length of the nasal is fairly uniform in width, although it does have moderate expansion caudally and a somewhat tapered and narrow rostral end. The ventral surface of the bone is concave mediolaterally. The lateral margin has a thin edge where the premaxilla would have overlain the bone. Near the midpoint, this edge curves laterally for the caudal half of the bone, where it would have articulated with the maxilla.

Both premaxillae are preserved with $\mathrm{I}^{1}$ and $\mathrm{I}^{2}$. While the left premaxilla is essentially complete (Fig. 4), the right premaxilla (not illustrated) is less complete with the $\mathrm{I}^{2}$ somewhat out of place in a slightly damaged alveolus and the caudal end of the bone missing. The left premaxilla has a thin, finger-like caudal process at the dorsal edge of the bone that would have contacted, and run lateral to, the nasal, partially overlapping this bone. This process extends caudally well beyond the level of $\mathrm{I}^{2}$ and when occluded with the maxilla it appears to extend beyond $\mathrm{C}^{1}$, but would not have extended far enough caudally to contact the frontal. The caudal margin of the bone appears unbroken and preserves the morphology of the surface that contacted the maxilla. It appears that this margin of the premaxilla would have overlain the maxilla at their 
suture. On the internal surface, the dorsal part of the premaxilla is notably thicker than the ventral part, with a ridge separating the two indicating a sudden change in thickness, which would have formed the contact with the nasal. The rostral end of the premaxilla does not appear to be broken, preserving the lateral edge of the nasal aperture, which is only gently curved.

The right maxilla is relatively complete (Fig. 5A). However, articulation of the isolated premaxilla and nasal bones with the maxilla (Figs. 3-4) reveals that a small piece of the dorsal end is missing. In addition, the rostrodorsal part of the maxilla is broken and shifted rostrally. This shifted piece houses two abraded alveoli for a double-rooted canine that, when viewed in comparison to the position of the canine in the left maxilla in near anatomical position (Figs. 1C, 5A-B), provides a measure for how far rostrally the broken piece has been displaced in the right maxilla. Also based on this comparison, it appears that most of the moderately long diastema between $\mathrm{P}^{2}-\mathrm{C}^{1}$ (completely preserved on the left) is preserved on the right maxilla. The distance between the rostral extent of the diastema on the right side and the caudal extent of the alveolus of the canine suggests that the broken piece shifted forward approximately $1.40 \mathrm{~mm}$.

While the nasals and premaxillae are isolated, well-preserved sutures make it clear that the maxilla contacted the premaxilla rostrally and the nasal dorsally. Poor preservation of the posterior aspects of the maxillae precludes identification of possible contacts with the lacrimal and frontal on the face. Though the full extent is not possible to assess because of broken edges, the maxilla made at least some contribution to the orbital margin. Most of the length of the dorsocaudal edge of the maxilla is marked with a groove that demarcates an articular surface, likely with the jugal. The groove ends rostrally (above $\mathrm{P}^{4}$ ) indicating the end of a contact with the jugal, which implies that the maxilla comprised part of the edge of the rostral orbital wall. A single, relatively large infraorbital foramen (Fig. 6) is located over $\mathrm{P}^{3}$ (Right: maximum diameter 
$=1.00 \mathrm{~mm}$, diameter perpendicular to that $=0.76 \mathrm{~mm}$; Left: maximum diameter $=0.95 \mathrm{~mm}$, diameter perpendicular to that $=0.80 \mathrm{~mm}$ ) and extends into a short canal through the maxilla, exiting in the orbit at a single opening. The root of the zygomatic process begins at $\mathrm{M}^{1}$ and extends caudally to a level near (or at) the front of $\mathrm{M}^{3}$. While absent on the left, the right side preserves a small fragment of bone that can be identified as part of the jugal (Fig. 5A; labelled "ju"), although its original relationship with the zygomatic process is unclear. The squamosal is pushed forward such that, in dorsal view, the zygomatic process of the squamosal overlies the zygomatic process of the maxilla (Fig. 5C), clearly indicating that the skull was somewhat compressed rostrocaudally.

While some of the dorsolateral aspect of the frontal is exposed and undistorted on the left side of the skull (Fig. 5B), the boundaries and contacts with other bones are mostly obscured by breakage and distortion of the rest of the cranium around it. Lack of a suture caudally suggests that the frontal was elongate and that its contact with the parietal might have been caudal to most of the dorsolateral exposure of the bone, although it is possible that this suture is obliterated and the caudalmost part of this fragment was made up of the parietal. This region demonstrates the presence of a strong postorbital constriction. Although there is no way of formally quantifying orbital convergence, it seems clear that the orbits faced generally laterally (interorbital breath = $\sim 2.5 \mathrm{~mm}$ measured off the external CT reconstruction).

Visualization of the internal anatomy using $\mu \mathrm{CT}$ data (Fig. 7) shows that the rostral part of the frontal is bilaterally symmetrical and appears to have a vertical plate of bone running down the midline for part of its length which likely made up the nasal septum (vomer?; indicated with an asterisk in Fig. 7C). As such, this section of the bone would be in the back of the nasal cavity between the orbits, and fragments of bone lateral to this structure may represent the 
broken remains of the nasal turbinates. Moving caudally through the $\mu \mathrm{CT}$ data, this vertical structure ends at a fragmentary bone that may represent parts of the cribriform plate. A foramen passing through the frontal can be tentatively identified as an ethmoidal foramen, which is the only well preserved orbital foramen (Fig. 7D). Further caudally the part of the endocranial cavity that would have housed the olfactory bulbs, and the annular ridge that separated them from the cerebrum, is preserved (Figs. 7E, 8). The part of the endocranial cavity preserved caudal to the annular ridge (Fig. 8) would have housed only the most rostral part of the rest of the brain (i.e., frontal lobes, olfactory tracts, anterior piriform cortex), because the bones (e.g., parietal; see Fig. 5B) that would have surrounded the more caudal aspects of the brain are either missing, or have been displaced rostroventrally to cover the preserved aspects of the frontal (Fig. $5 B, C)$.

On the left side of the specimen, at the front of the section of the cranium made up in large part by the frontal, there is a blunt lacrimal tubercle (Fig. 5B) that is continuous with a temporal crest running caudally (indicated with a dotted line on Fig. 5B). The lacrimal tubercle preserves the edge of a small foramen (Figs. 7B; 14) on its rostral aspect, which presumably represents the lacrimal foramen. Based on its position and relationship to the temporal line, the lacrimal tubercle would likely have sat on the orbital rim, although it is not clear whether it would have had a significant exposure on the face because the rostral aspect of the bone is missing. The temporal line on the frontal (Fig. 5B) presumably would have converged with the right temporal line to form the single sagittal crest, which is preserved on a fragment of the parietal that has been pushed forward over the frontal (Fig. 5C). The presence of fragments of the parietal and possibly occipital overlying the section of the cranium that is mostly comprised 
of the frontal implies that the cranium is somewhat telescoped, and its caudal aspect would have originally been longer than it currently appears.

While there is a small fragment of jugal preserved on the lateral aspect of the zygomatic process of the maxilla (Fig. 5A), it is not possible to tell whether it would have had a postorbital process. It is clear that no process was present on the frontal (Fig. 5B), so a postorbital bar was absent.

\section{Palatal anatomy}

In ventral view (Fig. 9) it is clear that the specimen has also experienced mediolateral distortion such that the right maxilla now overlies and obscures a substantial part of the left maxilla. While the palatines are not preserved, a part of the maxilla that would have articulated with the palatine at the back of the hard palate is evident (dotted line in Fig. 9). As the midline rostral to the maxillary-palatine contact is relatively complete, it is possible to infer that the palatine extended as far rostrally as $\mathrm{M}^{1}$, almost to the distal aspect of $\mathrm{P}^{4}$. Because the maxilla is damaged caudally and both $\mathrm{M}^{3}$ s are rotated partly out of place, it is unclear how far the maxilla would have extended caudal to $\mathbf{M}^{3}$. Although preservation is adequate to establish that there is no evidence for palatal fenestrae, it is unclear whether or not a postpalatine torus was present. While the rostral-most part of the maxilla is not preserved, the ventromedial surface of the premaxilla preserves the rostral edge of a moderately sized incisive foramen.

\section{Basicranium}


The basicranium (Fig. 9) of Dryomomys szalayi is poorly preserved with most bones crushed and some completely missing. However, many aspects of the squamosal and petrosal are well represented, allowing for detailed descriptions of at least these elements.

While only isolated fragments of the left squamosal were recovered, the right squamosal is well preserved (Figs. 5A, 9). A well-developed zygomatic process tapers to a point rostrally where the jugal would have articulated on its ventral surface (Fig. 5A). On the ventral aspect of the squamosal, the postglenoid and entoglenoid processes are located on the caudal margin of a large, relatively flat glenoid fossa (Fig. 9). The form of the glenoid fossa conforms in angle, size, and shape to the mandibular condyle of the associated right dentary (Fig. 2). The postglenoid process sits at the caudal extent of the fossa and the entoglenoid process is positioned more medially (Fig. 9). Externally the squamosal appears very inflated. This impression is confirmed by $\mu \mathrm{CT}$ data that show substantial air spaces in this bone (Figs. 7E, 10). Interpretation of the caudal aspect of the squamosal is complicated by the pneumatized nature of this bone. The caudolateral aspect of the postglenoid process is indented with a crescent-shaped, deep feature (Fig. 5A) that may initially appear to be a candidate for the postglenoid foramen. However, it is not perforate, and thus appears instead to be a fossa. Medial to the postglenoid process and ventral to the crescent-shaped fossa is a small opening, possibly the postglenoid foramen (Figs. 5A, 9), which seems to be an entry to a canal passing through the squamosal to the neurocranial cavity that is visible in the $\mu \mathrm{CT}$ data (Fig. 7F). However, the edges of this opening are somewhat ragged, making its identification as a foramen somewhat equivocal. Caudal to the postglenoid process and the crescent-shaped fossa indenting its caudal surface is the edge of the external auditory meatus (Fig. 5A). Medial to the postglenoid process, the entoglenoid process (Fig. 9) may have abutted the lateral neurocranium or the bulla and probably 
would not have appeared as an isolated process when this bone was in articulation. Because of damage in this region it is not entirely clear which features would have been within the tympanic cavity. For example, the crescent-shaped fossa caudal to the postglenoid process might have actually been in the roof of the auditory cavity as one of a series of spaces delineated by septa. No subsquamosal foramen is evident (Fig. 5A).

Although both petrosals are preserved, they are rotated out of anatomical orientation. This is evident, for example, in the orientation of the left internal acoustic meatus, which faces more laterally than it would have originally (Fig. 12C). The caudal part of the cranium (petrosal) is similar to the squamosal in being highly pneumatized, with three distinct accessory pneumatic spaces visible in the caudal view of the cranium where the back of the petrosal is broken away (Fig. 11). These air spaces are tentatively inferred as being in the mastoid based on their largely caudal location relative to the cochlear labyrinth, although their precise developmental origin cannot be definitively determined. Semicircular canals can also be visualized on both sides from the caudal aspect of the specimen, with the lateral and posterior canals visible on the left side, and just the posterior canal visible on the right. The offset in orientation between the two posterior canals reflects the rotation of the two petrosals with respect to one another (Fig. 11). Inflation of the mastoid extends around the semicircular canals. Exposure of the semicircular canals on the caudal aspect of both ears indicates that most of this area is broken away.

At the junction between the preserved part of the bulla and mastoid on the right side laterally (Fig. 5A) is an opening that can be identified as the stylomastoid foramen $(0.37 \mathrm{~mm} \mathrm{x}$ $0.21 \mathrm{~mm}$ ), which leads into the middle ear cavity (Fig. 12D). On the $\mu \mathrm{CT}$ data it is possible to trace the pathway of the facial nerve from the endocranial space, around the cochlear part of the bony labyrinth, to the foramen faciale, which opens into the middle ear space (Fig. 12B). There 
is no evidence for a fully enclosed canal connecting the foramen faciale and the stylomastoid foramen, suggesting that the facial nerve ran through an open sulcus in the middle ear cavity. Remnants of an inflated auditory bulla, enclosing a capacious tympanic cavity, are preserved on the right and left sides of the specimen (Figs 5A, C, 11). Although most of the right bulla is missing, on the left side of the specimen parts of the bulla are in place ventrally (Figs. 9, 13A). It is unclear exactly how much of the bone in the midline represents bulla. On the internal aspect of the bulla is a narrow groove extending the length of the preserved bullar fragment, which may have housed a ring-shaped ectotympanic (Fig. 14), although in the absence of any preserved remnant of the ectotympanic, this interpretation must remain very tentative.

The bulla surrounds a rounded promontorium that floors an inflated cochlear part of the bony labyrinth (Fig. 9), and is pierced by a laterally oriented fenestra vestibuli and a posterolaterally oriented fenestra cochleae (Fig. 13A). Lateral to the fenestra cochleae on the right side is a septum that extends from the promontorium to the bulla (indicated with a solid arrow in Fig. 13A). The $\mu \mathrm{CT}$ data show that these elements are continuous (Fig. 12E), consistent with a bulla that is at least partly petrosal in origin. However, sutures between bones in the bulla can fuse through ontogeny, and lack of a developmental series in most fossil taxa means there will always be uncertainty in fossils that seem to lack a suture in this region (see below). The broken nature of the bulla does not allow for assessment as to whether it had any other bony contributions. The septum lateral to the fenestra cochleae shields this structure from ventral view. In light of its position, it can be identified as a posterior septum, as seen in other non-microsyopid plesiadapiforms (see discussion below). On the ventral aspect of the posterior septum is a well-defined promontorial groove, which runs medial to the fenestra vestibuli. A more-subtle groove extends from the promontorial groove along the edge of the fenestra 
cochleae (perhaps for a stapedial artery). On the left promontorium there is also a well defined but very narrow transpromontorial groove running approximately rostrocaudally, medial to the fenestra vestibuli (Fig. 13B). The stapedial groove is even subtler on this side to the point that it can only be seen with certain lighting.

There are remnants of three additional septae that extend from the promontorium. They are located posteromedially (Fig. 9, s3), anteromedially (Fig. 9, s2) and anteriorly with respect to the promontorium (Fig. 9, s1; numbering scheme follows Boyer et al., 2012). The continuity between these septae and the promontorium is consistent with the interpretation that they are petrosal in origin.

\section{Petrosals previously attributed to Tinimomys graybulliensis}

Previously, only two cranial fragments have been attributed to the Micromomyidae, both tentatively identified as Eocene Tinimomys graybulliensis (Gunnell, 1989; MacPhee et al., 1995; Fig. 15). These specimens (UM 85176 and USNM 461202) differ in morphology, leading to controversy regarding their identification (MacPhee et al., 1995, Silcox, 2001).

Gunnell (1989) described the first known ear region thought to be associated with a micromomyid. Specifically, he described a specimen (UM 85176; Fig. 15B) prepared from a late Paleocene (Cf-3) limestone from the Bighorn Basin (UM locality SC-327) that includes a right mandible preserving $\mathrm{P}_{3}-\mathrm{M}_{3}$, two right upper teeth $\left(\mathrm{P}^{2-3}\right)$, a right petrosal, and some associated bone fragments identified as Tinimomys graybulliensis. Gunnell (1989) cautioned that, while the petrosal was "very small and primate-like," (p. 86), the association of the petrosal with the dentition was not certain. Within plesiadapiforms, Gunnell (1989) noted shared, primitive similarities of UM 85176 to those of previously described specimens of Microsyops 
(Szalay, 1969) including well-demarcated grooves for branches of the internal carotid artery on the promontorium and "a relatively large, bulbous tympanic process of the promontorium" (Gunnell, 1989: p. 88), characteristics absent in known plesiadapids and paromomyids. He also noted several differences from Microsyops, including a more laterally positioned stylomastoid foramen, a process that walls off the fenestra cochleae posteriorly, and the presence of a paroccipital process.

Beard (1993b) mentioned a possible association between a partial skeleton and ear region of Tinimomys graybulliensis (USNM 461202), also prepared from a Bighorn Basin limestone (UM locality SC-26, Wa-1), providing no description beyond noting that it was different from that of UM 85176. Following that, MacPhee et al. (1995) provided a brief description of USNM 461202, citing three anatomical features shared with plesiadapoids: (1) absence of large vascular grooves on the promontorium, (2) presence of very large epitympanic accessory spaces, and (3) marked cochlear 'shielding' by the posterior septum. They noted that USNM 461202 lacked critical features present in UM 85176 (thought to be characteristic of microsyopids) including well-demarcated grooves for branches of the internal carotid artery on the promontorium (Gunnell, 1989). The contrast between these two specimens threw into doubt which (if either) of the tentatively associated petrosals was actually properly attributed to Micromomyidae.

Re-evaluation of UM 85176 and USNM 461202

The very small size of the petrosal recovered with UM 85176 formed part of the basis for its identification as Tinimomys graybulliensis. In fact, many equally small mammals have been recovered from late Paleocene freshwater limestones (Bloch and Bowen, 2001). The most commonly recovered small mammals from limestones at the locality that yielded UM 85176 
(SC-327) are nyctitheriids (Bloch, 2001; Bloch and Bowen, 2001; Bloch and Boyer 2001), members of a family of extinct mammals variously classified in Eulipotyphla or Euarchonta (Manz et al., 2015). A comparison of dentally associated petrosals of two individual nyctitheriids attributed to Plagioctenodon rosei (Fig. 15A, 15C; see also Manz and Bloch, 2015; Manz et al., 2015) from SC-327 to UM 85176 (Fig. 15B) reveals the following similarities: 1) a well-developed caudal tympanic process of the petrosal that extends rostrally over the fenestra cochleae, 2) only a moderately inflated mastoid region, 3) a restricted epitympanic wing of the petrosal that extends lateral to the facial canal, and 4) overall similar size. In these ways, UM 85176 is markedly different from that of Dryomomys szalayi, the only known micromomyid with certain dental associations (Fig. 15E). While the diversity of petrosal morphology of smallbodied mammals in the assemblage is not fully documented and its specific identification is unknown, the morphology of UM 85176 strongly suggests that its affinities lie with the Nyctitheriidae and not the Micromomyidae as was previously suggested (Gunnell, 1989).

In contrast, comparison of the auditory region of USNM 461202 (Fig. 15D) also previously attributed to Tinimomys graybulliensis (MacPhee et al., 1995) to that of Dryomomys szalayi (Fig. 15E) confirms the attribution of this specimen to the Micromomyidae (MacPhee et al., 1995). Although fragmentary, this specimen preserves not only parts of both ear regions, but also parts of the neurocranium, fragments of the occipital, and possibly the squamosal, providing a first glimpse at the cranial anatomy of $T$. graybulliensis with confirmed dental associations. 


\section{Description of cranial anatomy of Tinimomys graybulliensis}

\section{Dentition}

The right maxilla of USNM 461202 preserves the buccal half of $\mathrm{P}^{4}$ and complete $\mathrm{M}^{1-2}$ (Fig. 16A, B). Characteristic features of Tinimomys (Szalay, 1974; Rose and Bown, 1976; Beard and Houde, 1989; Chester and Bloch, 2013) present on this specimen include a complete lingual cingulum on $\mathrm{M}^{1-2}$, clearly defined hypocones, and weakly defined pericones. Furthermore, USNM 461202 is distinguished from Tinimomys tribos from the late Paleocene (Clarkforkian) in being somewhat larger, having slightly more inflated paracone and metacone on $\mathrm{P}^{4}-\mathrm{M}^{2}$, and possessing a parastyle on $\mathrm{P}^{4}$ that is positioned somewhat higher relative to the paracone, resulting in a shorter, less vertical preparacrista (Chester and Beard, 2012). In all these ways, USNM 461202 fits the diagnosis of Tinimomys graybulliensis.

The right dentary of USNM 461202 preserves $\mathrm{M}_{1-3}$ and the roots of $\mathrm{P}_{4}$ (Fig. 16C, D). The $\mathrm{P}_{4}$ would have been considerably larger than $\mathrm{M}_{1}$, as is characteristic of micromomyids generally (Beard and Houde, 1989; Silcox and Gunnell, 2008; Chester and Bloch 2013). The lower molar cusps are relatively bunodont compared to those of other micromomyids, the talonid basins are large with pronounced talonid cusps, and $\mathrm{M}_{3}$ has an enlarged hypoconulid lobe, which are all characteristics of Tinimomys (Rose and Bown, 1976; Chester and Bloch, 2013). Dental measurements for USNM 461202 are as follows (in mm): $\mathrm{P}^{4}$ maximum length $(\mathrm{L})=1.4 ; \mathrm{M}^{1} \mathrm{~L}=$ 1.13, maximum width $(\mathrm{W})=1.75 ; \mathrm{M}^{2} \mathrm{~L}=1.06, \mathrm{~W}=1.73 ; \mathrm{M}_{1} \mathrm{~L}=1.17, \mathrm{~W}=1.01 ; \mathrm{M}_{2} \mathrm{~L}=1.12$, $\mathrm{W}=1.02 ; \mathrm{M}_{3} \mathrm{~L}=1.50, \mathrm{~W}=0.90$. As for the upper dentition, the lower molars are within the size range of Tinimomys graybulliensis and slightly larger than those of Tinimomys tribos (Chester and Beard, 2012). 


\section{Occipital}

A fragment of the left occipital is present on the ventral aspect of the specimen (Fig. 17A, C) preserving the occipital condyle, bordering a short part of the foramen magnum, and a small piece of the exoccipital rostrally. Rostral to the occipital condyle is the hypoglossal foramen (maximum diameter $=0.46 \mathrm{~mm}$, diameter perpendicular to maximum $=0.31 \mathrm{~mm}$ ). Rostral to the hypoglossal foramen there is a small notch that extends rostrally from the hypoglossal foramen on the ventral surface of the specimen, presumably for the passage of the hypoglossal nerve. Caudal and medial to the hypoglossal foramen there are two considerably smaller foramina at the base of the occipital condyle. Based on the $\mu \mathrm{CT}$ data, these foramina extend only into the substance of the bone, implying that they are nutrient foramina, rather than condylar canals.

\section{Auditory region}

Both promontoria are preserved, although the left promontorium has been somewhat crushed (Fig. 17A, C). The two promontoria are separated by approximately $1 \mathrm{~mm}$, although damage to the specimen makes it unlikely that this represents the original width of the central stem. The cochlear part of the bony labyrinth on the right side is extremely inflated with a pronounced indentation running approximately mediolaterally, which represents the juncture of two turns of the cochlea. The right promotorium preserves the fenestra cochleae, which faces approximately posteriorly, although the area around this opening is extensively damaged. Better preserved is the right fenestra vestibuli $(1.4 \mathrm{~mm} \times 0.7 \mathrm{~mm})$, which faces laterally (Fig. 18A). On the left the fenestra cochleae is broken open (Fig. 17A, C), and although the dorsal and lateral aspects of the fenestra are preserved in place, it is too damaged to measure accurately. Lateral and rostral to 
the broken open fenestra cochleae is the fenestra vestibuli (Fig. 18C), which is also too damaged to measure accurately. As noted by MacPhee et al. (1995), well-defined vascular grooves on the promontoria are not evident on either side.

Three narrow bony ridges extend medially and caudally from the left promontorium (Fig 17C; labeled s2, s3 and ps). These are likely parts of septae leading off the promontorium, which would have defined spaces within the tympanic cavity, possibly corresponding to the "very large epitympanic accessory spaces" of MacPhee et al. (1995: 42A). One of these ridges may represent a part of a posterior septum that would have "shielded" the fenestra cochleae when intact (MacPhee et al., 1995; Fig. 17C, ps). The other two septae were located posteromedially (Fig. 17C, s3) and anteromedially (Fig. 17C, s2). Although broken away on the left side, an additional anteriorly placed septum is present on the right side of the specimen, rostral to the fenestra vestibuli (Fig. 17C, s1). As all of these septae are continuous with the promontorium, they are interpreted as petrosal in origin.

Lateral to the right fenestra vestibuli is an open sulcus (Fig. 17A, C). Although not obvious on the surface of the specimen, it is possible to identify the foramen faciale dorsolateral to the rostral end of the fenestra vestibuli on the $\mu \mathrm{CT}$ data at the end of this sulcus, suggesting that it pertains to the passage of the facial nerve (Fig. 19A). Lateral and rostral to the sulcus for the facial nerve is a cup shaped indentation, which can be identified as the epitympanic recess (Fig. 17A, C).

Rostral and medial to the epitympanic recess is a fragment of bone, with remnants of two vacuities that may represent what remains of a pneumatized squamosal. A foramen in the squamosal is too far out of place to be definitively identified, but may be a foramen ovale (Fig. 18B). In dorsal view (Fig. 17B, D), the possible squamosal has a flat surface, likely the glenoid 
fossa, with a well-defined medial process, likely the entoglenoid process. Unfortunately this bone is heavily damaged, and other features that could confirm its identification as squamosal (e.g., postglenoid process, zygomatic process) are missing.

\section{Neurocranium}

In dorsal view there are a series of rostrally positioned, relatively flat bones that would have made up parts of the neurocranium (Fig. 17B, D). The most caudal among these flat bones is at least partly the parietal, because it bears weak temporal lines converging on a distinct sagittal crest. Rostral to this is a sheet of bone that is gently concave ventrally, which presumably made up part of the neurocranium more rostrally, and likely pertains in whole or part to the frontal. Rostral and ventral to the sheet of bone is a fragment that bears a sharp crest on its ventral/internal aspect (Fig. 17A, C), interpreted here as the annular ridge ("ar" in Figure 17A), which extends into the circular fissure of the brain between the olfactory bulb and the cerebral cortex (Rowe et al., 2005; Wible 2008), implying that this is a section of the frontal. A small fragment of the ascending ramus of the dentary is affixed to this element on the right side (Fig. 18A).

\section{Discussion}

The description of USNM 461202 is fundamentally consistent with observations made by MacPhee et al. (1995), although the further preparation of the specimen at the University of Florida allowed for description of additional features. The systematic importance of these observations is not as clear-cut as it seemed in 1995 as views have changed on the relationships amongst plesiadapiform families, with paromomyids generally no longer classified in 
Plesiadapoidea (Beard and Wang, 1995; Bloch et al., 2007; Silcox, 2008; Silcox and Gunnell, 2008). Discovery of new plesiadapiform crania has also broadened perspectives on the range of anatomy included in the group. For example, Bloch and Silcox (2006) documented the presence of grooves on the promontorium consistent in size with bearing functional arteries in a plesiadapoid (Carpolestes simpsoni), demonstrating that the absence of such grooves is not necessarily a diagnostic plesiadapoid trait. These features are evaluated in a cladistic analysis that includes newly documented cranial data for micromomyids and discussed in phylogenetic context below.

\section{Micromomyid comparative cranial anatomy}

\section{Face and braincase}

While measurements of the length of the skull and rostrum are estimates because of breakage and distortion of the type and only specimen, it is clear that Dryomomys szalayi had a distinctively longer snout than those of the Eocene euprimates that we studied, even falling outside of the range of that previously documented for plesiadapiforms (Bloch and Silcox, 2006) and within the range of variation of non-primate euarchontans (Scandentia and Dermoptera; Fig. 20). Thus, while generalization for the family should be viewed with caution considering that rostral length can be estimated for only a single species of a relatively late-occurring micromomyid, these observations are at least consistent with reconstructing a relatively long snout, in the range of extant treeshrews, as the primitive condition for Euarchonta.

The nasals of Dryomomys szalayi are similar to those of Ignacius, Palaechthon, Microsyops, Megadelphus, and dermopterans in having a wider caudal than rostral end, with a relatively broad contact with the frontal, but not to the same extreme as in Ignacius, Microsyops, 
or dermopterans, which have a very broad contact. In this way, the nasals of $D$. szalayi differ from those of plesiadapoids Carpolestes and Plesiadapis, which have a narrow caudal end and smaller contact with the frontal. The nasals of scandentians are variable in this characteristic (Wible, 2011) with Ptilocercus having a narrow caudal end and Tupaia having a somewhat more expanded caudal end (more like the condition in Dryomomys). This type of variability has also been noted among species of primitive euprimates (Bloch and Silcox, 2006).

The only known premaxilla published for micromomyids prior to this study is preserved on a single specimen of Tinimomys graybulliensis (Rose et al., 1993). While it clearly shows similarity to that of Dryomomys szalayi in the presence of two upper incisors, the specimen of $T$. graybulliensis is broken along the edges of the bone obscuring much of the rest of the morphology. The nearly complete premaxilla of $D$. szalayi illustrated here is the first to preserve detailed morphology for Micromomyidae. Presence of a narrow, finger-like posterodorsal process in D. szalayi is similar to that of known plesiadapiforms and Scandentia, but differs from that of dermopterans, which have a more dorsoventrally oriented premaxilla-maxillary suture and lack a posterodorsal process. Based on how the premaxilla would have articulated with the rest of the rostrum in D. szalayi, it would have been similar to that of most euarchontans for which the anatomy is known, including the plesiadapiforms Microsyops (Szalay, 1969), Ignacius (Kay et al., 1992), Carpolestes (Bloch and Silcox, 2006), and Palaechthon (Kay and Cartmill, 1977), euprimates, and dermopterans in not contacting the frontal. Among plesiadapiforms, plesiadapids appear to be unique in having a premaxilla-frontal contact (Boyer et al., 2012), similar to that found in the arboreal treeshrew Ptilocercus lowii (although it is variable within Scandentia, with Tupaia lacking a contact; Wible, 2011). The premaxilla of D. szalayi and other 
plesiadapiforms is similar to that of other euarchontans in forming a more substantial contribution to the rostrum than that of euprimates, which have a very short premaxilla.

While the badly crushed nature of the specimen makes determination of the composition of the orbital mosaic of Dryomomys szalayi difficult, it is clear that the maxilla makes at least some contribution to the orbital margin and moderate contribution to the rostral wall. In this way it is similar to that of euprimates and most plesiadapiforms for which the anatomy is known, including Plesiadapis, Carpolestes, and Ignacius (Kay et al., 1992; Bloch and Silcox, 2006), but not Megadelphus (Wible and Covert, 1987). More broadly within Euarchonta, a broadly expanded lacrimal excludes the maxilla from contributing to the orbital margin. This is especially true of Tupaia and dermopterans. While Ptilocercus lowii has a less expanded lacrimal, the maxilla is still excluded from the orbital margin (Wible, 2011).

The infraorbital foramen of Dryomomys szalayi is similar to that of other micromomyids (Beard and Houde, 1989; Chester and Beard, 2012) and all other plesiadapiforms for which the anatomy is known (e.g., Kay and Cartmill, 1977; Kay et al., 1992; Bloch and Silcox, 2006; Boyer et al., 2012) in being relatively large in diameter, also similar to that of many extant mammals. In contrast, extant euarchontans (including euprimates) have a relatively small infraorbital foramen compared to non-euarchontan mammals (Muchlinski, 2010), although there is some notable variability in this feature (e.g., Ptilocercus has a relatively larger foramen than Tupaia; Silcox, 2001). The area of the infraorbital foramina has been linked to tactile vibrissae count, associated with maxillary sensory acuity (Kay and Cartmill, 1977; Muchlinski, 2008a). The difference in relative infraorbital foramen size between fossil plesiadapiforms and most extant Euarchonta, coupled with the ecological implications, could be interpreted as a significant adaptive contrast with potential phylogenetic implications (Muchlinski, 2008b). However, some 
primitive euprimates (e.g., Cantius; Silcox, 2001) have relatively larger infraorbital foramina, and no fossil scandentian or dermopteran has been recovered with this feature preserved. As such, not only could a large infraorbital foramen be plesiomorphic for Primates, it could plausibly be inferred to be present in the common ancestor of Euarchonta, with multiple parallel reductions in size during the at least 65 million year history of the clade.

Among early euprimates, longer-snouted adapoids have long infraorbital canals, while omomyoids with shorter snouts have short canals, suggesting that snout length and infraorbital canal length are correlated in this group. The infraorbital canal of Dryomomys szalayi is relatively short (i.e., passing, essentially, directly through the maxilla) similar to that of other micromomyids, Ignacius, Carpolestes, and extant Ptilocercus lowii. In contrast, Plesiadapis, Tupaia, and dermopterans have more elongate canals that form more than a mere passage through the maxilla, extending some distance on the face. The presence of a short infraorbital canal in D. szalayi and the most plesiomorphic extant treeshrew Ptilocercus (Wible, 2011) could be interpreted as being primitive for Euarchonta, with this feature being independent of snout length, because both have relatively long snouts (Fig. 20). Variability of this character within Scandentia (e.g., Tupaia) and a longer canal in certain proposed stem-primates (e.g., Plesiadapis) and dermopterans make this interpretation far from certain.

As for other micromomyids, Carpolestes, euprimates, and dermopterans, the posterior edge of the zygomatic process of the maxilla is aligned with $\mathrm{M}^{3}$ in Dryomomys szalayi. In contrast, it ends more rostrally (aligned with more anterior molars) in treeshrews, Ignacius, and plesiadapids (Boyer et al., 2012) suggesting the independent evolution of this character within different euarchontan clades. 
The frontal of Dryomomys szalayi has postorbital constriction similar to that of treeshrews, dermopterans, and other plesiadapiforms including Ignacius, Megadelphus, Plesiadapis, Palaechthon, and Carpolestes (Bloch and Silcox, 2006). Postorbital constriction is less distinct in euprimates.

While there is no way of quantifying orbital convergence from the type and only cranial specimen of Dryomomys szalayi, it seems clear that the orbits faced generally laterally similar to those of other plesiadapiforms, treeshrews, and dermopterans, and unlike euprimates, which have more forward-facing orbits (Cartmill, 1972, 1974). Preservation makes it impossible to assess whether D. szalayi would have had a postorbital process on the jugal, yet it is clear that it was similar to most other plesiadapiforms in lacking a process on the frontal. In contrast, both euprimates and scandentians have a complete postorbital bar, while dermopterans and microsyopids have a strong postorbital process of the frontal.

Dryomomys szalayi had a blunt lacrimal tubercle associated with a small foramen, similar to that of Carpolestes, Palaechthon, Ignacius, certain euprimates (e.g., Shoshonius, Notharctus), and Tupaia but apparently different from Megadelphus, Plesiadapis, dermopterans, and Ptilocercus lowii, which lack a tubercle (Bloch and Silcox, 2006; Wible, 2011). The lacrimal foramen of $D$. szalayi is evident in the $\mu \mathrm{CT}$ data (Fig. 7B) and seems to be situated just rostral to the orbital rim, more similar to the condition in Carpolestes and Palaechthon nacimienti then that of Plesiadapis and Megadelphus in which it is located more rostrally on the face (Silcox and Bloch, 2006). In dermopterans and Ptilocercus lowii the lacrimal foramen is not exposed on the face, while it is in Tupaia (Wible, 2011).

Virtually cutting through the frontal, the $\mu \mathrm{CT}$ data reveal aspects of the endocranial cavity that would have housed the olfactory bulbs (Fig. 8) and the annular ridge that separated 
them from the cerebrum (Fig. 7E). While preservation is not adequate to reconstruct the endocast more caudally, it is clear that Dryomomys szalayi would have had relatively large olfactory bulbs similar to those reconstructed for other plesiadapiforms including Plesiadapis (Gingerich and Gunnell, 2005; Orliac et al., 2014), Ignacius (Silcox et al., 2009), and Microsyops (Silcox et al., 2010a). The position of the frontal relative to the maxilla is difficult to reconstruct because of distortion of the specimen, but the front of the olfactory bulbs is clearly fairly far forward, at the level of the orbit as in Ignacius, but not Microsyops or Plesiadapis, in which the endocast extends less far rostrally (Silcox et al., 2009, 2010a; Orliac et al., 2014). It has been suggested that the apparently more rostral extension of the olfactory bulbs shared between Ignacius graybullianus, dermopterans, and short-faced euprimates might be related to shortening of the face and occurred multiple times in euarchontan evolution (Silcox et al., 2010a). While it is not clear exactly how far the endocast would have extended, it is still of note that it was fairly far forward in the relatively long-snouted skull of D. szalayi.

While the external aspect of the neurocranium is only incompletely preserved for both Dryomomys szalayi and Tinimomys graybulliensis, remains of the frontal and parietal demonstrate that both had temporal lines that converged on a small but distinct sagittal crest. Sagittal crests are also known in microsyopids (Szalay, 1969), plesiadapids (Russell, 1964; Gingerich, 1976), paromomyids (Kay et al., 1992), and carpolestids (Bloch and Silcox, 2006). This is similar to the condition in many primitive euprimates (e.g., Notharctus; Gregory, 1920), in which the sagittal crest is well developed, but contrasts with both dermopterans and scandentians, in which the temporal lines are clearly demarcated but generally do not converge to form a crest. 


\section{Palatal anatomy}

The caudal midsagittal margin of the palate is not preserved in any known micromomyid specimen. While mostly not preserved, the maxillary-palatine suture of Dryomomys szalayi may have extended as far rostrally as $\mathrm{M}^{1}$, almost to the distal aspect of $\mathrm{P}^{4}$, similar to that of Ignacius and Megadelphus (Szalay, 1969; Kay et al., 1992), and different from that of dermopterans, scandentians, some early euprimates, Carpolestes, and plesiadapids, which end at $\mathrm{M}^{1}$ or even more caudally (Bloch and Gingerich, 1998; Boyer et al., 2012).

Unlike the hard palate of carpolestids, which have large palatal fenestrae (Jepsen, 1930; Rose, 1975; Krause, 1978; Bloch and Gingerich, 1998), the hard palate of Dryomomys szalayi is similar to that of other known plesiadapiforms and euprimates in lacking palatal fenestrae. Palatal fenestrae are absent in Ptilocercus lowii and dermopterans and present in Tupaia (Wible, 2011), making it unlikely that this feature was plesiomorphic for Euarchonta.

\section{Basicranium}

As for other plesiadapiforms, dermopterans, and some early primates, the zygomatic process of the squamosal of Dryomomys szalayi is dorsoventrally deep. This is different from that of scandentians, which have a shallower, more delicate zygomatic process (Wible, 2011).

As for euprimates, scandentians, and other plesiadapiforms, both postglenoid and entoglenoid processes of Dryomomys szalayi are present on the caudal and medial margins of the glenoid fossa (Tinimomys graybulliensis also has a medial entoglenoid process, but preservation is not adequate to evaluate the postglenoid process), respectively, whereas dermopterans lack an entoglenoid process. The postglenoid process and associated glenoid fossa is less curved in $D$. szalayi (the glenoid fossa is similarly flat in T. graybulliensis), other plesiadapiforms, 
euprimates, and scandentians, than that of dermopterans. The postglenoid foramen is located medial to the postglenoid process in D. szalayi, Ignacius (Kay et al., 1992), and plesiadapids (Boyer et al., 2012), whereas it is more caudally positioned in Carpolestes (Bloch and Silcox, 2006) and extant treeshrews (Wible, 2011), and completely absent in dermopterans.

While the squamosal of Carpolestes is somewhat inflated, and Ignacius has some degree of pneumatization, Dryomomys szalayi and likely Tinimomys graybulliensis are unique among plesiadapiforms in having a distinctly inflated and pneumatized squamosal. Likewise, the mastoid is similarly pneumatized in $D$. szalayi (preservation not adequate to evaluate in $T$. graybulliensis), with inflation extending around the semicircular canals. It is notable that a marked degree of pneumatization in the squamosal and mastoid is also found in extant dermopterans, but not early euprimates or scandentians. In fact, gliding squirrels (e.g., Glaucomys volans) are also distinctly pneumatized, and it might be tempting to infer similar types of gliding behaviors in micromomyids as found in these two extant groups (see Beard, 1993a,b). However, this conclusion should be tempered with the observation that the primitive gliroid Rhombomylus (inferred to be terrestrial based on postcrania; Meng et al., 2003) and a variety of other non-gliding mammals (e.g., lagomorphs, macroscelideans, proboscideans, certain extant arboreal euprimates) also have strongly pneumatized crania, and that D. szalayi lacks any known unique postcranial morphological characteristics correlated with glidingspecific positional behaviors (Boyer and Bloch, 2008).

For both Dryomomys szalayi and Tinimomys graybulliensis, a foramen faciale can be identified in the $\mu \mathrm{CT}$ data as opening into the middle ear cavity, suggesting that the facial nerve traversed that cavity in an open sulcus. This is similar to the condition in microsyopids (MacPhee et al., 1988), but differs from scandentians (Wible, 2011), Ignacius graybullianus 
(Kay et al., 1992), Carpolestes simpsoni (Bloch and Silcox, 2006), and plesiadapids (Boyer et al., 2012), in which the nerve is at least mostly enclosed in a bony canal. The morphology inferred for the micromomyids is similar to that observed in Paleogene euarchontogliran Labidolemur kayi (Silcox et al., 2010b), and in extant dermopterans (MacPhee et al., 1989), suggesting that it is primitive. Dryomomys szalayi possessed a single stylomastoid foramen, which contrasts with the double opening that has been documented for both I. graybullianus (Kay et al., 1992) and Plesiadapis tricuspidens (Russell, 1964), while this opening is single in both C. simpsoni (Bloch and Silcox, 2006) and Pronothodectes gaoi (Boyer et al., 2012) suggesting that this trait varies widely among plesiadapiforms.

Although damaged, it is clear that Dryomomys szalayi had an inflated, bony auditory bulla. This contrasts with the condition in microsyopids (Szalay, 1969; Gunnell, 1989), and in more primitive euarchontoglirans (e.g., Labidolemur kayi; Silcox et al., 2010b), in which there is no evidence for an ossified bulla. The only evidence for the makeup of the bulla in D. szalayi is the continuity between the remnants of the bulla and the promontorium in the form of a bony strut lateral to the fenestra cochleae (Fig. 13A). This is similar to the condition in Euprimates, as well as in plesiadapoid plesiadapiforms including Carpolestes simpsoni (Bloch and Silcox, 2006) and all plesiadapids in which the relevant area is preserved (Russell, 1959; Szalay, 1972; Szalay et al., 1987; Boyer et al., 2012). However, as MacPhee et al. (1983; see also MacPhee and Cartmill, 1986; Beard and MacPhee, 1994) have pointed out, obliteration of sutures in ontogeny can make it impossible to deduce the make-up of the bulla in fully adult specimens. Nonetheless, in light of the similarity in morphology amongst these taxa, the data available are most consistent with the interpretation that the composition of the bulla was similar in micromomyids, plesiadapoids, and primitive euprimates in incorporating at least some petrosal 
contribution. Positing any other cause for such similarity requires assuming a set of developmental events (e.g., fusion between the petrosal and an expanded entotympanic or ectotympanic) for which there is no evidence. Paromomyids, on the other hand, are distinctly different with a suture that intervenes between the promontorium and the bulla (Kay et al., 1990, 1992; Bloch and Silcox, 2001; Silcox, 2003), indicating that the latter is entotympanic rather than petrosal origin, similar to that of extant dermopterans and scandentians and perhaps characteristic of the euarchontan morphotype (Bloch and Silcox, 2001).

The tympanic cavity of both Dryomomys szalayi and Tinimomys graybulliensis is subdivided by four septae, including a posterior septum that shields the fenestra cochleae from ventral view, and posteromedial, anteromedial, and anterior septa that are also continuous with the promontorium (Figs. 9, 17A). The arrangement and number of these septae are very similar to the pattern described for plesiadapids by Boyer et al. (2012), and as described by those authors for plesiadapids, the subtle groove for the internal carotid plexus (their "g1 and g2") runs lateral to the posterior septum, which is also similar to the condition in paromomyids (Bloch and Silcox, 2001: fig. 5). Absent, however, are grooves on the more medial aspect of the promontorium, observable in plesiadapids ("g3" and "g4" of Boyer et al., 2012) and also some paromomyids (Bloch and Silcox, 2001: fig. 6). A posterior septum has also been described for Carpolestes simpsoni (Bloch and Silcox, 2006), which also possesses grooves for stapedial and promontorial arteries, but $C$. simpsoni lacks any more medial grooves. The fenestra cochleae is similarly shielded by a septum in Ignacius graybullianus (Bloch and Silcox, 2001: fig. 5), described as a "longitudinal" septum, located more anteriorly (Kay et al., 1992; Bloch and Silcox, 2001), which is similar in position to the anterior septum ("s1") in plesiadapids and micromomyids. An anterior septum has also been described for fossil euprimates and extant lemuroids and lorisoids 
(MacPhee and Cartmill, 1986; Boyer et al., 2012). While similar bony septae are present in the ear of scandentians, they are associated with the development of an expanded entotympanic element (Wible, 2011), and as such are likely not homologous with the septae observed in plesiadapiforms and euprimates (Boyer et al., 2012). Similar septae are entirely lacking in microsyopids (MacPhee et al., 1988: fig. 13) and dermopterans (MacPhee et al., 1989: fig. 8), in which the fenestra cochleae is clearly visible in ventral view.

With respect to the pathway of the internal carotid artery through the middle ear, in Dryomomys szalayi there is a well-defined groove lateral to the posterior septum, as well as a very faint groove that extends towards the fenestra vestibuli. Similarly positioned grooves in some other plesiadapiforms (e.g., microsyopids, Carpolestes simpsoni; MacPhee et al., 1988; Bloch and Silcox, 2006) have been interpreted as transmitting branches of the internal carotid artery, similar to the condition of certain primitive euarchontoglirans (e.g., Labidolemur kayi; Silcox et al., 2010b), and likely the primitive state more generally for mammals (MacPhee and Cartmill, 1986). However, because there are nerves as well as arteries that may traverse the promontorium (e.g., the internal carotid nerves; Wible, 1993: fig. 6), the simple presence of grooves is not enough to establish that there were functional arteries present. Kay et al. (1992) established that forms with functional internal carotid arteries had larger posterior carotid foramina (pcf) relative to cranial length than taxa in which these arteries were absent or nonfunctional. Although the pcf is not preserved in either specimen of D. szalayi or Tinimomys graybulliensis, it is possible to estimate its diameter based on the size of groove for the internal carotid artery before it bifurcates on the promontorium of D. szalayi (Supplementary Online Material [SOM] B) (following Bloch and Silcox, 2006). When plotted against an estimate of cranial length, the small size of this groove suggests that there was no functional internal carotid 
artery (ICA) in D. szalayi (Fig. 21). A similar inference has been made for paromomyids (Kay et al., 1992; but see Bloch and Silcox, 2001) and plesiadapids (Gingerich, 1976; Kay et al., 1992; but see Boyer et al., 2012), but contrasts with the condition in C. simpsoni, which likely had a functional ICA (Bloch and Silcox, 2006). The absence of a functional internal carotid artery is similar to the condition in dermopterans, in which the artery involutes entirely during ontogeny (Wible, 1993), and contrasts with the situation in primitive euprimates (MacPhee and Cartmill, 1986) and scandentians (Wible and Zeller, 1994) in which at least the stem of the internal carotid artery is not only present but enclosed in a bony tube.

With respect to the morphology of the ectotympanic, this bone is not preserved intact in either Dryomomys szalayi or Tinimomys graybulliensis. However, the presence of a distinctly curved, narrow groove on the internal aspect of the bulla on the left size of $D$. szalayi may represent the course of this bone (Fig. 14), indicating that the ectotympanic was aphaneric (i.e., covered by the bulla; MacPhee, 1981) and likely consisted of a narrow ring, perhaps similar to the condition in living strepsirrhines. In plesiadapids, the ectotympanic was also a relatively narrow ring fused to the wall of the bulla by way of a bony annular bridge (Russell, 1964; Gingerich, 1976). In the absence of the ring itself it is difficult to assess to what degree the condition in micromomyids would have been comparable, but the preserved anatomy is most consistent with the interpretation that for both taxa the ectotympanic would have been aphaneric, as it is for primitive euprimates and living scandentians. The only other plesiadapiform for which any morphology of the ectotympanic is known is Ignacius graybullianus. One specimen of I. graybullianus preserves a small fragment of bone interpreted to be the remains of a narrow ring (Bloch and Silcox, 2001), suggesting that it would also have been similar to the condition in 
micromomyids. This contrasts with the morphology of dermopterans, in which the ectotympanic forms a significant part of the bulla itself, and lacks a narrow bony ring.

\section{Phylogenetic Analysis}

In order to examine the phylogenetic implications of the newly documented cranial anatomy of micromomyids, we performed a cladistic analysis that included other plesiadapiforms, representative basal euprimates, extant non-primate euarchontans, and a range of fossil euarchontoglirans including Rhombomylus (Glires) and a number of apatemyid species. In order to provide a broader mammalian context for the analysis, living members of Eulipotyphla and Carnivora, and fossil eutherian mammals were also included, with the basal eutherian Ukhaatherium nessovi serving as the outgroup (see Silcox et al., 2010b). A total of 240 morphological characters (68 postcranial, 45 cranial, 127 dental; SOM C) were scored for 33 ingroup taxa and one outgroup taxon (SOM D).

Parsimony analysis was conducted using TNT (v1.1, software subsidized by the Willi Hennig Society; Goloboff et al., 2008) with all multistate characters treated as unordered. New Technology Search was implemented, the consensus was stabilized five times, and resulting most parsimonious trees (MPTs) were used as starting trees in a Traditional Heuristic Search that was carried out using tree bisection reconnection (TBR). Two resulting MPTs were used to obtain a strict consensus. Bremer branch support values were calculated using the Traditional Search option (10 replicates per run with TBR enforced) from 50,000 suboptimal trees up to 10 steps longer than the most parsimonious tree. Suboptimal trees were found by increasing the suboptimal option by one step for each heuristic search of 5,000 trees to avoid overestimating 
support values (Goloboff et al., 2008). Absolute Bremer support values were calculated once 50,000 suboptimal trees were found.

\section{Results}

The cladistic analysis yielded two equally most parsimonious cladograms (length $=1,089$, $\mathrm{CI}=0.297, \mathrm{RI}=0.523$; tree statistics calculated in TNT). The two trees differ only in the inferred sister taxon to Ottoryctes, with it being recovered as Pararyctes in one topology and Palaeoryctes in the other. A strict consensus tree was calculated in TNT from these trees (Fig. 22). In the consensus tree, Purgatorius falls out as the most primitive stem primate, with Micromomyidae + Microsyopidae forming the next branch as the sister clade to the rest of Primates.

To accommodate uncertainties in the interpretation of characters related to both the petrosal and the ectotympanic, the analysis was re-run using a series of modifications: i) with character 101 (presence of a petrosal bulla) coded as "?" instead of "1" for carpolestids and plesiadapids (this feature was coded as "?" for micromomyids in all analyses since the full make-up of the bulla is unknown; see SOM D); ii) as analysis i, but with character 97 (degree to which ectotympanic is covered by other bones) also coded as "?” for micromomyids, plesiadapids, and carpolestids; iii) as analysis ii, but with character 98 (ectotympanic shape) coded as “?” for Dryomomys; and iv) as analysis iii, but with character 98 also coded as "?" for paromomyids. The results of all four of these analyses were identical in yielding the same two most parsimonious trees as found in the original analysis (Fig. 22). 


\section{Discussion}

The tree topology resulting from the cladistic analysis is similar to that of previously published studies derived from the same list of characters, originally published in Silcox et al. (2010b) and then modified by Chester et al. (2015) to include tarsal characters for Purgatorius. In both those previous studies, preliminary scorings for micromomyid cranial traits were included based on initial impressions of the anatomy of Dryomomys szalayi, but restudy of the specimens here has led to revisions of nine character codings for Micromomyidae and six character codings for other taxa included in the analysis (see SOM C).

Results suggest that micromomyids are among the most primitive primates known. This result differs from the topology recovered by Bloch et al. (2007) in supporting a sister taxon relationship between micromomyids and microsyopids. This clade (Node 25: micromomyids and microsyopids) is supported by six dental characters (128[1], 189[2]. 192[1], 220[1], 221[1], 229[3]), all of which show a significant amount of homoplasy on the most parsimonious trees. Critically, there is no support for this node from cranial characters. Microsyopids are distinctly different in cranial morphology from micromomyids, retaining many likely primitive traits, such as the absence of a bony bulla, lack of shielding of the fenestra cochleae, and unreduced grooves for the promontorial and stapedial arteries.

Micromomyids share with non-microsyopid plesiadapiforms a bony bulla enclosing the middle ear cavity. As discussed above, continuity between the bulla and promontorium suggests that at least part of this bulla would have been formed from the petrosal. However, in light of uncertainty about how much of the bulla was formed from this bone, the relevant character (101) was coded as “?” for micromomyids. Micromomyids fall out in our analysis as more distantly related to plesiadapoids than are paromomyids, with the appearance of the petrosal bulla being 
inferred as a euprimateform (Plesiadapoidea+ Euprimates; Fig. 22, node 27) trait. This implies that if the bulla was predominantly composed of the petrosal in micromomyids, that feature evolved independently (or was reversed in paromomyids). Support for a closer relationship between paromomyids and Euprimateformes (Fig. 22, node 26) than either share with micromomyids comes from a few postcranial and many dental characters including, for example, upper molars with well-developed postprotocingulae (less pronounced in primitive micromomyids). The most significant piece of cranial evidence for the paromomyid + euprimateform clade is the presence of an enclosed pathway for the facial nerve (character 103[1]). Having a facial nerve that apparently passed through the middle ear cavity proper is one of the few similarities in cranial anatomy between microsyopids and micromomyids, and is inferred here to be primitive.

Another feature shared by micromomyids and some advanced plesiadapiforms is the likely loss of functionality of the internal carotid artery, based on the small caliber of the related groove on the promontorium. Evidence for reductions or loss of this vessel has also been documented in plesiadapids and paromomyids, whereas it has been inferred that carpolestids had a functional ICA (Bloch and Silcox, 2006). As carpolestids are supported dentally as closely related to plesiadapids in Plesiadapoidea (e.g., by possession of conules on the upper premolars), our results suggest multiple reductions to the internal carotid system in primate evolution. This feature has sometimes been suggested to support a relationship between some plesiadapiforms and dermopterans to the exclusion of Primates (e.g., Kay et al., 1992). Our results do not support this inference, suggesting instead multiple losses of this vessel in Euarchonta.

\section{Conclusions}


The cranium of Dryomomys szalayi described here is from the latest Paleocene (late Clarkforkian NALMA; 56 Ma; Secord, 2008), approximately four million years after the first appearance of micromomyids in the fossil record in the late Paleocene (middle Tiffanian NALMA; 60 Ma; Secord, 2008). The cranium of Tinimomys graybulliensis is slightly younger, from the early Eocene (early Wasatchian NALMA). Thus, a general characterization of the cranial anatomy for the family based on these relatively late occurring taxa should be treated with caution. We note, however, that these two taxa represent separate branches of micromomyid phylogeny, have similar cranial morphology in all comparable aspects, and thus can be inferred to characterize the cranial morphology for the family going back at least to the late Tiffanian NALMA (Ti5a; 58 Ma; Secord, 2008) when their clades are thought to have diverged (Chester and Bloch, 2013). The postcranial morphology of these two taxa is also remarkably consistent (Bloch et al., 2007; Boyer and Bloch, 2008). Micromomyid dentitions are also quite comparable throughout the evolutionary history of the family, from the oldest and most primitive micromomyids that are only known from teeth and partial dentitions (i.e., Foxomomys; Fox, 1984; Chester and Bloch, 2013), to the latest occurring species in the early Eocene such as T. graybulliensis and Dryomomys willwoodensis (Chester and Bloch, 2013). In light of the degree of conserved morphology in other anatomical regions, it is reasonable to expect that the skulls described here are similar in form to what we might eventually find for taxa at the base of the clade.

It has been argued that the primitive dental morphology of the first micromomyid (Foxomomys fremdi) is similar in many ways to that of the oldest known primate (Purgatorius; Fox, 1984; Chester and Bloch, 2013) whose ankle morphology also most closely resembles that of later occurring micromomyids (Chester et al., 2015). As such, among fossil euarchontans 
with well-preserved postcranial skeletons, micromomyids provide the most useful model from which we might infer aspects of the morphology of the first primates (Bloch et al., 2007). In this context it is perhaps not surprising that we see some plesiomorphic features, including a relatively more elongate snout that is more similar to that of other euarchontans (treeshrews and colugos) than to other plesiadapiforms. What is surprising is the presence of certain derived features, the inferred presence of a petrosal bulla for example, that are missing in taxa otherwise thought to be more nested in primate phylogeny (e.g., paromomyids). Early primate evolution must entail, therefore, a complex pattern of character evolution in the basicranium.

The presence of a highly inflated mastoid and squamosal is particularly interesting as a unique feature among plesiadapiforms for which the cranial anatomy has been documented. This type of inflation is known in a diversity of small mammals including terrestrial forms with saltatory locomotion (e.g., lagomorphs, kangaroo rats, macroscelidids), certain arboreal forms with gliding locomotion (e.g., dermopterans, flying squirrels), and some arboreal primates (e.g., lorises) (Hunt and Korth, 1980; MacPhee, 1981; MacPhee et al., 1989). While it might be tempting to interpret this micromomyid feature as evidence in support of shared gliding behaviors with extant dermopterans (Beard, 1993b) and flying squirrels, characteristics of the postcranial skeleton are not consistent with this interpretation (Boyer and Bloch, 2008). It is possible that the cranial inflation of micromomyids represents a shared-derived characteristic of a drastically modified version of Beard's (1993a) "Dermoptera" with micromomyids as the sister clade to "Galeopithecidae," to the exclusion of paromomyids and plesiadapoids. However, although the general nature of the inflation is similar in dermopterans and micromomyids, the details are quite different. In dermopterans pneumatization is accomplished by inflation of the epitympanic paratympanic cavity, leading to the development of air cells in the lateral walls of 
the neurocranium (i.e., see MacPhee et al., 1989: fig. 8B). Although the fragmentary nature of the cranium in both Dryomomys szalayi and Tinimomys graybulliensis makes it difficult to infer precisely how the pneumatization occurred, the presence of large air cells on the caudal aspect of the cranium, surrounding the semicircular canals, is quite distinct from the pattern of pneumatization in dermopterans, suggesting a distinct developmental origin. Given more recent phylogenetic analyses that place micromomyids as either stem primatomorphs (sensu lato; Ni et al., 2013) or stem primates (e.g., Bloch et al., 2007; Silcox et al., 2010b; Chester et al., 2015; this study), it is more parsimonious that the cranial inflation in micromomyids is autapomomorphic for the group, although the functional significance is unclear.

The unique cranial morphology of late Paleocene and early Eocene micromomyids presented here adds to the growing diversity of cranial form known for plesiadapiforms, and in some ways may represent the most primitive condition yet known for early primates. The results of a cladistic analysis that includes the new cranial data failed to support either Primatomorpha or a close relationship between micromomyids and dermopterans, instead suggesting that micromomyids are among the most primitive known primates. However, these results should be viewed in the context of a still very incomplete early euarchontan fossil record, especially in the earliest Paleocene, when they likely diversified as part of a radiation of placental mammals immediately following the Cretaceous-Paleogene boundary (O’Leary et al., 2013).

\section{Acknowledgements}

We are grateful to P.D. Gingerich, G.F. Gunnell, R. Purdy, K.C. Beard, and P. Houde for providing access to specimens. We thank D.M. Boyer, W. Sanders, C. Manz, and J. Bourque for help with fossil preparation, Z. Randall for generating digital images for Figs. 1-6, 9, 11, and 16, 
and D. Reed for access to the Visionary Digital (Palmyra, Virginia) System provided by the National Science Foundation (DEB 0845392) at the FLMNH. For assistance with micro-CT scanning, we thank Özgen Karacan (Center for Quantitative Imaging, Penn State University) and Josh Van Houten (Department of Internal Medicine, Yale University). We thank D.M. Boyer, E.J. Sargis, and G.F. Gunnell for helpful discussions, as well as J. R. Wible, K. C. Beard, and an anonymous reviewer for comments that improved the manuscript. This research was supported by National Science Foundation: NSF EF-0629836, to JIB, MTS, and E. Sargis; NSF BCS0129601 to G. Gunnell, P. Gingerich, and JIB; NSF SBE-1028505 to E. Sargis and SGBC. Additional support was provided by the Leakey Foundation and a Brooklyn College Tow Faculty Travel Fellowship to SGBC and an NSERC Discovery Grant to MTS. A part of this manuscript was revised when JIB was supported as an Edward P. Bass Distinguished Visiting Environmental Scholar in the Yale Institute for Biospheric Studies (YIBS). 


\section{Figure Legends}

Figure 1. Photographs of Dryomomys szalayi (holotype: UM 41870) cranium in right lateral (A), left lateral (B), ventral (C), dorsal (D), rostral (E), and caudal (F) views. Scale $=1 \mathrm{~mm}$.

Figure 2. Photograph of Dryomomys szalayi (holotype: UM 41870) left and right dentaries in occlusal view. Detailed illustrations, descriptions, and comparisons of these dentaries, upper and lower teeth, and associated partial postcranial skeleton have been published elsewhere (Bloch et al., 2007; Chester and Bloch, 2013). Note the very elongate central incisors and acute angle of the articulated dentaries, consistent with the interpretation that D. szalayi had an elongate snout with a tapering rostrum. Scale $=1 \mathrm{~mm}$.

Figure 3. Photographs of Dryomomys szalayi (holotype: UM 41870) isolated left nasal in dorsal (A) and ventral (B) views. Note that the nasal is expanded distally and tapers rostrally. Scale = $1 \mathrm{~mm}$.

Figure 4. Photographs of Dryomomys szalayi (holotype: UM 41870) isolated left premaxilla with $\mathrm{I}^{1}$ and $\mathrm{I}^{2}$ in buccal (A), lingual (B), and occlusal (C) views. Scale $=1 \mathrm{~mm}$.

Figure 5. Photographs of Dryomomys szalayi (holotype: UM 41870) cranium in right lateral (A), left lateral (B), and dorsal (C) views. Abbreviations: ASC = anterior semicircular canal bu = bulla; $\mathbf{e a m}=$ external auditory meatus; $\mathbf{e g}=$ entoglenoid process $\mathbf{f r}=$ frontal; $\mathbf{i o f}=$ infraorbital foramen; ju = jugal (zygomatic); LC = left maxillary canine; $\mathbf{L m x}=$ left maxilla; LSC = lateral semicircular canal; $\mathbf{I t}=$ lacrimal tubercle; $\mathbf{M}=$ maxillary molar; $\mathbf{R C}=$ right maxillary canine; $\mathbf{R m x}=$ right maxilla; $\mathbf{o c}=$ occipital; $\mathbf{P}=$ maxillary premolar; $\mathbf{p a}=$ parietal; $\mathbf{p e t}=$ petrosal; $\mathbf{p g f}=$ postglenoid foramen; $\mathbf{p g p}=$ postglenoid process; $\mathbf{s m f}=$ stylomastoid foramen; $\mathbf{s q}=$ squamosal . In left lateral view (B) the white arrow points to the left promontorium, the dashed arrow indicates the articular surface for the jugal on the maxilla, and the dotted line runs along the temporal line on the frontal. In dorsal view (C) the dotted line follows the sagittal crest and the dashed arrow points at the rostral extent of the groove for the jugal on the zygomatic process of the maxilla. Scale $=1 \mathrm{~mm}$.

Figure 6. Photograph of Dryomomys szalayi (holotype: UM 41870) cranium in rostral view. Abbreviations: $\mathbf{C}=$ left maxillary canine; $\mathbf{f r}=$ frontal; iof = infraorbital foramen; $\mathbf{j u}=$ jugal (zygomatic); Lmx = left maxilla; $\mathbf{P}=$ maxillary premolar; $\mathbf{p a}=$ parietal; $\mathbf{R m x}=$ right maxilla; Rpet $=$ right petrosal; $\mathbf{s q}=$ squamosal. Scale $=1 \mathrm{~mm}$.

Figure 7. 3D reconstruction based on $\mu \mathrm{CT}$ data (visualized using Avizo 6 software) of the cranium of Dryomomys szalayi (UM 41870) in ventral view oriented with rostral towards the top of the page. Six coronal 2D slices oriented with ventral towards the bottom of the page are illustrated from locations as indicated with dashed horizontal lines. The $\mu \mathrm{CT}$ data were visualized as 697 stacked slices (slice no. 1 is at the rostral extent). Slices illustrate the infraorbital canal labeled with an asterisk (A; slice no. 244), lacrimal foramen labeled with a dashed arrow (B; slice no. 306), and nasal septum labeled with an asterisk (C; slice no. 341). The ethmoidal foramen is labeled with a dashed arrow (D; slice no. 398). The annular ridge that corresponds to the circular fissure of the brain, between the olfactory bulbs and the cerebrum, is 
labeled with a black asterisk, and an air space in the squamosal is indicated with a dashed arrow (E; slice no. 412). The postglenoid foramen is labeled with a dashed arrow (F; slice 447).

Figure 8. 3D reconstruction based on $\mu \mathrm{CT}$ data of the cranium of Dryomomys szalayi (UM 41870) in oblique dorsal view oriented with rostral towards the right of the page. A single parasagittal 2D slice oriented with ventral towards the bottom of the page is illustrated from the location indicated with a horizontal line. The asterisk sits in the region of the endocranial cavity that would have housed the olfactory bulbs. Note the presence of the annular ridge just caudal to the asterisk. This structure corresponds to the circular fissure of the brain, between the olfactory bulbs and the cerebrum.

Figure 9. Photograph of Dryomomys szalayi (holotype: UM 41870) cranium in ventral view. Abbreviations: bu = bulla; $\mathbf{e g}=$ entoglenoid process; $\mathbf{f r}=$ frontal; $\mathbf{g l}=$ glenoid fossa; $\mathbf{j u}=$ jugal (zygomatic); Lmx = left maxilla; Lpet = left petrosal; $\mathbf{o c}=$ occipital; $\mathbf{p a}=$ parietal; $\mathbf{p g f}=$ postglenoid foramen; $\mathbf{p g p}=$ postglenoid process; $\mathbf{p r}=$ promontorium; $\mathbf{p s}=$ posterior septum; $\mathbf{R C}$ = right maxillary canine $\mathbf{R} \mathbf{m x}=$ right maxilla; $\mathbf{s} \mathbf{1}=$ first (anterior) septum; $\mathbf{s} \mathbf{2}=$ second septum; $\mathbf{s 3}=$ third septum. The dotted line indicates the likely position of a part of the palatine-maxilla suture. The asterisk indicates the inflection point thought to characterize postorbital constriction. Scale $=1 \mathrm{~mm}$.

Figure 10. 3D reconstruction based on $\mu \mathrm{CT}$ data of the cranium of Dryomomys szalayi (UM 41870) in right lateral view. A single transverse 2D slice illustrates multiple air spaces in the squamosal (indicated by dashed arrows).

Figure 11. Photograph of Dryomomys szalayi (holotype: UM 41870) cranium in caudal view. Abbreviations: $\mathbf{b u}=$ bulla; $\mathbf{f c}=$ fenestra cochleae; $\mathbf{L p e t}=$ left petrosal; $\mathbf{L S C}=$ lateral semicircular canal; $\mathbf{m a c}=$ mastoid air cavity; $\mathbf{p a}=$ parietal $; \mathbf{p r}=$ promontorium $; \mathbf{P S C}=$ posterior semicircular canal. Scale $=1 \mathrm{~mm}$.

Figure 12. 3D reconstruction based on $\mu \mathrm{CT}$ data of the cranium of Dryomomys szalayi (UM 41870 ) in ventral view oriented with rostral towards the top of the page. Six coronal 2D slices oriented with ventral towards the bottom of the page are illustrated from locations as indicated with dashed horizontal lines. Slices illustrate the malleus and incus in the middle ear cavity labeled with dashed arrows (A; slice no. 514), foramen faciale labeled with a dashed arrow (B; slice no. 546), right and left cochlear parts of the bony labyrinth indicated with dashed and solid arrows respectively (C; slice no. 568), and stylomastoid foramen labeled with a dashed arrow (D; slice no. 575). A strut of bone that is continuous between the cochlear part of the bony labyrinth and the bulla, is indicated by a dashed arrow (E; slice no. 585), suggesting that the bulla was at least partially petrosal in origin. The right posterior semicircular canal is labeled with a dashed arrow (F; slice 626).

Figure 13. Photograph of caudal portion of Dryomomys szalayi (holotype: UM 41870) cranium in oblique left lateral view (A), and enlargement of left promontorium (B) with dashed arrows marking the course of the promontorial (a) and stapedial (b) branches of the internal carotid artery. Other abbreviations: $\mathbf{A S C}=$ anterior semicircular canal; $\mathbf{b u}=$ bulla; $\mathbf{e g}=$ entoglenoid process $; \mathbf{f} \mathbf{c}=$ fenestra cochleae $; \mathbf{f r}=$ frontal $\mathbf{f} \mathbf{v}=$ fenestra vestibuli $; \mathbf{g l}=$ glenoid fossa $;$ LSC = 
lateral semicircular canal; $\mathbf{p a}=$ parietal; $\mathbf{p g f}=$ postglenoid foramen; $\mathbf{p g p}=$ postglenoid process; pr $=$ promontorium. The solid arrow indicates a strut of bone that is continuous between the cochlear part of the bony labyrinth and the bulla, suggesting that the bulla was at least partly petrosal in origin. Scale $=1 \mathrm{~mm}$.

Figure 14. 3D reconstruction based on $\mu \mathrm{CT}$ data of the cranium of Dryomomys szalayi (UM 41870) cranium in oblique left lateral view with arrow marking a well defined groove on the internal surface of the bulla that may have housed the ectotympanic ring. Abbreviations: $\mathbf{A S C}=$ anterior semicircular canal; bu = bulla; iof = infraorbital foramen; $\mathbf{L m x}=$ left maxilla; $\mathrm{LSC}=$ lateral semicircular canal; $\mathbf{l t}=$ lacrimal tubercle; $\mathbf{P}=$ maxillary premolar; $\mathbf{p a}=$ parietal. Asterisk is in lacrimal foramen. Scale $=1 \mathrm{~mm}$.

Figure 15. 3D reconstructions based on $\mu \mathrm{CT}$ data of the left petrosal (image reversed) of a dentally associated nyctitheriid insectivore Plagioctenodon rosei (Manz et al., 2015; UF 274601) with intact ectotympanic (A), isolated right petrosal previously attributed to micromomyid Tinimomys graybulliensis (Gunnell, 1989; UM 85176) based on size and proximity to teeth of that taxon (B), a left petrosal (image reversed) of a second dentally associated nyctitheriid insectivore (Manz et al., in prep; UF 274600) with ectotympanic not intact (C), all from UM locality SC-327 (late Paleocene, Clarkforkian NALMA). 3D reconstructions of right petrosal previously attributed to micromomyid Tinimomys graybulliensis (MacPhee et al., 1995; USNM 461202) based on size, morphology, and likely association with teeth (D), and the dentally associated right petrosal of micromomyid Dryomomys szalayi (UM 41870) described here (E). Abbreviations: $\mathbf{b u}=$ bulla; $\mathbf{c t p p}=$ caudal tympanic process of the petrosal (shielding the fenestra cochleae); $\mathbf{e c}=$ ectotympanic; $\mathbf{f n}=$ groove for facial nerve; $\mathbf{f v}=$ fenestra vestibuli; lep = lateral epitympanic petrosal wing; $\mathbf{m s}=$ malleolar sulcus; $\mathbf{p r}=$ promontorium; $\mathbf{p s}=$ posterior septum (obscuring view of the fenestra cochleae); $\mathbf{s} \mathbf{f}=$ stapedial fossa. Scale $=1 \mathrm{~mm}$.

Figure 16. Photographs of Tinimomys graybulliensis (USNM 461202) dentition upper (A, B) and lower $(\mathrm{C}, \mathrm{D})$. Scale $=1 \mathrm{~mm}$.

Figure 17. 3D reconstructions based on $\mu \mathrm{CT}$ data of partial cranium of Tinimomys graybulliensis (USNM 461202) labeled in rostral (A), caudal (B), ventral (C) and dorsal (D) views. Abbreviations: ar = annular ridge; $\mathbf{c v}=$ caudal vertebra; $\mathbf{e g}=$ ?entoglenoid process; $\mathbf{e r}=$ epitympanic recess; $\mathbf{f c}=$ fenestra cochleae; $\mathbf{f r}=$ frontal $\mathbf{f v}=$ fenestra vestibuli; $\mathbf{? g l}=$ ?glenoid process $; \mathbf{h f}=$ hypoglossal foramen; $\mathbf{o c}=$ occipital; $\mathbf{o c c}=$ occipital condyle; $\mathbf{?} \mathbf{p a}=$ ?parietal; $\mathbf{p c}=$ postcranial elements $; \mathbf{p r}=$ promontorium; $\mathbf{s c}=$ sagittal crest $; \mathbf{~} \mathbf{s q}=$ ?squamosal. Scale $=1 \mathrm{~mm}$

Figure 18. 3D reconstructions based on $\mu \mathrm{CT}$ data of partial cranium of Tinimomys graybulliensis (USNM 461202) labeled in right lateral (A), right dorsolateral (B), and left lateral (C) views. Abbreviations: $\mathbf{a s r}=$ ascending ramus of the mandible; ?at $=$ foramen that may relate to the auditory tube; $\mathbf{c v}=$ caudal vertebra; $\mathbf{e g}=$ ?entoglenoid process; $\mathbf{e r}=$ epitympanic recess; $\mathbf{f c}=$ fenestra cochleae $\mathbf{f r}=$ frontal $\mathbf{f} \mathbf{f}=$ fenestra vestibuli $; \mathbf{~ g l}=$ ?glenoid process; $\mathbf{h f}=$ hypoglossal foramen; $\mathbf{o c}=$ occipital; $\mathbf{o c c}=$ occipital condyle; $\mathbf{?} \mathbf{p a}=$ ?parietal; $\mathbf{p c}=$ postcranial elements; $\mathbf{p r}=$ promontorium $; \mathbf{s c}=$ sagittal crest $\mathbf{?} \mathbf{s q}=$ ?squamosal. Scale $=1 \mathrm{~mm}$ 
Figure 19. 3D reconstruction based on $\mu \mathrm{CT}$ data of the cranium of Tinimomys graybulliensis (USNM 461202) in left lateral view. The transverse 2D slice is from the locations indicated with dashed horizontal lines. The slice illustrates the pathway of the facial nerve (foramen faciale) labeled with a dashed arrow. Scale $=1 \mathrm{~mm}$

Figure 20. A) Bivariate plot of ln (snout length) vs. In (cranial length) based on data from Bloch and Silcox (2006), with members of Chiroptera removed, and data for Dryomomys szalayi added (see SOM A). Total cranial length for D. szalayi $(25.88 \mathrm{~mm})$ was estimated by adding the length of the dentary from the tip of the central incisor to the condyle $(19.24 \mathrm{~mm})$ to the length of the bulla $(6.64 \mathrm{~mm})$. Total rostral length $(7.94 \mathrm{~mm})$ was measured by adding the length from the inflection of the dorsal root of the zygomatic to the anterior most part of the maxilla $(5.26 \mathrm{~mm})$ to the length of the premaxilla $(2.68 \mathrm{~mm})$. The line derives from a least squares regression $\left(\ln \left[\right.\right.$ snout length] $=-3.35+1.57 x \ln \left[\right.$ cranial length] $\left.; \mathrm{r}^{2}=00.789 ; p<0.0001\right)$. B) Bar graph of the residuals from the regression line for each individual, plotted in increasing order. Note that $D$. szalayi falls well above the regression line, with a high, positive residual, contrasting with the other primates, which fall below the line and have negative residuals. This indicates that $D$. szalayi had a relatively longer snout than other primates sampled, making it more similar to Tupaia, and to primitive eutherians such as Asioryctes.

Figure 21. Bivariate plot of the natural logarithm of the posterior carotid foramen (pcf) diameter on the natural logarithm of cranial length based on data from Kay et al. (1992) and Bloch and Silcox (2006) with data for Dryomomys szalayi added (see SOM B). The lines derive from least squares regressions performed independently for the functional and non-functional groupings, excluding the fossils (Functional: $\ln [\mathrm{pcf}]=-5.172+1.242 \mathrm{x} \ln \left[\right.$ cranial length], $\mathrm{r}^{2}=0.757, p=0.001$; Non-functional: $\ln [\mathrm{pcf}]=-6.698+1.321 \times \ln \left[\right.$ cranial length] $; \mathrm{r}^{2}=0.374 ; p=0.388$ ). Pcf diameter was estimated for $D$. szalayi using the groove for the ICA on the promontorium. Although $D$.

szalayi falls outside the range of sampled modern taxa, its position is more consistent with a nonfunctional internal carotid artery.

Figure 22. Results of cladistic analysis based on 34 taxa and 240 morphological characters (68 postcranial, 45 cranial, 127 dental; SOM C). Resulting strict consensus cladogram based on two equally parsimonious trees was calculated in TNT. This character matrix was modified from that of Silcox et al. (2010b) with tarsal characters for Purgatorius (as presented in Chester et al., 2015) and additional modifications to cranial characters for Micromomyidae and other taxa based on new insights from this study (SOM D). Bremer support indices calculated in TNT for listed nodes are as follows: $\mathbf{0}$ (ingroup) $\mathbf{1}=1 ; \mathbf{2}$ (Paleoryctidae) $=3 ; \mathbf{3}$ (Leptictida) $=1 ; \mathbf{4}=1$; $\mathbf{5}($ Laurasiatheria $)=2 ; \mathbf{6}($ Carnivora $)=3 ; 7=1 ; 8($ Eulipotyphla $)=3 ; 9($ Soricomorpha sensu lato $)=2 ; \mathbf{1 0}($ Soricidae $)=>10 ; \mathbf{1 1}($ Erinaceomorpha $)=>10 ; \mathbf{1 2}=2 ; \mathbf{1 3}($ Euarchontoglires $)=2$; $\mathbf{1 4}=1 ; \mathbf{1 5}($ Apatemyidae $)=7 ; \mathbf{1 6}=2 ; \mathbf{1 7}=2 ; \mathbf{1 8}=1 ; \mathbf{1 9}=3 ; \mathbf{2 0}($ Euarchonta $)=1$; 21 $($ Sundatheria $)=1 ; 22($ Scandentia $)=5 ; 23$ (Primates $)=1 ; 24=1 ; 25=1 ; 26=2$; 27 $($ Euprimateformes $)=3 ; \mathbf{2 8}$ (Plesiadapoidea) $=2 ; \mathbf{2 9}($ Euprimates $)=7 ; \mathbf{3 0}=2$. Unambiguous synapomorphies calculated in TNT for listed nodes are as follows: 13(Euarchontoglires) = 25(1), 42(1), 69(1), 98(0), 119(2), 120(1), 122(1), 173(0), 193(1), 204(0), 208(0), 233(1); 20(Euarchonta) = 11(1), 16(1), 40(0), 95(1), 130(0), 145(0); 21 $($ Sundatheria $)=19(1), 58(1), 76(1), 142(1), 160(2), 189(0), 201(1), 212(0), 221(2), 235(3)$; 22(Scandentia) = 39(1), 42(0), 52(1), 66(2), 72(2), 103(1), 105(1), 149(1), 150(1), 153(1), 
170(1), 175(1), 194(1), 204(1), 218(1); 23(Primates) = 115(1), 116(2), 205(1), 226(1), 228(1), 232(1); 24 = 166(1), 179(1), 190(1), 206(1); 25 = 128(1), 189(2), 192(1), 220(1), 221(1), 229(3); $26=9(1), 27(1), 103(1), 116(3), 135(1), 138(0), 171(2), 176(0), 218(1), 227(1), 228(2), 231(2)$; 27(Euprimateformes) = 16(0), 21(2), 56(1), 101(1), 159(1), 168(1), 209(1), 212(0), 214(1), 215(1); 28(Plesiadapoidea) = 129(1), 131(1), 144(0), 146(1), 188(1), 194(1), 202(2), 204(1); 29(Euprimates $)=147(0), 149(1), 166(0), 171(1), 173(2), 185(1), 187(0), 193(0), 232(0) ; 30=$ 218(0), 227(0).

\section{Supplementary Online Material}

SOM A. Data for snout and cranial length in a select sample of extant and fossil mammals (see

Fig. 20). Modified from Bloch and Silcox (2006).

\begin{tabular}{|c|c|c|c|c|c|c|}
\hline Taxon & Specimen number & $\begin{array}{l}\text { Cranial } \\
\text { length } \\
(\mathrm{mm})\end{array}$ & $\begin{array}{l}\text { Snout } \\
\text { length } \\
(\mathrm{mm})\end{array}$ & $\begin{array}{c}\text { In } \\
\text { (cranial } \\
\text { length) }\end{array}$ & $\begin{array}{c}\text { In } \\
\text { (snout } \\
\text { length) }\end{array}$ & Residual \\
\hline $\begin{array}{l}\text { Shoshonius } \\
\text { cooperi }\end{array}$ & CM 60494 & 28.10 & 2.55 & 3.34 & 0.94 & -0.9511 \\
\hline $\begin{array}{l}\text { Shoshonius } \\
\text { cooperi }\end{array}$ & CM 31366 & 25.90 & 2.80 & 3.25 & 1.03 & -0.7295 \\
\hline $\begin{array}{l}\text { Smilodectes } \\
\text { gracilis }\end{array}$ & UM 32773 & 60.00 & 12.14 & 4.09 & 2.50 & -0.5816 \\
\hline $\begin{array}{l}\text { Cantius } \\
\text { abditus }\end{array}$ & USNM 494881 & 82.00 & 25.84 & 4.41 & 3.25 & -0.3166 \\
\hline $\begin{array}{l}\text { Megadelphus } \\
\text { lundeliusi }\end{array}$ & AMNH 55284 & 101.55 & 36.23 & 4.62 & 3.59 & -0.3144 \\
\hline $\begin{array}{l}\text { Plesiadapis } \\
\text { tricuspidens }\end{array}$ & MNHN Cr126 & 106.14 & 42.72 & 4.66 & 3.75 & -0.2190 \\
\hline $\begin{array}{l}\text { Cynocephalus } \\
\text { volans }\end{array}$ & $\begin{array}{l}\text { USNM(MA) } \\
536048\end{array}$ & 69.02 & 22.87 & 4.23 & 3.13 & -0.1682 \\
\hline $\begin{array}{l}\text { Ignacius } \\
\text { graybullianus }\end{array}$ & USMN 421608 & 47.60 & 14.21 & 3.86 & 2.65 & -0.0607 \\
\hline $\begin{array}{l}\text { Cynocephalus } \\
\text { volans }\end{array}$ & $\begin{array}{l}\text { USNM(MA) } \\
219056\end{array}$ & 72.25 & 27.72 & 4.28 & 3.32 & -0.0477 \\
\hline $\begin{array}{l}\text { Carpolestes } \\
\text { simpsoni }\end{array}$ & $\begin{array}{l}\text { USNM } 482354 \\
\text { (cranial length) and } \\
\text { UM } 86270 \text { (snout } \\
\text { length) }\end{array}$ & 39.56 & 10.95 & 3.68 & 2.39 & -0.0308 \\
\hline Cynocephalus & USNM(MA) & 68.13 & 26.32 & 4.22 & 3.27 & -0.0073 \\
\hline
\end{tabular}




\begin{tabular}{|c|c|c|c|c|c|c|}
\hline volans & 144656 & & & & & \\
\hline $\begin{array}{l}\text { Galeopterus } \\
\text { variegatus }\end{array}$ & $\begin{array}{l}\text { USNM(MA) } \\
253411\end{array}$ & 68.38 & 26.80 & 4.23 & 3.29 & 0.0050 \\
\hline $\begin{array}{l}\text { Cynocephalus } \\
\text { volans }\end{array}$ & $\begin{array}{l}\text { USNM(MA) } \\
144660\end{array}$ & 68.75 & 27.69 & 4.23 & 3.32 & 0.0292 \\
\hline $\begin{array}{l}\text { Cynocephalus } \\
\text { volans }\end{array}$ & $\begin{array}{l}\text { USNM(MA) } \\
144662\end{array}$ & 62.21 & 24.26 & 4.13 & 3.19 & 0.0539 \\
\hline $\begin{array}{l}\text { Galeopterus } \\
\text { variegatus }\end{array}$ & USNM(MA) 84420 & 76.03 & 33.31 & 4.33 & 3.51 & 0.0560 \\
\hline $\begin{array}{l}\text { Ptilocercus } \\
\text { lowii }\end{array}$ & $\begin{array}{l}\text { USNM(MA) } \\
112611\end{array}$ & 37.17 & 10.90 & 3.62 & 2.39 & 0.0624 \\
\hline $\begin{array}{l}\text { Galeopterus } \\
\text { variegatus }\end{array}$ & $\begin{array}{l}\text { USNM(MA) } \\
255716\end{array}$ & 70.16 & 29.98 & 4.25 & 3.40 & 0.0768 \\
\hline $\begin{array}{l}\text { Ptilocercus } \\
\text { lowii }\end{array}$ & $\begin{array}{l}\text { USNM(MA) } \\
121855\end{array}$ & 36.06 & 10.60 & 3.59 & 2.36 & 0.0821 \\
\hline $\begin{array}{l}\text { Ptilocercus } \\
\text { lowii }\end{array}$ & $\begin{array}{l}\text { USNM(MA) } \\
488052\end{array}$ & 36.84 & 11.01 & 3.61 & 2.40 & 0.0865 \\
\hline $\begin{array}{l}\text { Galeopterus } \\
\text { variegatus }\end{array}$ & USNM(MA) 83276 & 60.52 & 24.43 & 4.10 & 3.20 & 0.1041 \\
\hline $\begin{array}{l}\text { Galeopterus } \\
\text { variegatus }\end{array}$ & $\begin{array}{l}\text { USNM(MA) } \\
115493\end{array}$ & 69.02 & 30.03 & 4.23 & 3.40 & 0.1042 \\
\hline $\begin{array}{l}\text { Galeopterus } \\
\text { variegatus }\end{array}$ & $\begin{array}{l}\text { USNM(MA) } \\
253412\end{array}$ & 72.50 & 33.14 & 4.28 & 3.50 & 0.1255 \\
\hline $\begin{array}{l}\text { Ptilocercus } \\
\text { lowii }\end{array}$ & $\begin{array}{l}\text { USNM(MA) } \\
488061\end{array}$ & 35.76 & 11.08 & 3.58 & 2.41 & 0.1395 \\
\hline $\begin{array}{l}\text { Leptictis } \\
\text { dakotensis }\end{array}$ & AMNH 108194 & 67.50 & 31.74 & 4.21 & 3.46 & 0.1945 \\
\hline $\begin{array}{l}\text { Ptilocercus } \\
\text { lowii }\end{array}$ & $\begin{array}{l}\text { USNM(MA) } \\
291272\end{array}$ & 37.05 & 12.44 & 3.61 & 2.52 & 0.1999 \\
\hline Tupaia glis & $\begin{array}{l}\text { USNM(MA) } \\
487951\end{array}$ & 51.60 & 22.97 & 3.94 & 3.13 & 0.2929 \\
\hline Tupaia glis & $\begin{array}{l}\text { USNM(MA) } \\
487952\end{array}$ & 49.58 & 21.81 & 3.90 & 3.08 & 0.3037 \\
\hline $\begin{array}{l}\text { Dryomomys } \\
\text { szalayi }\end{array}$ & UM 41870 & 25.88 & 7.94 & 3.25 & 2.07 & 0.3140 \\
\hline Tupaia glis & $\begin{array}{l}\text { USNM(MA) } \\
487953\end{array}$ & 51.18 & 23.27 & 3.94 & 3.15 & 0.3187 \\
\hline $\begin{array}{l}\text { Asioryctes } \\
\text { nemegtensis }\end{array}$ & MgM-I/56 & 30.46 & 10.52 & 3.42 & 2.35 & 0.3397 \\
\hline Tupaia glis & $\begin{array}{l}\text { USNM(MA) } \\
487950\end{array}$ & 51.06 & 23.81 & 3.93 & 3.17 & 0.3453 \\
\hline Tupaia glis & $\begin{array}{l}\text { USNM(MA) } \\
487949\end{array}$ & 50.93 & 23.86 & 3.93 & 3.17 & 0.3514 \\
\hline
\end{tabular}


SOM B. Data for posterior carotid foramen (pcf) diameter and cranial length (see Fig. 21).

Modified from Kay et al. (1992) and Bloch and Silcox (2006).

\begin{tabular}{|c|c|c|c|c|}
\hline Taxon & pcf & Skull length & $\begin{array}{c}\text { Ln (skull } \\
\text { length) }\end{array}$ & Ln (pcf) \\
\hline $\begin{array}{l}\text { Ignacius } \\
\text { graybullianus }\end{array}$ & 0.17 & 48.20 & 3.8754 & -1.7720 \\
\hline Erinaceus sp. & 0.43 & 45.00 & 3.8067 & -0.8440 \\
\hline Tupaia glis & 0.62 & 49.10 & 3.8939 & -0.4780 \\
\hline Tupaia tana & 0.81 & 59.40 & 4.0843 & -0.2107 \\
\hline $\begin{array}{l}\text { Nycticebus } \\
\text { coucang }\end{array}$ & 0.45 & 59.20 & 4.0809 & -0.7985 \\
\hline $\begin{array}{l}\text { Perodicticus } \\
\text { potto }\end{array}$ & 0.18 & 61.90 & 4.1255 & -1.7148 \\
\hline $\begin{array}{l}\text { Galago } \\
\text { senegalensis }\end{array}$ & 0.20 & 46.80 & 3.8459 & -1.6094 \\
\hline $\begin{array}{l}\text { Galago } \\
\text { demidovii }\end{array}$ & 0.14 & 37.30 & 3.6190 & -1.9661 \\
\hline Eulemur fulvus & 0.68 & 87.30 & 4.4694 & -0.3857 \\
\hline Lemur sp. & 0.75 & 83.70 & 4.4272 & -0.2877 \\
\hline Tarsius sp. & 0.56 & 39.30 & 3.6712 & -0.5798 \\
\hline $\begin{array}{l}\text { Callithrix } \\
\text { argentata }\end{array}$ & 0.74 & 45.70 & 3.8221 & -0.3011 \\
\hline $\begin{array}{l}\text { Callicebus sp. } \\
\text { (Bolivia) }\end{array}$ & 1.05 & 59.00 & 4.0775 & 0.0488 \\
\hline $\begin{array}{l}\text { Saguinus } \\
\text { mystax }\end{array}$ & 0.99 & 50.70 & 3.9259 & -0.0101 \\
\hline $\begin{array}{l}\text { Saimiri } \\
\text { sciureus }\end{array}$ & 1.24 & 59.70 & 4.0893 & 0.2151 \\
\hline $\begin{array}{l}\text { Aotus } \\
\text { trivirgatus }\end{array}$ & 1.30 & 62.70 & 4.1384 & 0.2624 \\
\hline Cebus apella & 2.00 & 95.50 & 4.5591 & 0.6931 \\
\hline $\begin{array}{l}\text { Pithecia } \\
\text { pithecia }\end{array}$ & 1.37 & 82.60 & 4.4140 & 0.3148 \\
\hline Ateles geoffroyi & 2.42 & 102.90 & 4.6338 & 0.8838 \\
\hline Alouatta pigra & 2.50 & 104.40 & 4.6482 & 0.9163 \\
\hline $\begin{array}{l}\text { Carpolestes } \\
\text { simpsoni (pcf) }\end{array}$ & 0.40 & 39.56 & 3.6778 & -0.9163 \\
\hline $\begin{array}{l}\text { Carpolestes } \\
\text { simpsoni (ICA } \\
\text { stem) }\end{array}$ & 0.53 & 39.56 & 3.6778 & -0.6444 \\
\hline $\begin{array}{l}\text { Dryomomys } \\
\text { szalayi (ICA } \\
\text { stem) }\end{array}$ & 0.12 & 25.88 & 3.2535 & -2.1203 \\
\hline
\end{tabular}


SOM C. Descriptions of morphological characters (see SOM D) used in the cladistic analysis modified from Silcox et al. (2010b) based on new observations on the cranial anatomy described and discussed in this study as indicated in italics (Modified Character Codings: 69, 73, 74, 79, 97, 98, 103, 105, 107, 110). Characters were treated as unweighted and unordered. Characters are tagged so that the first one or two letters refer to the larger partition to which they belong (i.e., $\mathrm{PC}=$ postcranial; $\mathrm{Cr}=$ cranial; $\mathrm{D}=$ dental), and the word(s) or abbreviation that follows indicates to which element or part of the skeleton the character refers (e.g., characters tagged "Axial" all pertain to the axial skeleton, characters tagged " $\mathrm{P}_{4}$ " all pertain to that tooth).

1. PC, Scapula, Metacromion form: (0) absent; (1) small but present; (2) very large - larger than acromion.

2. PC, Humerus, Projection of greater tuberosity: (0) small tuberosity that does not extend superior to head; (1) even with or slightly above head; (2) extends far superior to head. 3. PC, Humerus, Projection of lesser tuberosity: (0) not projecting, small; (1) large and medially projecting .

4. PC, Humerus, Deltopectoral crest form: (0) sharp and elevated; (1) broad and elevated. 5. PC, Humerus, Deltopectoral crest tip form: (0) crest tapers to a point; (1) crest has broad, rounded, shelf-like distal end.

6. PC, Humerus, Deltopectoral crest proportional length: (0) less than 50\% humerus length; (1) between 50\% and 67\% humerus length: (2) greater than $67 \%$ humerus length.

7. PC, Humerus, Olecranon fossa depth: (0) shallow, or slit-like; (1) deep and pit-like; (2) deep, pit-like, and perforated. 
8. PC, Humerus, Medial epicondyle projection: (0) makes up less than $25 \%$ of entire distal end width; (1) makes up $25 \%$ or more of entire distal end width.

9. PC, Humerus, Supinator crest development: (0) present as a distinct ridge; (1) projects prominently posterolaterally; (2) absent - rounded lateral surface of distal humeral shaft.

10. PC, Humerus, Prominence of teres tubercle on medial side: (0) small or indistinct; (1) prominent and crest-like.

11. PC, Humerus, Capitulum shape: (0) spindle-shaped; (1) ovoid or spherical.

12. PC, Humerus, Humeral trochlear morphology: (0) medial keel only; (1) medial and lateral keels, trochlea and capitulum well-separated.

13. PC, Radius, Radial head shape: (0) minimum diameter greater than $70 \%$ maximum diameter; (1) minimum diameter between $70 \%$ and $60 \%$ maximum diameter; (2) minimum diameter less than or equal to $60 \%$ maximum diameter.

14. PC, Radius, Bicipital tuberosity presence: (0) present; (1) absent.

15. PC, Radius, Distal radius-ulna contact: (0) ligamentous or synovial; (1) synostosis.

16. PC, Radius, Ridge on dorsal surface of distal end presence: (0) absent; (1) present .

17. PC, Ulna, Olecranon relative length: (0) less than $20 \%$ total ulna length; (1) between $20 \%$ and $25 \%$ of total ulna length; (2) greater than $25 \%$ total ulna length.

18. PC, Ulna, Olecranon tip form: (0) straight, with no flare beyond more proximal part of olecranon; (1) tip flares somewhat medially; (2) tip flares prominently medially.

19. PC, Carpals, Scaphoid-lunate fusion: (0) unfused; (1) fused.

20. PC, Metapodial, MCIII dorsal surface form: (0) smooth; (1) with distinct extensor tubercle. 
21. PC, Phalanges, Digit elongation index ([Intermediate phalanx length + proximal phalanx length]/ humerus length) of digit III or IV: (0) less than 35\%; (1) 35\%-50\%; (2) greater than $50 \%$.

22. PC, Phalanges, Prehensility index of digit III of the manus: (0) intermediate phalanx less than $80 \%$ of metacarpal length; (1) greater than or equal to $80 \%$.

23. PC, Innominate, Anterior inferior iliac spine development: (0) absent; (1) distinct but small;

(2) pronounced and laterally projecting.

24. PC, Innominate, Ilium shape: (0) rod-like; (1) blade-like.

25. PC, Innominate, Buttressing of acetabulum: (0) no buttressing; (1) cranial buttressing; (2) caudal buttressing.

26. PC, Innominate, Ischiopubic symphysis presence and form: (0) absent; (1) present but narrow craniocaudally (2) robust - long craniocaudally.

27. PC, Femur, Greater trochanter projection: (0) below femoral head (ratio of femoral length including greater trochanter to that length not including trochanter, but measured to the superior surface of the head, is less than 1); (1) even with femoral head (ratio is between 1 and 1.05); (2) prominent, extending above femoral head (ratio is greater than 1.05).

28. PC, Femur, Greater trochanter relative anteroposterior (AP) expansion: (0) trochanter AP dimension less than $120 \%$ midshaft AP dimension; (1) trochanter AP dimension $120 \%$ or greater midshaft AP dimension.

29. PC, Femur, Lesser trochanter orientation: (0) medially projecting; (1) posteromedially or posteriorly projecting.

30. PC, Femur, Third trochanter position: (0) far distal to lesser trochanter; (1) slightly distal to lesser trochanter; (2) proximal to lesser trochanter. 
31. PC, Femur, Third trochanter lateral projection: (0) small, not projecting; (1) prominently projecting.

32. PC, Femur, Patellar groove form: (0) proximodistal length less than $150 \%$ of mediolateral dimension; (1) proximodistal length greater than or equal to $150 \%$ of mediolateral dimension. 33. PC, Tibia-Fibula, Relative shaft length: (0) tibia no longer than femur; (1) tibia longer than femur.

34. PC, Tibia-Fibula, Tibia shaft shape: (0) straight; (1) bowed and thus laterally concave.

35. PC, Tibia-Fibula, Popliteal tuberosity (process on the anteromedial surface of the proximal tibia) presence: (0) present; (1) absent.

36. PC, Tibia-Fibula, Distal contact form: (0) ligamentous or synovial; (1) synostosis - fused.

37. PC, Tibia-Fibula, Tibial posterior process development: (0) small or absent; (1) prominently distally projecting.

38. PC, Tibia-Fibula, Medial malleolus form: (0) well-developed; (1) small; (2) absent.

39. PC, Tibia-fibula, Medial malleolus relation to sustentaculum tali (scored as inapplicable if medial malleolus was scored as "absent" in the preceding character): (0) no posterior contact; (1) posterior contact.

40. PC, Astragalus, Form of trochlea of body: (0) shallowly grooved; (1) deeply grooved. 41. PC, Astragalus, Regions of trochlea of body: (0) not clearly separated into regions or regions equal in mediolateral width; (1) lateral region wider than medial region; (2) medial region wider than lateral region.

42. PC, Astragalus, Relative height of trochlear borders: (0) medial border less than $90 \%$ height of lateral border; (1) medial border 90\% to 110\% height of lateral border; (2) medial border greater than $110 \%$ height of lateral border. 
43. PC, Astragalus, Astragalar body medial aspect: (0) flat; (1) deeply concave, cotylar fossa. 44. PC, Astragalus, Astragalar medial border of body crimped (medial margin is relatively deeper dorsoventrally than long proximodistally): (0) absent; (1) present.

45. PC, Astragalus, Sustentacular and navicular facet contact: (0) no contact; (1) contact on lateral side; (2) contact on medial side; (3) contact on ventral side.

46. PC, Astragalus, Fibular facet form and orientation: (0) flat and faces laterodorsally; (1) faces laterally but has laterally-flaring, dorsally-facing shelf; (2) flat and faces laterally with no shelf. 47. PC, Astragalus, Ectal facet form (0) evenly concave, (1) unevenly concave or "peaked." 48. PC, Astragalus, Head shape: (0) maximum diameter less than $140 \%$ of minimum diameter; (1) greater than or equal to $140 \%$.

49. PC, Astragalus, Flexor fibularis groove presence: (0) present, separate from trochlea; (1) absent.

50. PC, Calcaneum, Fibular facet orientation: (0) large and lateral; (1) large and distal; (2) small or absent.

51. PC, Calcaneum, Plantar pit on cuboid facet presence: (0) absent; (1) present.

52. PC, Calcaneum, Peroneal tubercle position: (0) distal; (1) proximal.

53. PC, Calcaneum, Ectal facet proximal margin shape: (0) convex; (1) concavoconvex.

54. PC, Calcaneum, Shaft (body and tuber) shape: (0) straight or laterally bowed; (1) medially bowed (= laterally convex).

55. PC, Entocuneiform, Plantodistal process presence: (0) present; (1) absent.

56. PC, Entocuneiform, Proximal extension of medial metatarsal 1 facet presence: (0) absent; (1) present.

57. PC, Metapodial, Metatarsal I torsion: (0) absent; (1) present. 
58. PC, Metapodial, Bifurcate keel on metatarsal I presence: (0) absent; (1) present.

59. PC, Metapodial, Cylindrical (instead of spherical) metapodial heads presence (score from the central metapodials of either the manus or pes): (0) absent; (1) present.

60. PC, Phalanges, Distal phalanx of pedal digit I shape: (0) claw shaped; (1) flattened as a nail. 61. PC, Phalanges, Ungual pedal phalanx of digit III-IV relative length: (0) greater than $110 \%$ length of respective intermediate phalanges; (1) less than or equal to $110 \%$.

62. PC, Phalanges, Asymmetrical manual or pedal intermediate phalanx distal ends presence: (0) absent; (1) present.

63. PC, Phalanges, Flexor sheath attachments on proximal phalanges of the manus or pes:

(0) reduced or present as bony processes; (1) present as long ridges but not substantially ventrally projecting; (2) substantially ventrally projecting.

64. PC, Axial, Axis spinous process orientation: (0) caudal; (1) cranial.

65. PC, Axial, Anapophysis number: (0) present on all or all but ultimate lumbar vertebrae; (1) lacking on all or all but first lumbar vertebrae.

66. PC, Axial, Sacral vertebra spinous process: (0) all equal; (1) first reduced or absent; (2) first two reduced or absent.

67. PC, Axial, Manubrium sterni form: (0) not enlarged; (1) enlarged with ventral keel that extends to anterior margin; (2) dorsoventrally thickened with ventral keel poorly developed; (3) with prominent anterior process and short posterior process.

68. PC, Axial, Rib morphology: (0) narrow; (1) broad.

69. Cr, Snout, Length: (0) long; (1) moderate; (2) very short. Coding for micromomyids changed from Silcox et al (2010b). Was coded as State "0," now coded as State "1." 
70. Cr, Nasal, Posterior extension: (0) extends to $\mathrm{M}^{3}$; (1) extends to $\mathrm{M}^{1}$; (2) extends to $\mathrm{P}^{4}$.

71. Cr, Nasal, Frontonasal contact relative size: (0) broad, nasals reach lacrimal and maxilla is separated from frontal; (1) semi expanded - nasals flare posteriad but do not touch lacrimal; (2) restricted - nasals narrow posteriad.

72. Cr, Jugal, Zygomatic arch form: (0) incomplete - jugal absent; (1) complete without postorbital bar; (2) complete with postorbital bar.

73. Cr, Lacrimal, Tubercle development: (0) distinctly present; (1) poorly defined or absent. Coding for micromomyids changed from Silcox et al (2010b). Was coded as State "?, " now coded as State “0.”

74. Cr, Premaxilla, Frontal contact: (0) absent; (1) present. Coding for micromomyids changed from Silcox et al (2010b). Was coded as State "?," now coded as State "0."

75. Cr, Maxilla, Orbital mosaic maxillary contacts: (0) frontal; (1) palatine excludes from frontal contact; (2) non-palatine bone prevents maxillary-frontal contact.

76. Cr, Maxilla, Infraorbital foramen size: (0) larger than $15 \%$ maximum breadth between cheek tooth arcades; (1) $15 \%$ or less.

77. Cr, Maxilla, Infraorbital foramen position: (0) above $\mathrm{M}^{1}$; (1) above $\mathrm{P}^{4}$; (2) above $\mathrm{P}^{3}$.

78. Cr, Palatine, Postpalatine spine presence: (0) large; (1) small or absent.

79. Cr, Alisphenoid ,Tympanic process development: (0) small or absent; (1) substantial - may form anterior margin of bulla. Coding for micromomyids changed from Silcox et al (2010b). Was coded as State "1," now coded as State "?."

80. Cr, Alisphenoid, Ectopterygoid crest development: (0) no alisphenoid-tipped ectopterygoid crest; (1) alisphenoid-tipped crest equal or smaller than entopterygoid crest; (2) alisphenoidtipped crest much larger than entopterygoid crest. 
81. Cr, Alisphenoid, Canal for ramus infraorbitalis presence: (0) present; (1) absent.

82. Cr, Alisphenoid, Foramen rotundum presence: (0) present; (1) absent.

83. Cr, Alisphenoid, Borders of foramen ovale: (0) foramen ovale contained by alisphenoid; (1) between alisphenoid and squamosal and/or petrosal.

84. Cr, Alisphenoid, Transverse canal (foramen subovale) presence: (0) absent; (1) present.

85. Cr, Basisphenoid, Tympanic process development: (0) small to absent; (1) substantial - may form much of anteromedial wall and floor of bulla.

86. Cr, Basisphenoid, Morphology relating to vidian nerve: (0) foramen for vidian nerve in basisphenoid in tympanic cavity; (1) groove leads to foramen outside of tympanic cavity; (2) no morphological evidence of vidian nerve.

87. Cr, Basisphenoid, Anterior carotid foramen composition: (0) piriform fenestra; (1) basisphenoid.

88. Cr, Basioccipital, Tympanic process development: (0) absent; (1) distinctly present.

89. Cr, Basioccipital, Central stem breadth: (0) mediolaterally broad central stem, tympanic cavities well separated; (1) mediolaterally narrow central stem, tympanic cavities nearly in contact.

90. Cr, Basioccipital, Dorsum sellae presence: (0) absent; (1) present, with prominent posterior clinoid processes.

91. Cr, Occipital, Tentorium cerebelli condition: (0) unossified; (1) ossified.

92. Cr, Occipital, Nuchal crest development: (0) poorly developed or absent; (1) distinct and large.

93. Cr, Squamosal, Postglenoid process form: (0) absent; (1) present rostral to postglenoid foramen; (2) present lateral or caudal to postglenoid foramen. 
94. Cr, Squamosal, Entoglenoid process form: (0) absent; (1) present but small (smaller than postglenoid process - if present); (2) present and large.

95. Cr, Squamosal, Pathway for the ramus inferior of the stapedial artery location: (0) separate from chorda tympani nerve and Glaserian fissure; (1) within Glaserian fissure with chorda tympani nerve.

96. Cr, Squamosal/Petrosal, Epitympanic recess size: (0) small (less than half the width of the promotorium); (1) large (more than half the width of the promontorium).

97. Cr, Ectotympanic, Degree to which it is covered by other bones: (0) phaneric; (1) completely covered by bony bulla. Coding for micromomyids changed from Silcox et al (2010b). Was coded as State "0," now coded as State "1." Paromomyidae has also been changed to state "1" (see Bloch and Silcox, 2001; contra Kay et al., 1992). The coding of Ottoryctes has been changed from "1" to "?" (as preservation is really not adequate to determine the state; see Bloch et al., 2004), Leptictidae from "1" to "0" (following Novacek, 1986 who notes that the ring is not completely covered), and Pararyctes, previously coded as "1" (following Asher et al., 2002) to "O" following our own observation that the condition is similar to that of Solenodon in having a visable ectotympanic ring laterally that is not covered by entotympanic bulla.

98. Cr, Ectotympanic, Shape: (0) very narrow ring; (1) moderately expanded ring; (2) vastly expanded - may form much or all of ossified bulla. Dryomomys and Ignacius were previously coded as "2" in Silcox et al (2010b). The codings have been changing to "0" based on the observation that they both have very similar ectotypmanic rings incorporated in to the walls of the bulla. Plesiadapis is coded as "?" as it differs from that of the other taxa with the ring separated from the wall of the bulla by bony struts. 
99. Cr, Petrosal, Caudal tympanic process development: (0) absent or very small; (1) present and not very small (small to extensive sensu MacPhee et al., 1988).

100. Cr, Petrosal, Rostral tympanic process presence: (0) small or absent; (1) present.

101. Cr, Petrosal, Bulla presence (score as inapplicable if rostral tympanic process is absent): 0 absent; (1) present.

102. Cr, Petrosal, Piriform fenestra development: (0) expansive medially, laterally, and/or caudally; (1) reduced or absent

103. Cr, Petrosal, Facial nerve pathway: (0) open sulcus; (1) fully closed canal. Coding for micromomyids changed from Silcox et al (2010b). Was coded as State “1,” now coded as State “0."

104. Cr, Petrosal, Expression of promontory branch of ICA on promontorium: (0) groove; (1) tube; (2) no expression.

105. Cr, Petrosal, Stapedial branch of internal carotid artery (ICA) on promontorium expression: (0) distinct groove; (1) tube; (2) little or no expression. Coding for micromomyids changed from Silcox et al (2010b). Was coded as State "?," now coded as State "2."

106. Cr, Petrosal Bony tube for stapedial artery condition (1.0) (score as inapplicable if bony tube is absent): (0) stops at fenestra vestibule; (1) continues through fenestra vestibuli 107. Cr, Petrosal, Fenestra cochleae visibility: (0) visible (when bulla, if present, is removed); 1 shielded by petrosal. Coding for carpolestids changed from Silcox et al (2010b). Was coded as State "0," now coded as State "1."

108. Cr, Entotympanic, Presence and degree of development: (0) absent; (1) present, small; (2) present and contributes to much of an ossified bulla. 
109. Cr, Parietal/Occiptal, Foramina in the lateral braincase (likely for the rami temporales;

Wible, 2008; =sinus canal Novacek, 1986) presence: (0) absent; (1) one or two present; (2) many present, proliferated.

110. Cr, Parietal, Temporal lines or crest form: (0) single sagittal crest; (1) parallel parasagittal crests or temporal lines. Coding for micromomyids changed from Silcox et al (2010b). Was coded as State "?," now coded as State "0."

111. Cr, Parietal, Orbitotemporal canal (sensu Wible 2008; =sinus canal McDowell, 1958;

=ophthalmic sulcus Novacek, 1986) for ramus supraorbitalis of ramus superior presence: (0)

present - groove on internal aspect of braincase; (1) absent.

112. Cr, Dentary, Internal ridge caudal to toothrow development: (0) incomplete, reduced or absent ridge between $\mathrm{M}_{3}$ and condyle; (1) prominent ridge between $\mathrm{M}_{3}$ and condyle.

113. Cr, Dentary, Posteriormost mental foramen position: (0) beneath $\mathrm{m} 1$ or farther distal; (1) beneath $\mathrm{P}_{4} ;(2)$ beneath $\mathrm{P}_{3}$ or farther mesial.

114. D, $\mathrm{I}^{1}$, Size: (0) similar in size to other incisors or premolars (if $\mathrm{I}^{2-3}$ are missing); (1) much larger than other incisors or premolars (if $\mathrm{I}^{2-3}$ are missing); (2) tooth absent.

115. D, I ${ }^{1}$, Tip strongly recurved presence: (0) absent; (1) present.

116. D, $\mathrm{I}^{1}$, Accessory cuspules presence: (0) no accessory cuspules; (1) posterocone present but no apical cuspules; (2) posterocone and small cuspules developed around the tip; no strong apical division; (3) strong apical division into an anterocone and laterocone in addition to the presence of a protocone.

117. D, $\mathrm{I}^{1}$, Restricted enamel presence and distribution: (0) absent (enamel surrounds the entire tooth); (1) restricted to an anterior band; (2) bands of enamel present on both anterior and posterior surfaces. 
118. D, I' $\mathrm{I}^{2}$, Presence: (0) present; (1) absent.

119. D, I ${ }^{2}$, Size: (0) tooth absent; (1) present but small (2) large.

120. D, I $\mathrm{I}^{3}$, Presence: (0) present; (1) absent.

121. D, $C^{1}$, Upper canine root number: (0) single rooted; (1) double rooted; (2) tooth absent.

122. D, $\mathrm{P}^{1}$, Presence: (0) present; (1) absent.

123. D, $\mathrm{P}^{2}$, Root number: (0) tooth absent; (1) double rooted; (2) single rooted, (3) triple rooted.

124. D, $\mathrm{P}^{2}$, Parastyle (anterior basal cusp) presence: (0) poorly developed or absent; (1) distinct.

125. D, $\mathrm{P}^{3}$, Root number: (0) triple rooted; (1) double rooted; (2) single rooted; (3) tooth absent.

126. D, $\mathrm{P}^{3}$, Shape (buccal length/lingual length): (0) less than 1.8; (1) 1.8-2.0; (2) more than 2.0.

127. D, $\mathrm{P}^{3}$, Size relative to $\mathrm{P}^{4}$ based on $\left(\ln (\right.$ buccal length $\mathrm{x}$ width $\left.) \mathrm{P}^{3}\right) /(\ln ($ buccal length $\mathrm{x}$

width) $\left.\mathrm{P}^{4}\right)$ : (0) less than 0.6; (1) 0.6-1.2; (2) more than 1.2.

128. D, $\mathrm{P}^{3}$, Parastyle (anterior basal cusp) presence: (0) distinct; (1) absent.

129. D, $\mathrm{P}^{3}$, Metacone presence: (0) absent; (1) present.

130. D, $\mathrm{P}^{3}$, Metastyle presence: (0) absent; (1) present.

131. D, $\mathrm{P}^{3}$, Conules presence and number: (0) absent; (1) one present; (2) two present.

132. D, $\mathrm{P}^{3}$, Protocone presence: (0) absent; (1) present.

133. D, $\mathrm{P}^{3}$, Hypocone presence: (0) absent; (1) present.

134. D, $\mathrm{P}^{4}$, Number of roots: (0) one; (1) two; (2) three.

135. D, $\mathrm{P}^{4}$, Shape (buccal length/lingual length): (0) more than 1.8; (1) less than or equal to 1.8.

136. D, $\mathrm{P}^{4}$, Cusp acuteness: (0) acute; (1) bulbous.

137. D, $\mathrm{P}^{4}$, Carnassial shear with $\mathrm{m} 1$ presence: (0) absent; (1) present.

138. $\mathrm{D}, \mathrm{P}^{4}$, Size relative to $\mathrm{M}^{1}$ based on ( $\ln \left(\right.$ buccal length $\mathrm{x}$ width) $\left.\mathrm{P}^{4}\right) /(\ln ($ buccal length $\mathrm{x}$ width) $\mathrm{M}^{1}$ ): (0) less than 0.9; (1) 0.90-0.98; (2) more than 0.98 . 
139. D, $\mathrm{P}^{4}$, Width relative to $\mathrm{M}^{1}$ : (0) $\mathrm{P}^{4}$ not as wide transversely as $\mathrm{M}^{1}$; (1) $\mathrm{P}^{4}$ as wide as or wider transversely as $\mathbf{M}^{1}$.

140. D, $\mathrm{P}^{4}$, Cusp height in lateral view relative to $\mathrm{M}^{1}$ : (0) $\mathrm{P}^{4}$ lower than $\mathrm{M}^{1}$; (1) $\mathrm{P}^{4}$ equal to or greater in height than $\mathrm{M}^{1}$.

141. D, $\mathrm{P}^{4}$, Stylar shelf development: (0) wide laterally and very narrow in the middle because of a strong ectoflexus; (1) ectoflexus weak with little or no stylar shelf.

142. D, $\mathrm{P}^{4}$, Parastyle presence: (0) present; (1) absent.

143. D, $\mathrm{P}^{4}$, Parastylar lobe morphology: (0) large, projecting; (1) small, not projecting.

144. D, $\mathrm{P}^{4}$, Metacone presence: (0) present; (1) absent.

145. D, $\mathrm{P}^{4}$, Metastyle presence: (0) absent ; (1) present.

146. $\mathrm{D}, \mathrm{P}^{4}$, Conules presence and size: (0) absent; (1) one large conule present located near the midline of the tooth mesiodistally; (2) small paraconule present; (3) both conules present, strong; (4) metaconule present, no paraconule.

147. D, $\mathrm{P}^{4}$, Protocone lobe shape: (0) shorter mesiodistally than wide; (1) equally long and wide. 148. D, $\mathrm{P}^{4}$, Preprotocrista presence: (0) present; (1) absent.

149. D, $\mathrm{P}^{4}$, Protocone position: (0) not mesial to paracone; (1) mesial to paracone.

150. D, $\mathrm{P}^{4}$, Postprotocrista presence: (0) present; (1) absent.

151. D, $\mathrm{P}^{4}$, Postprotocingulum presence: (0) absent; (1) present.

152. D, $\mathrm{P}^{4}$, Hypocone presence: (0) totally absent; (1) present, at least incipiently.

153. $D, M^{1}$, Length relative to transverse width compared to $M^{2}$ or $M^{3}$ : (0) $M^{1}$ similarly elongate relative to transverse width than $\mathrm{M}^{2}$ or $\mathrm{M}^{3}$; (1) $\mathrm{M}^{1}$ more elongate relative to transverse width than $\mathrm{M}^{2}$ or $\mathrm{M}^{3}$. 
154. D, $\mathrm{M}^{1}$, Ectoflexus depth: (0) deep with the stylar shelf wide at the corners and almost disappearing in the middle; (1) shallow.

155. D, $\mathrm{M}^{1}$, W-shaped ectoloph presence: (0) absent; (1) present.

156. D, $\mathrm{M}^{1}$, Precingulum presence: (0) present, doesn't connect to postcingulum; (1) present, connects to postcingulum in at least some specimens; (2) precingulum absent.

157. D, $\mathrm{M}^{1}$, Pre- and paracingula continuity: (0) not continuous; (1) continuous; (2) no paracingulum.

158. D, $\mathrm{M}^{1}$, Parastylar lobe morphology: (0) projecting beyond the plane of the mesiolingual corner of the tooth; (1) not projecting.

159. D, $\mathrm{M}^{1}$, Preparacrista orientation: (0) angled buccally; (1) straight; (2) crest absent.

160. D, $\mathrm{M}^{1}$, Paracone and metacone relative sizes: (0) paracone larger than metacone or metacone absent; (1) cusps are subequal; (2) metacone larger than paracone.

161. D, $\mathrm{M}^{1}$, Paracone and metacone bases relationship (0) $\mathrm{M}^{1}$ paracone and metacone clearly separated at their bases; (1) $\mathrm{M}^{1}$ paracone and metacone connate (no separation at the bases of the cusps).

162. D, $\mathrm{M}^{1}$, Metastylar region buccal projection: (0) greater than parastylar region; (1) less than or equal to parastylar region.

163. D, $\mathrm{M}^{1}$, Metastyle presence: (0) absent; (1) present.

164. D, $\mathrm{M}^{1}$, Post- and metacingula continuity: (0) not continuous; (1) continuous.

165. D, $\mathrm{M}^{1}$, Conules presence: (0) both conules presen; (1) metaconule absent; (2) both weak or absent; (3) paraconule absent.

166. $\mathrm{D}, \mathrm{M}^{1}$, Conules position: (0) central or closer to protocone than to paracone and metacone; (1) appressed to paracone and metacone. 
167. D, $\mathrm{M}^{1}$, Protocone size relative to the buccal half of the tooth: (0) large; (1) small.

168. D, $\mathrm{M}^{1}$, Protocone position: (0) skewed mesiobuccally; (1) central on the tooth.

169. D, $\mathrm{M}^{1}$, Protoloph presence: (0) absent; (1) present.

170. D, $\mathrm{M}^{1}$, Hypocone presence: (0) absent; (1) present (true hypocone, coming off the cingulum); (2) present (pseudohyopcone, budding off the postprotocingulum).

171. D, $\mathbf{M}^{1}$ or $\mathrm{M}^{2}$, Postprotocingulum presence: (0) absent; (1) weak; (2) pronounced.

172. D, $\mathbf{M}^{2}$, Ectoflexus depth: (0) deep with the stylar shelf wide at the corners and almost disappearing in the middle; (1) shallow.

173. D, $\mathrm{M}^{2}$, Hypocone size: (0) small, distinctly smaller than the protocone; (1) large, similar in size to the protocone; (2) hypocone absent.

174. D, $\mathrm{M}^{3}$, Presence: (0) present; (1) absent.

175. D, $\mathrm{M}^{3}$, Relative size based on $\left(\ln (\right.$ buccal $\left.\mathrm{L} x \mathrm{~W}) \mathrm{M}^{3}\right)\left(\ln (\right.$ buccal $\left.\mathrm{LxW}) \mathrm{M}_{1}\right):(0)$ more than $0.9 ;(1)$ less than or equal to 0.9 .

176. D, $\mathrm{M}^{3}$, Prominent parastylar lobe presence: (0) not prominent or absent; (1) prominent. 177. D, $\mathrm{M}^{3}$, Metacone presence: (0) metacone present as a well-developed cusp; (1) metacone absent.

178. D, $\mathrm{M}^{3}$, Hypocone size: (0) very small or absent; (1) large.

179. D, Upper Molar, Stylar shelf morphology: (0) broad; (1) narrow (buccal cingulum only) or absent.

180. D, Upper Molar, Mesostyles presence (0) absent; (1) one or more present.

181. D, Upper Molar, Centrocrista morphology: (0) moderate; (1) strong and straight; (2) absent or very weak; (3) strong and V-shaped.

182. D, Anteriormost Lower Incisor, Continuous growth presence: (0) absent; (1) present. 
183. D, Anteriormost Lower Incisor, Enamel restricted to an anterior band: (0) not restricted; (1) restricted.

184. D, Anteriormost Lower Incisor, Root extent relative to $\mathrm{M}_{3}$ : (0) does not extend below $\mathrm{M}_{3}$;

(1) extends below $\mathrm{M}_{3}$.

185. D, $I_{1}$, Size: (0) much larger than other incisors (or premolars if $\mathrm{I}_{2-3}$ are lost); (1) comparable to other incisors (or premolars if $\mathrm{I}_{2-3}$ are lost); (2) very reduced; (3) tooth absent

186. D, $\mathrm{I}_{1}$, Form: (0) simple, not laterally compressed; (1) laterally compressed with no broad, flattened surface; (2) as 1, with flattened dorsal surface; (3) as 2, but rotated medially.

187. D, $\mathrm{I}_{1}$, Orientation: (0) essentially vertical (between vertical and 45 degrees); (1) procumbent-horizontal (greater than 45 degrees).

188. D, $\mathrm{I}_{1}$, Margoconid presence: (0) absent; (1) present.

189. D, $\mathrm{I}_{2}$, Presence: (0) present, large and/or larger than i1; (1) present, small; (2) absent.

190. D, I $\mathrm{I}_{3}$, Presence: (0) present; (1) absent.

191. D, $\mathrm{C}_{1}$, Lower canine root number: (0) one; (1) two; (2) tooth absent.

192. D, $C_{1}$, Lower canine relative size: (0) larger than adjacent teeth; (1) smaller than adjacent teeth; (2) tooth absent.

193. D, $P_{1}$, Presence: (0) present; (1) absent.

194. D, $\mathrm{P}_{2}$, Alveoli number: (0) two; (1) one; (2) tooth absent.

195. D, $\mathrm{P}_{2}$, Crown, Large, procumbent, with a hatchet-like slicing anterior projection: (0) absent;

(1) present.

196. D, $\mathrm{P}_{3}$, Root number: (0) two; (1) one; (2) tooth absent.

197. D, $\mathrm{P}_{3}$, Paraconid (anterior basal cusp) presence: (0) present; (1) absent.

198. D, $\mathrm{P}_{4}$, Number of roots: (0) one; (1) two roots fused with apical division; (2) two. 
199. $\mathrm{D}, \mathrm{P}_{4}$, Mesiodistal length relative to $\mathrm{M}_{1}$ : (0) $\mathrm{P}_{4}$ somewhat shorter than $\mathrm{M}_{1} ;$; 1 ) $\mathrm{P}_{4}$ and $\mathrm{M}_{1}$ subequal in length; (2) $\mathrm{P}_{4}$ much longer than $\mathrm{M}_{1}$; (3) $\mathrm{M}_{1}$ much longer than $\mathrm{P}_{4}$.

200. D, $\mathrm{P}_{4}$, Paraconid presence: (0) paraconid distinct, cuspate; (1) cusp indistinct but paracristid present, not markedly elongate; (2) paraconid and paracristid absent or weak; (3) paracristid elongate with or without a distinct cusp.

201. D, $\mathrm{P}_{4}$, Metaconid presence: (0) absent; (1) present.

202. D, $\mathrm{P}_{4}$, Cristid obliqua position : (0) joins postvallid near midline of tooth or more lingually;

(1) joins postvallid near buccal margin of trigonid; (2) cristid obliqua absent.

203. D, $\mathrm{P}_{4}$, Hypoflexid morphology: (0) distinct, deep; (1) not distinct, shallow.

204. D, $\mathrm{P}_{4}$, Talonid morphology: (0) basined; (1) not basined.

205. D, $\mathrm{P}_{4}$, Talonid cusp number: (0) three well defined; (1) two well defined; (2) one solo distinct cusp; (3) all poorly defined.

206. $\mathrm{D}, \mathrm{M}_{1}$, Crown height $\left(\mathrm{M}_{1}\right.$ trigonid height over tooth length): (0) high crowned (index value more than 0.79); (1) moderate (index value 0.60-0.78); (2) low crowned (index value less than $0.6)$.

207. D, $\mathrm{M}_{1}$, Trigonid degree of mesiodistal compression: (0) strongly compressed mesiodistally; (1) longer, with the paraconid positioned more mesially relative to the metaconid.

208. D, $\mathrm{M}_{1}$, Trigonid height: (0) taller than the talonid but less than two times the height of the talonid; (1) of a similar height to talonid; (2) trigonid two times taller than the talonid or more. 209. D, $\mathrm{M}_{1}$, Trigonid basal: (0) not swollen at the base; (1) swollen basally.

210. D, $\mathrm{M}_{1}$, Mesiobuccal projection presence: (0) absent; (1) present.

211. D, $\mathrm{M}_{1}$, Paraconid distinctiveness from paracristid: (0) indistinct from paracristid; (1) distinct from paracristid. 
212. D, $\mathrm{M}_{1}$, Paraconid size: (0) large; (1) small, markedly smaller than metaconid; (2) paraconid absent.

213. D, $\mathrm{M}_{1}$, Protoconid and metaconid relative height: (0) protoconid higher; (1) subequal; (2) metaconid higher.

214. D, $\mathrm{M}_{1}$, Metaconid position relative to protoconid: (0) metaconid and protoconid in line or metaconid in front of protoconid; (1) metaconid positioned well behind the level of the protoconid.

215. D, $\mathrm{M}_{1}$, Stepped postvallid presence: (0) absent; (1) present.

216. D, $\mathrm{M}_{1}$, Talonid basin form: (0) talonid with well defined basin surrounded by ridges continuous with or comprised of the entoconid, hypoconid, and or hypoconulid; (1) talonid basin reduced or absent.

217. D, $\mathrm{M}_{1}$, Talonid width near cusp apices: (0) somewhat narrower than trigonid; (1) wider than trigonid; (2) much narrower than trigonid (the distance between the lingual margin and the point at which the cristid obliqua contacts the postvallid is less than half the width of the trigonid). 218. D, $\mathrm{M}_{1}$, Talonid cusps relative height: (0) hypoconid taller than entoconid; (1) entoconid taller than hypoconid.

219. D, $\mathrm{M}_{1}$, Entoconid notch presence (between the entoconid and hypoconulid): (0) absent; (1) present.

220. D, $\mathrm{M}_{1}$, Hypoconulid notch presence (between the hypoconulid and hypoconid): (0) absentweak; (1) present.

221. D, $\mathrm{M}_{1}$, Hypoconulid and entoconid relative positions (see Silcox, 2001: fig. 3.18): (0) unpaired; (1) paired (hypoconulid lingual of the central axis of the tooth but not directly 
appressed to the entoconid); (2) twinned (hypoconulid appressed to the entoconid in the distolingual corner of the tooth).

222. $\mathrm{D}, \mathrm{M}_{1}$, Hypoconulid position relative to the central axis of the tooth: (0) hypoconulid centrally placed or lingual of the central axis of the tooth; (1) hypoconulid buccal of central axis; (2) cusp absent.

223. D, $\mathrm{M}_{2}$, Mesiobuccal projection presence: (0) absen; (1) present.

224. $\mathrm{D}, \mathrm{M}_{2}$, Paraconid distinctiveness compared to $\mathrm{M}_{1}$ : (0) comparably distinct to the paraconid on $\mathrm{m} 1$; (1) less distinct than the paraconid on $\mathrm{M}_{1}$.

225. D, $\mathrm{M}_{3}$, Presence: (0) present; (1) absent.

226. $D, M_{3}$, Length relative to $M_{2}$ : (0) $M_{3}$ less than or equal to $M_{2}$; (1) $M_{3}$ greater than $M_{2}$.

227. D, $\mathrm{M}_{3}$, Talonid width: (0) much narrower than trigonid; (1) similar in breadth to trigonid or wider; (2) talonid absent.

228. $\mathrm{D}, \mathrm{M}_{3}$, Hypoconulid size: (0) similar to that cusp on $\mathrm{M}_{1-2}$; (1) larger than on $\mathrm{M}_{1-2}$ but not developed into a lobe; (2) developed into a lobe.

229. D, Lower Molar, Relative sizes: (0) lower molars get progressively smaller distally from $\mathrm{M}_{1-3}$; (1) lower molars get progressively larger from $\mathrm{M}_{1-3}$; (2) all lower molars similar in size; (3) $\mathrm{M}_{2}$ is the smallest lower molar; (4) $\mathrm{M}_{2}$ is the largest lower molar.

230. D, Lower Molar, Lingual curvature ("sweeps smoothly from the paraconid to the rear of the talonid"; McKenna, 1963: p. 17): (0) absent; (1) present.

231. D, Lower Molar, Trigonid length along the tooth row: (0) trigonids become less mesiodistally compressed from $\mathrm{M}_{1-3}$; (1) no change; (2) trigonids become more mesiodistally compressed from $\mathrm{M}_{1-3}$. 
232. D, Lower Molar, Trigonid mesial inflection presence (in mesially oriented trigonids the postvallid is at a greater than ninety degree angle to the floor of the talonid basin; see Silcox, 2001: fig. 3.13): (0) absent; (1) weak; (2) pronounced.

233. D, Lower Molar, Curving paracristids presence: (0) absent; (1) present.

234. D, Lower Molar, Protoconid-metaconid notch morphology: (0) strong and sharp; (1) more rounded; (2) fold of enamel bridges notch.

235. D, Lower Molar, Buccal cingulid(s) presence: (0) anterobuccal "precingulid" only; (1)

separate anterior and posterior cingulids; (2) continuous buccal cingulid; (3) absent (no buccal cingulid or "precingulid").

236. D, Lower Molar, Hypoflexid distinctiveness: (0) distinct, invaginated; (1) not distinct

237. D, Molar, Enamel roughness: (0) smooth; (1) crenulated.

238. D, Molar, Cusp acuteness: (0) relative acute; (1) blunter (more bunodont).

239. D, Diastema, Large upper diastema presence: (0) diastema absent or shorter than the molar toothrow; (1) diastema longer than the molar toothrow.

240. D, Diastema, Diastema between the lower incisors and the cheek teeth presence: (0) absent;

(1) present.

SOM D. Matrix used in the cladistic analysis. Originally from Silcox et al. (2010b), modified in Chester et al. (2015), and further modified here (as indicated in SOM C). This matrix will also be made publicly available on Morphobank (O’Leary and Kaufman, 2012;

http://www.morphobank.org) with the publication of this study.

\section{Ukhaatherium}

$\begin{array}{llllllllllllllllllllllllll}1 & 0 & 1 & 0 & 0 & 0 & 1 & 0 & 0 & 0 & 0 & 0 & 0 & 0 & 0 & 0 & 0 & 0 & 0 & 0 & ? & ? & 0 & 0 & ? & 1\end{array}$

$\begin{array}{lllllllllllllllllllllllll}0 & 0 & 1 & 1 & 0 & 0 & 1 & 0 & 0 & 0 & 0 & 0 & 0 & 0 & 0 & 2 & 0 & 0 & 2 & 0 & 0 & 0 & 0 & ? & 1\end{array}$

$\begin{array}{lllllllllllllllllllllllll}0 & 0 & 1 & \text { ? } & 0 & 0 & 0 & 1 & 0 & 1 & 0 & 0 & 0 & \text { ? } & 0 & 0 & 0 & 0 & 0 & 0 & 1 & 1 & 0 & \text { ? } & 0\end{array}$ 
$\begin{array}{lllllllllllllllllllllllll}2 & 1 & 0 & ? & 1 & 1 & 1 & 0 & 0 & ? & 1 & 0 & 1 & ? & ? & 0 & 2 & 1 & ? & 0 & 0 & 1 & 1 & 0 & \text { ? }\end{array}$ $\begin{array}{lllllllllllllllllllllllll}0 & 0 & 0 & 0 & ? & 0 & 0 & 0 & 0 & 0 & 0 & 0 & 0 & 0 & 0 & 0 & 0 & 1 & 0 & 0 & 0 & 2 & 0 & 0 & 2\end{array}$ $\begin{array}{lllllllllllllllllllllllll}1 & 0 & 0 & 1 & 0 & 1 & 0 & 2 & 0 & 0 & 0 & 1 & 0 & 0 & 0 & 0 & 0 & 1 & 1 & 0 & 0 & 0 & 0 & 0 & 0\end{array}$ $\begin{array}{lllllllllllllllllllllllll}0 & 0 & 1 & 0 & 2 & ? & 0 & 0 & 0 & 1 & 1 & 1 & 0 & 0 & 0 & 1 & 1 & 0 & 0 & 0 & 0 & 2 & 0 & 0 & 1\end{array}$ $\begin{array}{lllllllllllllllllllllllll}0 & 0 & 0 & 0 & 0 & 0 & 0 & 0 & 1 & 0 & 1 & 0 & 1 & 0 & 0 & 0 & 0 & 0 & 0 & 0 & 0 & 2 & 0 & 1 & 0\end{array}$ $\begin{array}{lllllllllllllllllllllllll}0 & 0 & 1 & 2 & 0 & 0 & 2 & 0 & 0 & 1 & 1 & 0 & 0 & 0 & 0 & 0 & 0 & 1 & 0 & 0 & 0 & 0 & 0 & 0 & 0\end{array}$ $\begin{array}{llllllllllllll}0 & 0 & 2 & 0 & 0 & 0 & 0 & 0 & 0 & 0 & 0 & 0 & 0 & 0\end{array}$

\section{Leptictidae}

$\begin{array}{lllllllllllllllllllllllll}? & 0 & 1 & 1 & 0 & 0 & 0 & 1 & 0 & 0 & 0 & 0 & 1 & 0 & 0 & 0 & 0 & 0 & ? & 1 & ? & ? & 2 & 1 & 0\end{array}$ $\begin{array}{lllllllllllllllllllllllll}? & 2 & 1 & 1 & 0 & 1 & 1 & 1 & 0 & 0 & 1 & 1 & 0 & 0 & 1 & 1 & 0 & 0 & 0 & 0 & 1 & 0 & 1 & 0 & 2\end{array}$ $\begin{array}{lllllllllllllllllllllllll}0 & 0 & 0 & 0 & 0 & 0 & 0 & 0 & 1 & ? & 1 & 0 & 0 & 0 & 0 & ? & 1 & 0 & 1 & 2 & 2 & 1 & 0 & 0 & 1\end{array}$ $\begin{array}{lllllllllllllllllllllllll}1 & 0 & 0 & 0 & 2 & 0 & 1 & 0 & 1 & 0 & 0 & 0 & 1 & 0 & 1 & 0 & 0 & 1 & 1 & 1 & 0 & 0 & 0 & 0 & 1\end{array}$ $\begin{array}{lllllllllllllllllllllllll}0 & 1 & 1 & 0 & 0 & ? & 0 & 2 & 2 & 0 & 0 & 1 & 1 & 0 & ? & 0 & ? & 0 & 1 & 1 & 0 & 0 & 2 & 0 & 0\end{array}$ $\begin{array}{lllllllllllllllllllllllll}2 & 1 & 0 & 1 & 0 & 2 & 1 & 0 & 2 & 0 & 0 & 0 & 2 & 0 & 1 & 0 & 0 & 0 & 0 & 0 & 3 & 0 & 0 & 0 & 0\end{array}$ $\begin{array}{lllllllllllllllllllllllll}0 & 0 & 0 & 1 & 0 & 0 & 0 & 0 & 1 & 0 & 0 & 0 & 1 & 0 & 0 & 1 & 1 & 0 & 0 & 0 & 0 & 0 & 0 & 0 & 1\end{array}$ $\begin{array}{llllllllllllllllllllllll}1 & 0 & 0 & 0 & 0 & 0 & 0 & 0 & 0 & 1 & 0 & 0 & 0 & 1 & 0 & 2 & 0 & 0 & 0 & 0 & 0 & 1 & 2 & 0\end{array}$

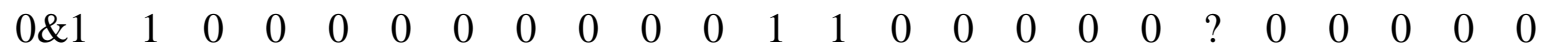
$\begin{array}{lllllllllllllllll}0 & 0 & 0 & 0 & 0 & 3 & 0 & 0 & 0 & 0 & 0 & 0 & 0 & 0 & 0 & 0 & 0\end{array}$

\section{Erinaceus}

$\begin{array}{lllllllllllllllllllllllll}2 & 0 & 0 & 1 & 0 & 1 & 1 & 0 & 2 & 0 & 0 & 0 & 2 & 1 & 0 & 0 & 1 & 1 & 0 & 0 & 0 & 0 & 0 & 1 & 0\end{array}$ $\begin{array}{lllllllllllllllllllllllll}0 & 1 & 0 & 1 & 0 & 0 & 0 & 1 & 0 & 0 & 1 & 0 & 2 & ? & 0 & 0 & 2 & 0 & 0 & 1 & 2 & 1 & 1 & 0 & 1\end{array}$ $\begin{array}{lllllllllllllllllllllllll}0 & 0 & 1 & 1 & ? & 0 & 0 & 0 & 1 & 0 & 0 & 0 & 0 & 0 & 0 & 0 & 2 & 0 & 1 & 1 & 2 & 1 & 0 & 0 & 0\end{array}$ $\begin{array}{lllllllllllllllllllllllll}1 & 1 & 0 & 0 & 2 & 1 & 1 & 0 & 0 & 1 & 0 & 1 & 1 & 0 & 0 & 0 & 1 & 2 & 1 & 0 & 0 & 0 & 1 & 1 & 1\end{array}$ $\begin{array}{lllllllllllllllllllllllll}0 & 1 & 0 & 0 & 0 & ? & 0 & 0 & 1 & 0 & 0 & 0 & 1 & 1 & 0 & 0 & 0 & 0 & 1 & 1 & 1 & 0 & 1 & 0 & 2\end{array}$ $\begin{array}{lllllllllllllllllllllllll}0 & 0 & 1 & 0 & 1 & 0 & 0 & 0 & 2 & 1 & 0 & 0 & 0 & 1 & 1 & 1 & 1 & 1 & 1 & 1 & 0 & 1 & 0 & 1 & 1\end{array}$ $\begin{array}{lllllllllllllllllllllllll}0 & 1 & 1 & 0 & 0 & 0 & 1 & 1 & 1 & 1 & 0 & 0 & 1 & 1 & 3 & 0 & 0 & 0 & 1 & 1 & 0 & 0 & 1 & 0 & 1\end{array}$ $\begin{array}{lllllllllllllllllllllllll}1 & 1 & 0 & 0 & 0 & 0 & 0 & 0 & 0 & 0 & 0 & 1 & 0 & 1 & 1 & 0 & 0 & 1 & 2 & ? & 1 & 1 & 2 & 0 & 0\end{array}$ $\begin{array}{lllllllllllllllllllllllll}1 & 2 & 1 & 1 & 3 & 1 & 1 & 1 & 1 & 0 & 1 & 0 & 1 & 0 & 0 & 0 & 1 & 1 & \text { ? } & \text { ? } & \text { ? } & 2 & 0 & 0 & 0\end{array}$ $\begin{array}{llllllllllllllll}0 & 2 & 0 & 0 & 0 & 2 & 0 & 0 & 0 & 2 & 0 & 0 & 0 & 0 & 0\end{array}$

\section{Echinosorex}

$\begin{array}{lllllllllllllllllllllllll}2 & 1 & 0 & 1 & 0 & 1 & 1 & 1 & 2 & 0 & 0 & 0 & ? & 1 & 0 & 0 & 1 & 2 & 0 & 0 & 0 & 0 & 1 & 1 & 0\end{array}$ $\begin{array}{lllllllllllllllllllllllll}0 & 2 & 1 & 1 & 0 & 0 & 1 & 1 & 0 & 0 & 1 & ? & ? & 0 & 1 & 0 & 2 & 0 & 0 & 0 & 2 & 1 & 1 & 0 & 0\end{array}$ $\begin{array}{lllllllllllllllllllllllll}0 & 0 & 1 & 1 & 0 & 0 & 0 & 0 & 1 & 0 & 0 & 0 & 0 & 0 & 0 & 0 & 1 & 0 & 0 & 1 & 2 & 1 & 0 & 0 & 0\end{array}$ $\begin{array}{lllllllllllllllllllllllll}0 & 1 & 0 & 0 & 2 & 0 & 1 & 0 & 0 & 1 & 0 & 1 & 1 & 0 & 0 & 0 & 1 & 1 & 0 & 0 & 0 & 0 & 1 & 1 & 0\end{array}$ $\begin{array}{lllllllllllllllllllllllll}? & 1 & 0 & 0 & 0 & ? & 0 & 0 & 1 & 0 & 0 & 0 & 1 & 1 & 0 & 0 & 0 & 0 & 1 & 0 & 1 & 0 & 1 & 0 & 0\end{array}$ $\begin{array}{lllllllllllllllllllllllll}2 & 1 & 0 & 0 & 1 & 0 & 1 & 0 & 2 & 1 & 0 & 0 & 1 & 1 & 1 & 1 & 0 & 0 & 1 & 1 & 0 & 1 & 0 & 1 & 1\end{array}$ $\begin{array}{lllllllllllllllllllllllll}0 & 1 & 1 & 1 & 0 & 0 & 1 & 1 & 1 & 1 & 0 & 0 & 1 & 1 & 3 & 0 & 0 & 0 & 1 & 1 & 0 & 1 & 1 & 0 & 1\end{array}$ $\begin{array}{lllllllllllllllllllllllll}0 & 0 & 1 & 1 & 0 & 0 & 0 & 0 & 0 & 0 & 0 & 1 & 0 & 0 & 0 & 0 & 0 & 0 & 1 & 0 & 0 & 1 & 2 & 0 & 0\end{array}$ $\begin{array}{lllllllllllllllllllllllll}0 & 0 & 1 & 0 & 3 & 2 & 1 & 1 & 0 & 0 & 1 & 0 & 1 & 0 & 0 & 0 & 1 & 1 & \text { ? } & \text { ? } & \text { ? } & 2 & 0 & 0 & 0\end{array}$ $\begin{array}{lllllllllllllll}0 & 0 & 0 & 0 & 0 & 2 & 0 & 0 & 0 & 2 & 0 & 0 & 0 & 0 & 0\end{array}$

\section{Hemiechinus}


$\begin{array}{lllllllllllllllllllllllll}2 & 1 & 0 & 1 & 1 & 0 & 1 & 0 & 2 & 0 & 0 & 0 & 2 & 1 & 0 & 0 & 0 & 0 & ? & ? & ? & ? & 0 & 1 & 1\end{array}$ $\begin{array}{lllllllllllllllllllllllll}0 & 1 & 0 & 0 & 0 & 0 & 0 & 1 & 0 & 0 & 1 & 1 & 2 & ? & ? & ? & ? & ? & ? & ? & ? & ? & ? & ? & ?\end{array}$ ? $\begin{array}{llllllllllllllllllllllll}1 & 2 & 0 & 1 & 2 & 0 \& 1 & 1 & 0 & 0 & 1 & 0 & 1 & 1 & 1 & 0 & 0 & 1 & 2 & 1 & 0 & 0 & 0 & 1 & 1\end{array}$ $\begin{array}{lllllllllllllllllllllllll}1 & 0 & 1 & 0 & 0 & 0 & ? & 0 & 0 & 1 & 0 & 0 & 0 & 1 & 1 & 0 & 0 & 0 & 0 & 1 & 1 & 1 & 0 & 2 & 0\end{array}$ $\begin{array}{lllllllllllllllllllllllll}0 & 2 & 0 & 0 & 0 & 1 & 0 & 1 & 0 & 2 & 1 & 0 & 0 & 1 & 1 & 1 & 1 & 1 & 0 & 1 & 1 & 0 & 1 & 0 & 1\end{array}$ $\begin{array}{lllllllllllllllllllllllll}1 & 0 & 1 & 1 & 1 & 0 & 0 & 1 & 1 & 1 & 1 & 0 & 0 & 1 & 1 & 2 & ? & 0 & 0 & 1 & 1 & 0 & 1 & 1 & 0\end{array}$ $\begin{array}{lllllllllllllllllllllllll}1 & 1 & 1 & 0 & 1 & 0 & 0 & 0 & 0 & 0 & 0 & 0 & 1 & 0 & 1 & 1 & 0 & 0 & 1 & 2 & ? & 1 & 1 & 2 & 0\end{array}$ $\begin{array}{lllllllllllllllllllllllll}0 & 0 & 0 & 1 & 0 & 3 & 2 & 1 & 1 & 0 & 0 & 1 & 0 & 2 & 0 & 0 & 0 & 1 & 1 & 0 & 0 & 0 & 0 & 0 & 0\end{array}$ $\begin{array}{llllllllllllllll}0 & 0 & 2 & 0 & 0 & 0 & 2 & 0 & 0 & 0 & 3 & 0 & 0 & 0 & 0 & 0\end{array}$

Ottoryctes

$\begin{array}{llllllllllllllllllllllllllll}? & ? & ? & ? & ? & ? & ? & ? & ? & ? & ? & ? & ? & ? & ? & ? & ? & ? & ? & ? & ? & ? & ? & ? & ? \\ ? & ? & ? & ? & ? & ? & ? & ? & ? & ? & ? & ? & ? & ? & ? & ? & ? & ? & ? & ? & ? & ? & ? & ? & ? \\ ? & 0 & ? & ? & ? & ? & ? & ? & ? & ? & ? & ? & ? & ? & ? & ? & ? & ? & 0 & 2 & 1 & 0 & 1 & 0 & 0 \\ ? & ? & 2 & ? & 0 & ? & 0 & 1 & 0 & 1 & 0 & 0 & 0 & 1 & 1 & ? & 0 & 0 & 1 & 1 & 0 & 1 & ? & 1 & 1 \\ 1 & 0 & 1 & 1 & 1 & 1 & 0 & 0 & 2 & 1 & 0 & 0 & 1 & 1 & 0 & 0 & ? & ? & 0 & 1 & 0 & 1 & 1 & 2 & 1 \\ 0 & 2 & 1 & 0 & 1 & 1 & 0 & 0 & 0 & 2 & 0 & 0 & 0 & 1 & 0 & 1 & 1 & 0 & 0 & 0 & 1 & 0 & 0 & 0 & 0 \\ 0 & 0 & 0 & 0 & 0 & 0 & 0 & 0 & 0 & 0 & 1 & 1 & 1 & 1 & 0 & 1 & 0 & 1 & 1 & 0 & 0 & 0 & 0 & 2 & 0 \\ 0 & 1 & 0 & 0 & 0 & 0 & 0 & 0 & 0 & 0 & 2 & 0 & 0 & 0 & 0 & 0 & 0 & 0 & 1 & 1 & 0 & 0 & 0 & 2 & 1 \\ 0 & 0 & 0 & 0 & 1 & 2 & 0 & 0 & 2 & 0 & 0 & 1 & 1 & 0 & 0 & 0 & 0 & 2 & 0 & 0 & 0 & 0 & 0 & 0 & 0 \\ 0 & 1 & 0 & 0 & 2 & 1 & 1 & 0 & 0 & 0 & 0 & 0 & 0 & 0 & 0 & 0 & & & & & & & & & \end{array}$

\section{Pararyctes}

$\begin{array}{lllllllllllllllllllllllll}? & ? & ? & ? & ? & ? & ? & ? & ? & ? & ? & ? & ? & ? & ? & ? & ? & ? & ? & ? & ? & ? & ? & ? & ? \\ 1 & ? & ? & ? & ? & ? & ? & ? & ? & ? & 1 & 1 & 0 & ? & ? & ? & ? & ? & ? & ? & ? & ? & ? & ? & ? \\ ? & ? & ? & ? & ? & ? & ? & ? & ? & ? & ? & ? & ? & ? & ? & ? & ? & ? & 0 & 2 & ? & 0 & 0 & 0 & ? \\ ? & 1 & ? & 0 & 2 & 0 & ? & 0 & ? & 0 & ? & ? & 1 & 1 & ? & ? & 0 & 1 & 1 & ? & 0 & 0 & 1 & 1 & 1 \\ 0 & 1 & ? & 0 & 0 & ? & 0 & 2 & 1 & 0 & ? & 1 & 0 & ? & ? & ? & ? & ? & ? & 0 & 1 & 1 & 1 & 0 & 1 \\ 2 & 0 & 0 & 0 & 1 & 0 & 0 & 0 & 2 & 0 & 0 & 0 & 2 & 0 & 1 & 1 & 0 & 0 & 1 & 1 & 0 & 0 & 0 & 0 & 0 \\ 0 & 0 & 0 & 1 & 0 & 0 & 0 & 0 & 0 & 0 & 1 & 0 & 1 & 0 & 2 & ? & 1 & 1 & 0 & 1 & 0 & 0 & 0 & 0 & 0 \\ 1 & 0 & 0 & 0 & 0 & 0 & 0 & 0 & 0 & 3 & ? & ? & ? & 0 & 1 & 0 & 0 & 1 & 1 & 0 & 1 & 1 & 2 & 0 & 0 \\ 0 & 0 & 0 & 0 & 2 & 0 & 0 & 2 & 0 & 0 & 1 & 1 & 0 & 0 & 0 & 0 & 2 & 0 & 0 & 0 & 0 & 0 & 0 & 0 & 0 \\ 1 & 0 & 1 & 1 & 1 & 1 & 0 & 0 & 0 & 0 & 0 & 0 & 0 & 0 & 0 & & & & & & & & & & \end{array}$

\section{Paleoryctes}

$$
\begin{array}{lllllllllllllllllllllllll}
? & ? & ? & ? & ? & ? & ? & 1 & 0 & ? & ? & 0 & ? & ? & ? & ? & ? & ? & ? & ? & ? & ? & ? & ? & ? \\
? & ? & ? & ? & ? & ? & ? & ? & ? & ? & ? & ? & ? & ? & ? & ? & ? & ? & ? & ? & ? & ? & ? & ? & ? \\
? & ? & ? & ? & ? & ? & ? & ? & ? & ? & ? & ? & ? & ? & ? & ? & ? & ? & 0 & ? & ? & 0 & ? & ? & ? \\
? & ? & ? & 0 & ? & ? & ? & ? & ? & 0 & ? & ? & 0 & 1 & ? & ? & ? & 1 & 2 & ? & ? & ? & ? & ? & 1 \\
0 & ? & ? & ? & ? & ? & ? & ? & ? & ? & ? & ? & 1 & ? & ? & ? & ? & ? & ? & ? & 0 & 1 & 2 & 0 & 0 \\
2 & 0 & 0 & 1 & 1 & 0 & 0 & 0 & 2 & 0 & 0 & 0 & 0 & 0 & 1 & 1 & 1 & 0 & ? & 1 & 0 & 0 & 0 & 1 & 0 \\
0 & 0 & 0 & 1 & 0 & 2 & ? & 0 & 0 & 0 & 1 & 1 & 1 & ? & 0 & 0 & 1 & 1 & 0 & 0 & 0 & 0 & 2 & 0 & 0 \\
1 & 0 & 0 & 0 & 0 & 0 & ? & 0 & 0 & 2 & 0 & 0 & 0 & 0 & 0 & 0 & 0 & 1 & 1 & 0 & 0 & 0 & 2 & 1 & 0 \\
0 & 0 & 0 & 1 & 2 & 0 & 0 & 2 & 0 & 0 & 0 & 1 & 0 & 0 & 0 & 0 & 2 & 0 & 0 & 0 & 0 & 0 & 0 & 0 & 0 \\
0 & 0 & 0 & 2 & 1 & 1 & 0 & 0 & 0 & 0 & 0 & 0 & 0 & 0 & 0 & & & & & & & & & &
\end{array}
$$




\section{Uintacyon}

$\begin{array}{llllllllllllllllllllllllllllll}? & ? & ? & ? & ? & ? & ? & ? & ? & ? & ? & ? & ? & ? & ? & ? & ? & ? & ? & ? & ? & ? & ? & ? & ? \\ ? & ? & ? & ? & ? & ? & ? & ? & ? & ? & ? & ? & ? & ? & ? & ? & ? & ? & ? & ? & ? & ? & ? & ? & ? \\ ? & ? & ? & ? & ? & ? & ? & ? & ? & ? & ? & ? & ? & ? & ? & ? & ? & ? & 0 & ? & ? & 1 & ? & ? & ? \\ ? & ? & ? & ? & ? & ? & ? & ? & ? & ? & ? & ? & ? & ? & ? & ? & ? & ? & ? & ? & ? & ? & ? & ? & ? \\ ? & ? & ? & ? & ? & ? & ? & ? & ? & 0 & ? & 0 & ? & ? & ? & ? & ? & 0 & ? & 0 & 0 & 0 & 2 & 0 & 1 \\ 0 & 1 & 1 & 0 & 1 & 0 & 0 & 0 & 2 & 0 & 0 & 1 & 2 & 0 & 1 & 1 & 0 & 0 & 1 & 1 & 0 & 1 & 0 & 1 & 0 \\ 0 & 0 & 0 & 0 & 0 & 0 & 0 & 0 & 0 & 0 & 0 & 1 & 1 & 0 & 1 & 0 & 1 & 0 & 0 & 0 & 0 & 1 & 2 & 0 & ? \\ ? & ? & ? & 0 & 0 & 0 & 0 & 0 & 0 & ? & ? & ? & ? & 1 & 0 & 0 & 0 & 0 & 0 & 0 & 0 & 0 & 2 & 0 & 0 \\ 0 & 1 & 1 & 1 & 1 & 0 & 1 & 2 & 0 & 0 & 1 & 0 & 0 & 0 & 0 & 0 & 2 & 0 & ? & ? & ? & 2 & 0 & 0 & 0 \\ 0 & 0 & 0 & 0 & 1 & 2 & 0 & 0 & 0 & 0 & 0 & 0 & 0 & 0 & 0 & & & & & & & & & & \end{array}$

Vulpavus profectus

$$
\begin{array}{llllllllllllllllllllllllll}
? & 0 & 1 & 0 & 0 & 0 & 0 & 1 & 0 & 0 & 0 & 0 & 0 & ? & 0 & ? & 0 & 0 & 1 & 0 & ? & ? & 2 & 1 & ? \\
? & 1 & 0 & 0 & ? & 0 & 0 & 0 & 0 & 1 & 0 & 0 & 0 & 0 & 0 & 2 & 0 & 0 & 0 & 0 & 0 & 0 & 1 & 0 & 2 \\
0 & 0 & 0 & 0 & ? & 1 & ? & 0 & 0 & 0 & 1 & 1 & ? & 0 & 0 & ? & ? & 0 & 0 & 1 & 1 & 1 & 0 & 0 & ? \\
1 & 1 & 0 & 0 & 0 & ? & ? & 0 & ? & 0 & 1 & 0 & 0 & 0 & ? & 1 & 1 & 1 & 2 & 0 & 0 & 0 & ? & 0 & 0 \\
? & 0 & 0 & 0 & 2 & ? & 0 & 0 & 1 & 0 & ? & 0 & ? & 0 & 0 & 0 & 0 & 0 & 1 & 0 & 0 & 0 & 2 & 0 & 0 \\
0 & 1 & 1 & 0 & 1 & 0 & 0 & 0 & 2 & 0 & 0 & 1 & 0 & 0 & 1 & 1 & 0 & 0 & 1 & 1 & 0 & 1 & 0 & 1 & 1 \\
0 & 0 & 0 & 0 & 0 & 1 & 0 & 0 & 0 & 0 & 0 & 1 & 0 & 1 & 2 & 0 & 0 & 0 & 0 & 1 & 0 & 1 & ? & 0 & 1 \\
1 & 0 & 0 & 0 & 0 & 0 & 0 & 0 & 0 & 1 & 0 & 0 & 0 & 1 & 0 & 0 & 0 & 0 & 0 & 0 & 0 & 1 & 2 & 0 & 0 \\
0 & 1 & 1 & 1 & 2 & 1 & 1 & 0 & 0 & 0 & 1 & 0 & 0 & 0 & 0 & 0 & 0 & 0 & ? & ? & ? & 2 & 0 & 0 & 0 \\
0 & 1 & 0 & 0 & 0 & 2 & 0 & 0 & 0 & 0 & 0 & 0 & 0 & 0 & 0 & & & & & & & & & &
\end{array}
$$

Solenodon

$$
\begin{aligned}
& \begin{array}{lllllllllllllllllllllllll}
1 & 0 & 1 & 1 & 0 & 1 & 1 & 1 & 0 & 1 & 1 & 0 & 0 & 0 & 0 & 0 & 1 & 2 & 0 & 0 & 0 & 0 & 0 & 1 & 1
\end{array} \\
& \begin{array}{llllllllllllllllllllllllll}
0 & 1 & 0 & 0 & 0 & 1 & 0 & 1 & 0 & 1 & 1 & 1 & 1 & 0 & 1 & 1 & 2 & 0 & 1 & 0 & 1 & 0 & 1 & 0 & 0
\end{array} \\
& \begin{array}{lllllllllllllllllllllllll}
0 & 0 & 0 & 0 & 0 & 0 & 0 & 0 & 1 & 0 & 0 & 0 & 0 & 0 & 1 & 0 & 1 & 0 & 0 & 1 & 2 & 0 & 1 & 0 & 0
\end{array} \\
& \begin{array}{llllllllllllllllllllllll}
0 & 0 & 1 & 0 & 0 & 0 & 1 & 0 & 1 & 0 & 0 & 0 \& 1 & 0 & 0 & 0 & 0 & 1 & 0 & 2 & 0 & ? & 0 & 1 & 1
\end{array} \\
& \begin{array}{lllllllllllllllllllllll}
1 & 0 & 0 & 0 & 0 & 0 & ? & 0 & 0 & 1 & 0 & 0 & 1 & 0 \& 1 \& 2 & 1 & 0 & 0 & 0 & 0 & 1 & 0 & 1 & 0
\end{array} \\
& \begin{array}{lllllllllllllllllllllllll}
0 & ? & 1 & 0 & 1 & 1 & 0 & 0 & 0 & 0 & 0 & 2 & 0 & 1 & 0 & 2 & 0 & 1 & 0 & 0 & 0 & 1 & 1 & 0 & 1
\end{array} \\
& \begin{array}{llllllllllllllllllllllllll}
0 & 1 & 1 & 0 & 1 & 1 & 0 & 0 & 2 & ? & 0 & 0 & 0 & ? & 1 & 1 & ? & 2 & ? & 0 & 1 & 0 & 1 & 0 & 0
\end{array} \\
& \begin{array}{lllllllllllllllllllllllllllll}
1 & 0 & 0 & 1 & ? & 0 & 0 & 0 & ? & 0 & 0 & 0 & 2 & 0 & 1 & 1 & 1 & 0 & 0 & 0 & 0 & 0 & 0 & 2 & \text { ? }
\end{array} \\
& \begin{array}{lllllllllllllllllllllllll}
2 & 3 & 0 & 1 & 2 & 1 & 1 & 3 & 0 & 1 & 2 & 0 & 0 & 1 & 1 & 0 & 0 & 0 & 1 & 2 & ? & ? & ? & \text { ? } & 2
\end{array} \\
& \begin{array}{llllllllllllllllll}
0 & 0 & 0 & 1 & 0 & 0 & 2 & 0 & 1 & 0 & 0 & 0 & 0 & 0 & 0 & 0 & 0 & 0
\end{array}
\end{aligned}
$$

Sorex sp.

$\begin{array}{lllllllllllllllllllllllll}2 & 0 & 1 & 1 & 1 & 0 & 0 & 0 & 0 & 1 & 0 & 0 & 0 & 0 & 0 & 0 & ? & 2 & ? & ? & ? & ? & 1 & 1 & 1\end{array}$ $\begin{array}{llllllllllllllllllllllll}0 & 1 & 0 & 1 & 0 & 1 & 0 & 1 & 0 & 0 & 1 & 0 & ? & 0 & 0 & 0 & 2 & 0 & 1 & 0 & 2 & ? & 0 \& 1 & 0\end{array}$ $\begin{array}{lllllllllllllllllllllllll}0 & 0 & 0 & 1 & 1 & 0 & 0 & 0 & 0 & 1 & 0 & 1 & 0 & 0 & 0 & 0 & 0 & 2 & 0 & 0 & 0 & 0 & 0 & 1 & 0\end{array}$ $\begin{array}{llllllllllllllllllllllllll}0 & 0 & 0 & 1 & 0 & 0 & 1 & 0 & 0 & 0 & 0 & ? & 0 & 0 & 0 & 0 & 0 & 0 & 0 & 2 & 0 & 0 & 0 & 1 & 1\end{array}$ $\begin{array}{lllllllllllllllllllllllll}1 & 0 & 0 & 0 & 0 & 0 & ? & 0 & 0 & 1 & 1 & 0 & 0 & 0 & 1 & 1 & 1 & 0 & 0 & 1 & 0 & 0 & 1 & 1 & 0\end{array}$ $\begin{array}{lllllllllllllllllllllllll}2 & 0 & 0 & 1 & 0 & 0 & 0 & 0 & 0 & 2 & 1 & 0 & 0 & 1 & 1 & 1 & 1 & 0 & 0 & 1 & 1 & 0 & 1 & 0 & 1\end{array}$ $\begin{array}{lllllllllllllllllllllllll}0 & 0 & 1 & 0 & 1 & 1 & 0 & 0 & 1 & 0 & 2 & 0 & 0 & 1 & 1 & 0 & 0 & 0 & 0 & 0 & 1 & 0 & 1 & 0 & 0\end{array}$ $\begin{array}{lllllllllllllllllllllllll}1 & 1 & 1 & 0 & 0 & 1 & 3 & 0 & 0 & ? & 0 & 1 & 1 & 1 & 2 & 1 & 0 & 1 & 1 & 2 & ? & 2 & ? & 0 & 3\end{array}$ 
$\begin{array}{lllllllllllllllllllllllll}1 & 1 & 2 & 1 & 1 & 3 & 0 & 1 & 0 & 0 & 0 & 1 & 0 & 0 & 0 & 0 & 0 & 1 & 1 & 1 & 0 & 2 & 0 & 0 & 0\end{array}$ $\begin{array}{lllllllllllllllll}0 & 0 & 0 & 0 & 1 & 0 & 1 & 1 & 0 & 0 & 2 & 0 & 0 & 0 & 0 & 0\end{array}$

\section{Suncus murinus}

$\begin{array}{lllllllllllllllllllllllll}2 & 0 & 1 & 1 & 1 & 1 & 0 & 0 & 0 & 1 & 1 & 0 & ? & 1 & 0 & 0 & ? & ? & 1 & 1 & 0 & 0 & 0 & 1 & 2\end{array}$ $\begin{array}{lllllllllllllllllllllllll}0 & 0 & 0 & 1 & 0 & 1 & 0 & 1 & 0 & 1 & 1 & 0 & 2 & ? & 1 & 0 & 2 & 0 & 1 & 1 & 2 & 1 & 1 & 0 & 0\end{array}$ $\begin{array}{lllllllllllllllllllllllll}0 & 0 & 1 & 1 & 0 & 0 & 0 & 0 & 1 & 0 & 1 & 0 & 0 & ? & 0 & 0 & 1 & 0 & 0 & 0 & 2 & 0 & 1 & 0 & 0\end{array}$ $\begin{array}{lllllllllllllllllllllllll}0 & 0 & 1 & 0 & 0 & 1 & 1 & 0 & 0 & 0 & 1 & 0 & 0 & 0 & 0 & 0 & 1 & 0 & 2 & 0 & 0 & 0 & 1 & 1 & 1\end{array}$ $\begin{array}{lllllllllllllllllllllllll}0 & 0 & 0 & 0 & 0 & ? & 0 & 0 & 1 & 1 & 0 & 0 & ? & 1 & 1 & 1 & 0 & 0 & 2 & 1 & 0 & 1 & 1 & 0 & 2\end{array}$ $\begin{array}{lllllllllllllllllllllllll}0 & 0 & 1 & 0 & 0 & 0 & 0 & 0 & 2 & 0 & 0 & 0 & 1 & 0 & 1 & 1 & 0 & 0 & 1 & 1 & 0 & 1 & 0 & 0 & 0\end{array}$ $\begin{array}{lllllllllllllllllllllllll}0 & 1 & 0 & 1 & 1 & 0 & 0 & 0 & 0 & 2 & 0 & 0 & 1 & 1 & 2 & ? & 0 & 0 & 0 & 1 & 0 & 1 & 0 & 0 & 1\end{array}$ $\begin{array}{lllllllllllllllllllllllll}1 & 1 & 0 & 0 & 1 & 3 & 0 & 0 & 0 & 0 & 1 & 1 & 0 & 2 & 1 & 0 & 1 & 1 & 2 & ? & 2 & ? & 0 & 3 & 1\end{array}$ $\begin{array}{lllllllllllllllllllllllll}0 & 2 & 1 & 1 & 3 & 0 & 1 & 0 & 0 & 0 & 1 & 0 & 0 & 0 & 0 & 0 & 1 & 1 & 1 & 0 & 2 & 0 & 0 & 0 & 0\end{array}$ $\begin{array}{llllllllllllllll}0 & 0 & 0 & 1 & 0 & 1 & 0 & 0 & 0 & 2 & 0 & 0 & 0 & 0 & 0\end{array}$

\section{Rhombomylus}

$\begin{array}{lllllllllllllllllllllllll}2 & 0 & 0 & 0 & 0 & 1 & 1 & 1 & 0 & 0 & 0 & ? & 1 & 0 & 0 & ? & 0 & 0 & ? & 0 & ? & 0 & ? & 1 & \text { ? }\end{array}$ $\begin{array}{lllllllllllllllllllllllll}? & 2 & 0 & 1 & 0 & 0 & 1 & 1 & 0 & 0 & 0 & 1 & 0 & ? & 1 & 1 & 1 & 0 & 0 & 0 & 1 & 0 & 0 & 1 & 1\end{array}$ $\begin{array}{lllllllllllllllllllllllll}0 & ? & 0 & 0 & \text { ? } & ? & 0 & 0 & ? & ? & 1 & \text { ? } & 0 & \text { ? } & 0 & 0 & \text { ? } & \text { ? } & 1 & 2 & 2 & 1 & 1 & 1 & 0\end{array}$ $\begin{array}{lllllllllllllllllllllllll}0 & 2 & 0 & 0 & 2 & 0 & 1 & 0 & 0 & 0 & ? & ? & 0 & 1 & ? & 0 & 0 & 0 & 0 & ? & 1 & 0 & 2 & 1 & 1\end{array}$ $\begin{array}{lllllllllllllllllllllllll}0 & 0 & 1 & 2 & 2 & ? & 0 & 0 & 1 & 0 & ? & 0 & 1 & 2 & 0 & ? & 1 & 1 & 0 & 1 & 2 & 1 & 0 & ? & 0\end{array}$ $\begin{array}{lllllllllllllllllllllll}0 & 1 & 0 & 0 \& 1 & 1 & 0 & 1 & 0 & 2 & 1 & 1 & 0 & 1 & 0 & 1 & 1 & 0 & 1 & 0 \& 1 & 1 & 0 & 1 & 0\end{array}$ $\begin{array}{lllllllllllllllllllllllll}0 & 0 & 1 & 0 & 0 & 1 & 0 & 2 & ? & 1 & 2 & 0 & 0 & 1 & 1 & 1 & 2 & ? & 0 & 1 & 1 & 1 & 0 & 1 & 1\end{array}$ $\begin{array}{lllllllllllllllllllllllll}0 & 0 & 0 & 0 & 1 & 1 & 0 & 2 & ? & 1 & 1 & 3 & ? & ? & ? & 2 & 1 & 2 & 2 & 1 & 2 & ? & 0 & 0 & 2\end{array}$ $\begin{array}{lllllllllllllllllllllllll}0 & 0 & 1 & 0 & 0 & 0 & 0 & 0 & 0 & 0 & 0 & 0 & 0 & 2 & 2 & 0 & 0 & 0 & 0 & 1 & 1 & 1 & 0 & 1 & 0\end{array}$ $\begin{array}{lllllllllllllllll}0 & 0 & 1 & 0 & 1 & 1 & 0 & 1 & 1 & 1 & 1 & 0 & 0 & 0 & 1 & 1 & 1\end{array}$

Ptilocercus lowii

$\begin{array}{lllllllllllllllllllllllll}1 & 0 & 1 & 0 & 0 & 0 & 0 & 1 & 1 & 0 & 1 & 1 & 0 & 0 & 0 & 1 & 0 & 0 & 1 & 0 & ? & ? & 1 & 0 & 1\end{array}$ $\begin{array}{lllllllllllllllllllllllll}1 & 0 & ? & 0 & 0 & 0 & 0 & 0 & 0 & 0 & 0 & 0 & 0 & 1 & 0 & 0 & 0 & 0 & 0 & 2 & 0 & 0 & 1 & 0 & 2\end{array}$ $\begin{array}{lllllllllllllllllllllllll}0 & 1 & 0 & 0 & 0 & 1 & 0 & 1 & 0 & 0 & 1 & 0 & 1 & 1 & 0 & 2 & 1 & 1 & 1 & 1 & 2 & 2 & 1 & 0 & 1\end{array}$ $\begin{array}{lllllllllllllllllllllllll}1 & 2 & 1 & 0 & 1 & 0 & 1 & 0 & 0 & 0 & 1 & 0 & 0 & 1 & 1 & 0 & 0 & 1 & 0 & 1 & 0 & 1 & 0 & 1 & 1\end{array}$ $\begin{array}{lllllllllllllllllllllllll}0 & 1 & 1 & 1 & 1 & 1 & 1 & 2 & 1 & 1 & 0 & 0 & 1 & 1 & 0 & 0 & 0 & 0 & 2 & 1 & 1 & 1 & 2 & 0 & 0\end{array}$ $\begin{array}{lllllllllllllllllllllllll}0 & 1 & 0 & 0 & 0 & 0 & 1 & 0 & 2 & 1 & 0 & 0 & 1 & 0 & ? & 1 & 1 & 0 & 1 & 0 & 0 & 1 & 0 & 1 & 1\end{array}$

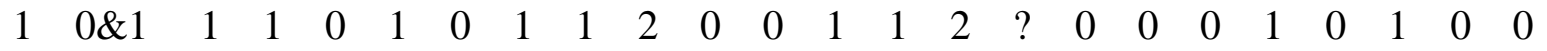
$\begin{array}{lllllllllllllllllllllllll}1 & 1 & 0 & 0 & 0 & 0 & 0 & 0 & 0 & 0 & 1 & 0 & 1 & 0 & 0 & 0 & 0 & 0 & 1 & 1 & 0 & 1 & 1 & 2 & 3\end{array}$ $\begin{array}{llllllllllllllllllllllll}0 & 1 & 0 \& 2 & 0 & 1 & 3 & 0 & 1 & 0 & 0 & 0 & 1 & 0 & 0 & 0 & 0 & 0 & 0 & 1 & 1 & 0 & 2 & 0 & 0\end{array}$ $0 \begin{array}{lllllllllllllllll}0 & 0 & 0 & 0 & 0 & 0 & 0 & 1 & 0 & 1 & 0 & 2 & 0 & 0 & 0 & 0 & 0\end{array}$

\section{Tupaia glis}

$\begin{array}{lllllllllllllllllllllllll}1 & 0 & 0 & 1 & 0 & 0 & 0 & 1 & 0 & 0 & 0 & 0 & 0 & 0 & 0 & 0 & 0 & 0 & 1 & 0 & 0 & 0 & 2 & 1 & 0\end{array}$ $\begin{array}{lllllllllllllllllllllllll}2 & 2 & 1 & 0 & 0 & 1 & 1 & 0 & 0 & 0 & 0 & 0 & 0 & 1 & 0 & 0 & 0 & 0 & 0 & 2 & 2 & 0 & 1 & 0 & 2\end{array}$ $\begin{array}{lllllllllllllllllllllllll}0 & 1 & 0 & 0 & 0 & 0 & 0 & 1 & 0 & 0 & 1 & 0 & 0 & 0 & 0 & 2 & ? & 0 & 0 & 2 & 2 & 2 & 1 & 0 & 1\end{array}$ $\begin{array}{lllllllllllllllllllllllll}1 & 2 & 0 & 0 & 2 & 0 & 0 & 0 & 0 & 0 & 0 & 0 & 0 & 1 & 1 & 0 & 0 & 1 & 1 & 1 & 0 & 1 & 0 & 1 & 0\end{array}$ $\begin{array}{lllllllllllllllllllllllll}? & 1 & 1 & 1 & 1 & 1 & 0 & 2 & 1 & 0 & 0 & 0 & 1 & 1 & 0 & 0 & 0 & 0 & 2 & 1 & 0 & 1 & 2 & 0 & 0\end{array}$ $\begin{array}{llllllllllllllllllllllll}2 & 1 & 0 & 0 & 0 & 0 & 0 \& 1 & 0 & 2 & 0 & 0 & 0 & 1 & 0 & 1 & 1 & 1 & 0 & 1 & 0 & 0 & 0 & 0 & 1\end{array}$ 
$\begin{array}{lllllllllllllllllllllllll}1 & 1 & 0 & 1 & 1 & 1 & 2 & ? & 0 & 0 & 2 & 0 & 1 & 1 & 0 & 2 & ? & 0 & 0 & 0 & 1 & 0 & 0 & 0 & 0\end{array}$ $\begin{array}{lllllllllllllllllllllllll}1 & 1 & 0 & 0 & 0 & 1 & 3 & 0 & 0 & 0 & 1 & 0 & 1 & 0 & 0 & 0 & 0 & 0 & 1 & 1 & 0 & 0 & 1 & 2 & 3\end{array}$ $\begin{array}{llllllllllllllllllllllll}0 & 1 & 0 \& 2 & 0 & 1 & 3 & 0 & 1 & 0 & 0 & 0 & 1 & 0 & 0 & 0 & 0 & 0 & 1 & 1 & 1 & 0 & 2 & 0 & 0\end{array}$ $\begin{array}{lllllllllllllllll}0 & 0 & 0 & 0 & 0 & 0 & 0 & 1 & 0 & 1 & 0 & 3 & 0 & 0 & 0 & 0 & 0\end{array}$

Genetta sp.

$\begin{array}{lllllllllllllllllllllllll}2 & 0 & 1 & 0 & 0 & 0 & 1 & 1 & 0 & 0 & 0 & 0 & 1 & 0 & 0 & 0 & 0 & 1 & 1 & 0 & 0 & 0 & 1 & 1 & 0\end{array}$ $\begin{array}{lllllllllllllllllllllllll}2 & 1 & 0 & 1 & 0 & 0 & 1 & 0 & 0 & 1 & 0 & 0 & 0 & 0 & 1 & 1 & 2 & 0 & 0 & 0 & 1 & 1 & 1 & 0 & 2\end{array}$ $\begin{array}{lllllllllllllllllllllllll}0 & 0 & 0 & 0 & 0 & 0 & 0 & 0 & 0 & 0 & 0 & 1 & 0 & 0 & 0 & 0 & 3 & 0 & 1 & 2 & 2 & 1 & 0 & 0 & 1\end{array}$ $0 \begin{array}{lllllllllllllllllllllll}0 & 1 & 0 \& 1 & 0 & 1 & 0 & 0 & 0 & 1 & 0 & 0 \& 1 & 0 & 1 & 0 & 1 & 1 & 0 & 2 & 0 & 0 & 0 & 0 & 1\end{array}$ $\begin{array}{lllllllllllllllllllllllll}0 & 0 & ? & 1 & 0 & 0 & 2 & ? & 0 & 2 & 0 & 0 & 1 & 0 & 1 & 0 & 0 & 0 & 0 & 0 & 1 & 0 & 0 & 0 & 2\end{array}$ $\begin{array}{lllllllllllllllllllllllll}0 & 0 & 2 & 1 & 0 & 0 & 1 & 0 & 1 & 0 & 2 & 0 & 0 & 1 & 2 & 0 & 1 & 1 & 0 & 0 & 1 & 1 & 0 & 1 & 0\end{array}$ $\begin{array}{lllllllllllllllllllllllll}1 & 0 & 0 & 0 & 1 & 0 & 0 & 0 & ? & 0 & 0 & 1 & 0 & 1 & 0 & ? & 2 & ? & 0 & 0 & 0 & 0 & 0 & 0 & 2\end{array}$ $\begin{array}{lllllllllllllllllllllllll}1 & ? & 1 & ? & ? & 0 & 0 & 0 & 0 & 0 & 0 & 1 & 0 & 0 & 0 & 1 & 0 & 0 & 1 & 0 & 0 & 0 & 0 & 0 & 2\end{array}$ $\begin{array}{lllllllllllllllllllllllll}0 & 0 & 1 & 2 & 1 & 1 & 3 & 1 & 1 & 2 & 0 & 0 & 1 & 0 & 0 & 0 & 0 & 0 & 0 & 0 & ? & ? & ? & 2 & 0\end{array}$ $\begin{array}{lllllllllllllllll}1 & 1 & ? & ? & ? & 0 & 0 & 2 & 0 & 0 & 0 & 0 & 0 & 0 & 0 & 0 & 0\end{array}$

\section{Cynocephalus volans}

$\begin{array}{lllllllllllllllllllllllll}1 & 0 & 1 & 0 & 0 & 0 & 1 & 0 & 0 & 0 & 1 & 0 & 0 & 1 & 1 & 1 & 0 & 0 & 1 & 0 & 1 & 0 & 0 & 0 & 1\end{array}$ $\begin{array}{lllllllllllllllllllllllll}1 & 0 & 0 & 0 & 0 & 0 & 0 & 0 & 0 & 0 & 0 & 0 & 0 & 0 & 0 & 0 & 1 & 0 & 0 & 2 & 0 & 0 & 0 & 0 & 2\end{array}$ $\begin{array}{lllllllllllllllllllllllll}1 & 0 & 0 & 1 & 1 & 0 & 0 & 1 & 0 & 0 & 1 & 0 & 2 & 1 & 1 & 0 & 3 & 1 & 1 & 2 & 1 & 1 & 1 & 0 & 1\end{array}$ $\begin{array}{lllllllllllllllllllllllll}1 & 2 & 0 & 0 & 2 & 1 & 1 & 0 & 0 & 0 & 0 & 0 & 0 & 0 & 1 & 0 & 0 & 0 & 2 & ? & 1 & 0 & 2 & 0 & 0\end{array}$ $\begin{array}{lllllllllllllllllllllllll}? & 1 & 0 & 2 & 2 & ? & 0 & 1 & 0 & 1 & 1 & 0 & 1 & 0 & 0 & 0 & 0 & 0 & 2 & 0 & 1 & 1 & 0 & ? & 0\end{array}$ $\begin{array}{lllllllllllllllllllllllll}2 & 1 & 1 & 1 & 0 & 0 & 0 & 0 & 2 & 1 & 0 & 0 & 2 & 0 & 1 & 1 & 1 & 1 & 0 & 0 & 3 & 1 & 0 & 0 & 0\end{array}$ $\begin{array}{lllllllllllllllllllllllll}0 & 0 & 0 & 1 & 1 & 2 & ? & 1 & 0 & 2 & 0 & 1 & 0 & 0 & 0 & 0 & 0 & 1 & 0 & 0 & 0 & 1 & 2 & 0 & 0\end{array}$ $\begin{array}{lllllllllllllllllllllllll}0 & 0 & 0 & 0 & 0 & 3 & 0 & 0 & 0 & 1 & ? & 1 & 0 & 0 & 0 & 1 & 0 & 1 & 0 & ? & 0 & 1 & 2 & 1 & 0\end{array}$ $\begin{array}{lllllllllllllllllllllllll}1 & 1 & 0 & 0 & 0 & 0 & 1 & 1 & 0 & 0 & 1 & 0 & 0 & 1 & 0 & 0 & 1 & 0 & 1 & 1 & 2 & 0 & 0 & 0 & 0\end{array}$ $\begin{array}{lllllllllllllll}0 & 1 & 0 & 0 & 0 & 2 & 0 & 0 & 0 & 3 & 0 & 1 & 0 & 0 & 0\end{array}$

\section{Gypsonictops}

$\begin{array}{lllllllllllllllllllllllllllllll}\text { ? } & ? & ? & ? & ? & ? & ? & ? & ? & ? & ? & ? & ? & ? & ? & ? & ? & ? & ? & ? & ? & ? & ? & ? & \text { ? }\end{array}$

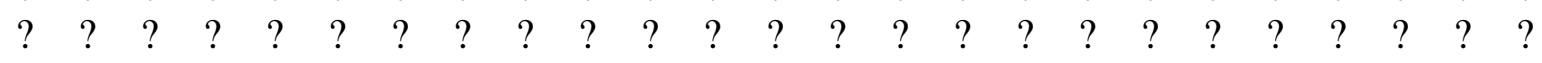

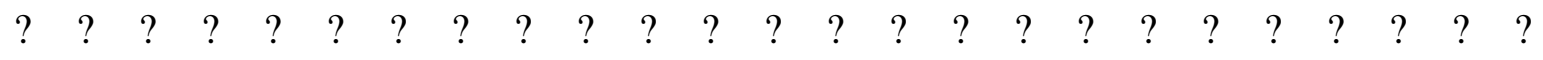

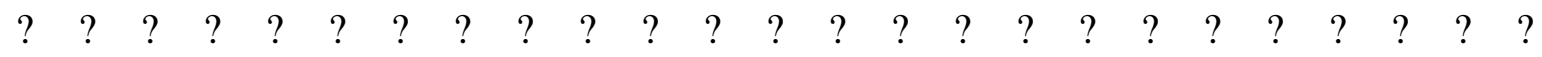

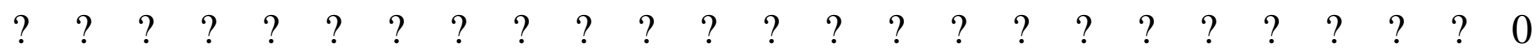
$\begin{array}{lllllllllllllllllllllllll}1 & 1 & 0 & 1 & 1 & 0 & 1 & 0 & 2 & 0 & 0 & 0 & 2 & 0 & 1 & 1 & 0 & 0 & 0 & 1 & 3 & 1 & 0 & 0 & 0\end{array}$ $\begin{array}{lllllllllllllllllllllllll}0 & 1 & ? & 1 & 0 & 0 & 0 & 0 & 0 & ? & 0 & ? & ? & 0 & 0 & 1 & 1 & 0 & 0 & 0 & 0 & 0 & 2 & 0 & 0\end{array}$ $\begin{array}{lllllllllllllllllllllllll}1 & 0 & 0 & 0 & 0 & 0 & ? & ? & ? & ? & ? & ? & ? & ? & ? & 0 & ? & 0 & 0 & 0 & 0 & 1 & 2 & 1 & 0\end{array}$ $\begin{array}{llllllllllllllllllllllll}1 & 0 & 0 & 0 & 0 \& 1 & 0 & 0 & 0 & 1 & 0 & 1 & 1 & 1 & 0 & 0 & 0 & 1 & ? & ? & ? & 0 & 0 & 0 & 0\end{array}$ $\begin{array}{llllllllllllllll}0 & 0 & 0 & 0 & 2 & 0 & 1 & 0 & 1 & 0 & 0 & 0 & 0 & 0 & 0 & 0\end{array}$

\section{Carcinella sigei}

$\begin{array}{llllllllllllllllllllllllllllll}? & ? & ? & ? & ? & ? & ? & ? & ? & ? & ? & ? & ? & ? & ? & ? & ? & ? & ? & ? & ? & ? & ? & ? & ? \\ ? & ? & ? & ? & ? & ? & ? & ? & ? & ? & ? & ? & ? & ? & ? & ? & ? & ? & ? & ? & ? & ? & ? & ? & ? \\ ? & ? & ? & ? & ? & ? & ? & ? & ? & ? & ? & ? & ? & ? & ? & ? & ? & ? & 1 & 1 & 1 & ? & ? & 1 & ? \\ ? & 0 & 0 & 1 & ? & 0 & 1 & 0 & 0 & 1 & ? & 0 & 1 & 0 & ? & 0 & 1 & ? & 0 & 0 & 0 & 0 & ? & 1 & ?\end{array}$




$$
\begin{array}{llllllllllllllllllllllllllll}
0 & 0 & 0 & 0 & 0 & ? & 0 & ? & 2 & 0 & ? & ? & ? & 1 & ? & ? & ? & 0 & 2 & 1 & 2 & 1 & 1 & 1 & 3 \\
? & ? & ? & ? & ? & ? & ? & ? & 1 & 1 & 0 & 0 & 0 & 0 & 1 & 1 & 0 & 0 & 1 & 0 & 0 & 1 & 1 & ? & 1 \\
0 & 0 & 0 & 1 & 0 & 2 & ? & 0 & 1 & 0 & 0 & 1 & 1 & 1 & 2 & ? & 1 & 0 & 0 & 1 & 0 & 0 & 0 & 0 & ? \\
1 & 0 & 0 & 0 & 0 & 0 & ? & ? & ? & ? & ? & ? & ? & ? & ? & ? & ? & ? & ? & ? & ? & ? & ? & ? & ? \\
? & ? & ? & ? & ? & ? & ? & ? & ? & ? & ? & ? & ? & ? & ? & ? & ? & ? & ? & ? & ? & ? & ? & ? & ? \\
? & ? & ? & ? & ? & ? & ? & ? & ? & ? & ? & 0 & 0 & 0 & ? & & & & & & & & & &
\end{array}
$$

\section{Labidolemur kayi}

$\begin{array}{lllllllllllllllllllllllll}1 & 0 & 1 & 1 & 0 & 0 & 0 & 1 & 0 & 0 & 0 & 0 & 0 & 0 & 0 & 0 & 0 & 1 & 0 & 0 & 2 & 0 & 2 & 1 & 1\end{array}$

$\begin{array}{lllllllllllllllllllllllll}2 & 1 & 1 & 0 & 0 & 1 & 1 & 0 & 0 & 0 & 0 & 0 & 0 & 0 & 1 & 1 & 0 & 0 & 0 & 2 & 1 & 0 & 0 & 1 & 2\end{array}$

$\begin{array}{lllllllllllllllllllllllllllllll}0 & 0 & 0 & 0 & 0 & 0 & 0 & ? & 0 & 0 & 1 & 0 & 0 & 0 & 0 & 2 & 2 & 0 & 1 & 0 & 1 & 1 & ? & 1 & 0\end{array}$

$\begin{array}{lllllllllllllllllllllllll}0 & 0 & ? & 1 & 0 & 0 & ? & 0 & 0 & 1 & 0 & 0 & 0 & 0 & 1 & 0 & 1 & 1 & 0 & 0 & 0 & 0 & 0 & 1 & 1\end{array}$

$\begin{array}{lllllllllllllllllllllllll}0 & 1 & 0 & 0 & 0 & ? & 0 & ? & 0 & 0 & 0 & 0 & 0 & 1 & 1 & 1 & 0 & 0 & 2 & 1 & 2 & 1 & 1 & 1 & 3\end{array}$ ? $\begin{array}{lllllllllllllllllllllllll}0 & 0 & 1 & 1 & 0 & 2 & ? & 0 & 1 & 0 & 0 & 1 & 0 & 0 & 1 & 1 & 0 & 0 & 0 & 1 & 0 & 0 & 0 & 0 & 0\end{array}$ $\begin{array}{lllllllllllllllllllllllllllllll}1 & 0 & 0 & 0 & 0 & 0 & 0 & 0 & 1 & 0 & 2 & 1 & 0 & 2 & 1 & 2 & 2 & 1 & 1 & 1 & 1 & 1 & 1 & 3 & 1\end{array}$ $\begin{array}{lllllllllllllllllllllllll}0 & 1 & 1 & 0 & 2 & 1 & 1 & 0 & 1 & 1 & 1 & 1 & 1 & 1 & 0 & 0 & 1 & 1 & 0 & 0 & 0 & 0 & 1 & 0 & 0\end{array}$ $\begin{array}{lllllllllllllll}0 & 0 & 0 & 2 & 1 & 1 & 0 & 1 & 0 & 3 & 0 & 0 & 0 & 0 & 0\end{array}$

\section{Apatemys}

$\begin{array}{llllllllllllllllllllllllllll}? & 0 & 1 & ? & 0 & 0 & ? & 1 & 0 & ? & 0 & 0 & ? & ? & 0 & ? & 0 & ? & ? & ? & 2 & 0 & 2 & 1 & \text { ? }\end{array}$ $\begin{array}{lllllllllllllllllllllllll}2 & 0 & ? & ? & 0 & 1 & ? & 0 & 0 & 0 & 0 & 0 & 0 & 0 & ? & ? & ? & 0 & 0 & ? & ? & ? & ? & 1 & 2\end{array}$ $\begin{array}{llllllllllllllllllllllllll}\text { ? } & 0 & ? & ? & 0 & 0 & 0 & ? & 0 & 0 & 1 & \text { ? } & 0 & \text { ? } & ? & ? & ? & 0 & 1 & ? & ? & 0 & \text { ? } & 1 & \text { ? }\end{array}$ $\begin{array}{lllllllllllllllllllllllllll}0 & 0 & ? & ? & ? & ? & ? & \text { ? } & \text { ? } & \text { ? } & \text { ? } & \text { ? } & \text { ? } & \text { ? } & \text { ? } & \text { ? } & 1 & \text { ? } & \text { ? } & \text { ? } & \text { ? } & 0 & 0 & \text { ? } & \text { ? }\end{array}$ ? $0 \begin{array}{lllllllllllllllllllllllll} & 0 & ? & ? & ? & ? & ? & 2 & ? & ? & 0 & ? & 1 & 1 & 1 & 0 & 0 & 2 & 1 & 2 & 1 & 1 & 1 & 3\end{array}$ ? $\begin{array}{lllllllllllllllllllllllll}0 & 0 & 1 & 1 & 0 & 0 & 0 & 0 & 1 & 0 & 0 & 1 & 1 & 1 & 1 & 1 & 0 & 0 & 0 & 1 & 0 & 0 & 0 & 0 & 0\end{array}$ $\begin{array}{lllllllllllllllllllllllll}1 & 0 & 0 & 0 & 0 & 0 & 0 & 0 & 1 & 0 & 2 & 1 & 0 & 2 & 1 & 2 & 2 & 1 & 1 & 1 & 2 & ? & 0 \& 2 & 3\end{array}$

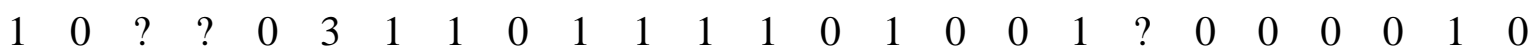
$\begin{array}{llllllllllllllll}0 & 1 & 0 & 1 & 4 & 1 & 1 & 0 & 1 & 0 & 3 & 0 & 0 & 0 & 0 & 0\end{array}$

Heterohyus nanus

$$
\begin{array}{llllllllllllllllllllllllllll}
? & 0 & ? & ? & 0 & 0 & ? & ? & 0 & ? & ? & ? & 0 & ? & 0 & ? & 0 & ? & 0 & 0 & 2 & 0 & ? & 1 & ? \\
2 & ? & ? & ? & ? & ? & ? & 0 & 0 & 0 & 0 & 0 & 0 & 0 & 1 & 1 & 0 & 0 & ? & ? & 1 & 0 & ? & ? & ? \\
? & 0 & ? & ? & 0 & 0 & 0 & ? & 0 & 0 & 1 & ? & 0 & ? & 0 & ? & ? & 0 & 2 & ? & ? & 1 & ? & 1 & ? \\
0 & 0 & ? & ? & ? & ? & ? & ? & ? & 1 & ? & ? & ? & ? & ? & ? & 1 & ? & ? & ? & ? & ? & ? & ? & ? \\
? & ? & ? & ? & ? & ? & ? & ? & 2 & ? & ? & ? & 0 & 1 & 1 & ? & 0 & 0 & 2 & 1 & 2 & 1 & 1 & 1 & 3 \\
? & ? & ? & ? & ? & ? & ? & ? & 0 & 1 & 1 & 0 & 0 & ? & 0 & 1 & 0 & 0 & 0 & 0 & ? & 1 & 0 & ? & 0 \\
0 & 0 & 1 & 1 & 0 & 2 & ? & 0 & 1 & 0 & 0 & 1 & 1 & 1 & 1 & 0 & 0 & 1 & 0 & 1 & 0 & 0 & 1 & 0 & 0 \\
1 & 0 & 1 & 1 & 0 & 0 & 0 & 0 & 1 & 0 & 2 & 1 & 0 & 2 & 1 & 2 & 2 & 1 & 1 & 1 & 2 & ? & 0 & 3 & ? \\
? & ? & ? & ? & ? & 1 & 1 & 0 & 1 & 1 & 1 & 1 & 0 & 1 & 0 & 0 & 1 & 0 & 0 & 0 & 0 & 0 & 1 & 0 & 0 \\
1 & 1 & 1 & 1 & 1 & 2 & 1 & 1 & 1 & 3 & 0 & 0 & 1 & 0 & 0 & & & & & & & & & &
\end{array}
$$

\section{Jepsenella}

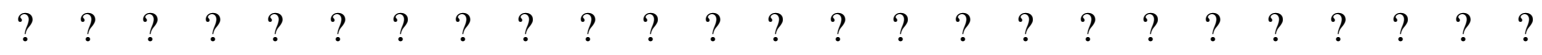
? 


$$
\begin{array}{lllllllllllllllllllllllllllll}
? & ? & ? & ? & ? & ? & ? & ? & ? & ? & ? & ? & ? & ? & ? & ? & ? & ? & ? & ? & ? & ? & ? & ? & ? \\
? & ? & ? & ? & ? & ? & ? & ? & ? & ? & ? & ? & ? & ? & ? & ? & ? & ? & ? & ? & ? & ? & ? & ? & ? \\
? & ? & ? & ? & ? & ? & ? & ? & ? & ? & ? & 0 & 0 & ? & ? & ? & ? & ? & ? & ? & ? & ? & ? & ? & ? \\
? & ? & ? & ? & ? & ? & ? & ? & ? & ? & ? & 0 & ? & ? & ? & ? & ? & ? & ? & ? & ? & ? & ? & ? & ? \\
? & ? & 0 & 1 & 0 & 2 & ? & 0 & 0 & 0 & 0 & 1 & 1 & 0 & 1 & 1 & 1 & 0 & 0 & 1 & 0 & 0 & 0 & 0 & 0 \\
0 & 0 & 0 & 0 & 0 & 0 & 0 & 0 & 0 & 0 & 2 & 1 & 0 & 2 & 1 & 2 & 2 & 1 & 1 & 1 & 1 & ? & 0 & 3 & 1 \\
0 & ? & ? & 0 & 3 & 0 & 1 & 0 & 1 & 1 & 1 & 1 & 0 & 0 & 0 & 0 & 1 & 0 & 0 & 0 & 0 & 0 & 0 & 0 & 0 \\
0 & 0 & 0 & 4 & 1 & 1 & 0 & 1 & 0 & 0 & 0 & 0 & 0 & ? & 0 & & & & & & & & & &
\end{array}
$$

\section{Sinclairella}

$\begin{array}{lllllllllllllllllllllllll}? & ? & ? & ? & ? & ? & ? & ? & ? & ? & ? & ? & ? & ? & ? & ? & ? & ? & ? & ? & ? & ? & ? & ? & ? \\ ? & ? & ? & ? & ? & ? & ? & ? & ? & ? & ? & ? & ? & ? & ? & ? & ? & ? & ? & ? & ? & ? & ? & ? & ? \\ ? & ? & ? & ? & ? & ? & ? & ? & ? & ? & ? & ? & ? & ? & ? & ? & ? & ? & 2 & 1 & 0 & 1 & ? & ? & ? \\ 0 & 0 & ? & ? & 0 & ? & ? & ? & ? & ? & ? & ? & ? & 0 & ? & ? & 1 & 1 & 0 & ? & 0 & 0 & ? & ? & ? \\ ? & ? & ? & ? & ? & ? & ? & ? & 2 & 1 & ? & 0 & 0 & 1 & ? & 0 & 2 & 0 & 2 & 1 & 2 & 1 & 2 & 0 & 3 \\ ? & ? & ? & ? & ? & ? & ? & ? & 1 & 0 \& 1 & 1 & 0 & 0 & 0 & 0 & 1 & 1 & 0 & 1 & 1 & 0 & 1 & 0 & 0 \\ 0 & 0 & 0 & 1 & 1 & 0 & 2 & ? & 0 & 1 & 0 & 0 & 1 & 1 & 1 & 1 & 1 & 0 & 1 & 0 & 1 & 0 & 0 & 1 & 0 \\ 0 & 1 & 0 & 1 & 1 & 0 & 0 & 0 & 1 & 1 & 0 & 2 & 1 & 0 & 2 & 1 & 2 & 2 & 1 & 1 & 1 & 2 & ? & 0 & 3 \\ ? & ? & ? & ? & ? & ? & 1 & 1 & 1 & 1 & 1 & 0 & 1 & 0 & 1 & 0 & 0 & 1 & 0 & 0 & 0 & 0 & 0 & 1 & 0 \\ 0 & 1 & 1 & 2 & 1 & 1 & 1 & 1 & 1 & 1 & 3 & 0 & 0 & 1 & 0 & 0 & & & & & & & & & \end{array}$

\section{Purgatorius}

$$
\begin{array}{rllllllllllllllllllllllll}
? & ? & ? & ? & ? & ? & ? & ? & ? & ? & ? & ? & ? & ? & ? & ? & ? & ? & ? & ? & ? & ? & ? & ? & ? \\
? & ? & ? & ? & ? & ? & ? & ? & ? & ? & ? & ? & ? & ? & 0 & 0 & 1 & 0 & 0 & 2 & 0 & 0 & 1 & 0 & 2 \\
1 & 0 & 0 & 0 & ? & ? & ? & ? & ? & ? & ? & ? & ? & ? & ? & ? & ? & ? & ? & ? & ? & ? & ? & ? & ? \\
? & ? & ? & ? & ? & ? & ? & ? & ? & ? & ? & ? & ? & ? & ? & ? & ? & ? & ? & ? & ? & ? & ? & ? & ? \\
? & ? & ? & ? & ? & ? & ? & ? & ? & ? & ? & ? & ? & 1 & 1 & 2 & 0 & ? & ? & ? & ? & ? & ? & ? & 0 \\
2 & 1 & 0 & 1 & 0 & 0 & 1 & 0 & 2 & 0 & 0 & 0 & 1 & 0 & 1 & 1 & 0 & 0 & 0 & 0 & 0 & 0 & 0 & 0 & 0 \\
1 & 0 & 0 & 1 & 0 & 0 & 0 & 0 & 0 & 0 & 0 & 0 & 0 & 0 & 0 & 0 & 0 & 0 \& 1 & 0 & 0 & 0 \& 1 & 0 & 0 \\
0 & 0 & 1 & 0 & 0 & 0 & 0 & 0 & ? & 0 & ? & 0 & ? & 1 & ? & 1 & 0 & 0 & 0 & 0 & 0 & 0 & 0 & 1 & 2 \\
0 & 0 & 0 & 0 & 0 & 0 & 1 & 0 & 1 & 0 & 0 & 0 & 0 & 1 & 1 & 0 & 0 & 0 & 0 & 0 \& 1 & 0 & 0 & 0 & 0 \\
0 & 0 & 0 & 0 & 1 & 0 & 1 & 1 & 0 & 0 \& 1 & 1 & 1 & 0 & 0 & 0 & 0 & 0 & ? & 0 & & & & & \\
\text { Carpolestida } & & & & & & & & & & & & & & & & & & & & & \\
? \\
?
\end{array}
$$

\section{Carpolestidae}

Plesiadapidae 
$\begin{array}{lllllllllllllllllllllllll}? & 0 & 1 & 0 & 0 & 0 & 0 & 1 & 0 & 0 & 1 & 0 & 0 & 0 & 0 & 0 & 0 & 0 & 0 & 0 & 0 & 0 & 1 & 1 & 1\end{array}$ $\begin{array}{lllllllllllllllllllllllll}1 & 0 & 0 & 0 & 1 & 0 & 0 & 0 & 0 & 0 & 0 & 0 & 0 & 0 & 0 & 0 & 0 & 0 & 0 & 2 & 0 & 0 & 1 & 0 & 2\end{array}$ $0 \& 1 \quad 0 \quad \begin{array}{llllllllllllllllllllll}0 & 0 & 0 & 1 & 0 & 0 & 0 & ? & 0 & 0 & 1 & 0 & 0 & 0 & 1 & 0 & 1 & 2 & 2 & 1 & 0 & 1\end{array}$ $\begin{array}{lllllllllllllllllllllllll}0 & 1 & 2 & 1 & ? & 2 & 1 & 0 & \text { ? } & \text { ? } & 0 & \text { ? } & \text { ? } & 0 & 1 & \text { ? } & 0 & 0 & 2 & 1 & 0 & 0 & 1 & ? & 1\end{array}$ $\begin{array}{lllllllllllllllllllllllll}1 & 1 & 1 & 1 & 0 & 2 & ? & 1 & ? & 0 & 0 & ? & 0 & 1 & 1 & 1 & 3 & 0 & 0 & 1 & 1 & 0 & 1 & 2 & 1\end{array}$ $\begin{array}{llllllllllllllllllllllll}0 & 1 & 1 & 0 & 1 & 0 & 1 & 1 & 0 & 1 & 1 & 1 & 0 & 0 & 0 & 1 & 1 & 0 \& 1 & 1 & 0 & 0 & 1 & 1 & 0\end{array}$ $\begin{array}{llllllllllllllllllllllll}0 & 1 & 1 & 0 & 0 & 1 & 0 & 0 \& 1 & 1 & 1 & 1 & 0 & 0 & 1 & 0 & 1 & 0 & 1 & 0 & 1 & 0 & 0 & 2 & 1\end{array}$ $\begin{array}{lllllllllllllllllllllllll}0 & 0 & 0 & 0 & 0 & 0 & 1 & 0 & 2 & 0 & 0 & 0 & 0 & 2 & 1 & 1 & 1 & 1 & 0 & 1 & 1 & 1 & 0 & 0 & 1\end{array}$ $\begin{array}{lllllllllllllllllllllll}2 & 3 & 2 & 0 & 2 & 0 & 1 & 3 & 1 & 1 & 0 \& 1 & 1 & 0 & 1 & 0 & 0 \& 1 & 1 & 1 & 0 & 1 & 1 & 0 & 0\end{array}$ $\begin{array}{llllllllllllllllllll}0 & 0 & 0 & 0 & 0 & 1 & 1 & 2 & 1 & 0 & 2 & 1 & 1 & 1 & 0 & 0 & 0 & 1 & 0 & 0\end{array}$

Paromomyidae

$\begin{array}{lllllllllllllllllllllllll}? & 1 & 1 & 0 & 0 & 0 & 0 & 1 & 1 & 0 & 1 & 0 & 0 & 0 & 0 & 1 & 0 & 0 & 0 & 0 & 1 & 1 & 1 & 1 & 1\end{array}$ $\begin{array}{lllllllllllllllllllllllll}2 & 1 & 0 & 0 & 1 & 0 & 0 & 0 & 0 & 0 & 0 & 0 & 0 & 0 & 0 & 0 & 0 & 0 & 0 & 2 & 0 & 0 & 1 & 0 & 2\end{array}$

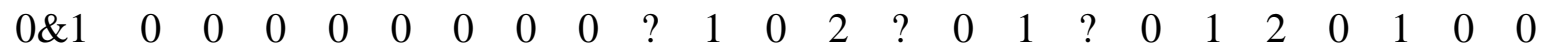
$\begin{array}{lllllllllllllllllllllllll}? & 0 & 2 & 1 & 1 & 2 & 1 & 1 & ? & ? & 0 & \text { ? } & ? & 1 & 1 & 1 & 1 & 1 & 2 & 1 & ? & 1 & 1 & 0 & 1\end{array}$ $\begin{array}{lllllllllllllllllllllllll}1 & 0 & 1 & 1 & 1 & 2 & ? & 1 & 2 & 2 & 0 & 0 & 0 & 1 & 1 & 1 & 3 & 0 & 0 & 1 & 1 & 0 & 1 & 2 & ?\end{array}$ $\begin{array}{lllllllllllllllllllllll}0 & 0 & 1 & ? & 0 & 0 & 0 & 0 & 0 & 2 & 1 & 0 & 0 & 0 \& 2 & 0 & 1 & 1 & 0 \& 1 & 0 & 1 & 0 & 0 & 1\end{array}$ $\begin{array}{lllllllllllllllllllllllll}0 & 0 & 1 & 1 & 0 & 0 & 1 & 0 & 0 & 0 & 1 & 0 & 0 & 0 & 0 & 0 & 1 & 1 & 1 & 0 & 0 & 0 & 0 & 2 & 1\end{array}$ $\begin{array}{lllllllllllllllllllllll}0 & 0 & 1 & 0 & 0 & 0 & 1 & 0 & 0 & 0 & 0 & 0 & 0 & 1 \& 2 & 1 & 0 & 1 & 1 & 0 & 0 \& 1 & 1 & 0 & 0\end{array}$ $\begin{array}{lllllllllllllllllllllllll}0 & 0 & 2 & 0 & 1 & 0 & 0 & 0 & 0 & 1 & 1 & 1 & 1 & 0 & 1 & 1 & 1 & 1 & 0 & 0 & 0 & 1 & 1 & 0 & 0\end{array}$ $\begin{array}{llllllllllllllllllll}0 & 0 & 0 & 1 & 0 & 1 & 1 & 2 & 1 & 0 & 2 & 2 & 1 & 2 & 2 & 0 & 1 & 0 & 0 & 0\end{array}$

Microsyopidae

$\begin{array}{lllllllllllllllllllllllll}? & ? & ? & ? & ? & ? & ? & ? & ? & ? & ? & 1 & 0 & ? & ? & ? & ? & ? & ? & ? & ? & ? & ? & ? & ? \\ ? & ? & ? & ? & ? & ? & ? & ? & ? & ? & ? & ? & ? & ? & ? & ? & ? & ? & ? & ? & ? & ? & ? & ? & ? \\ 1 & ? & ? & ? & ? & ? & ? & ? & ? & ? & ? & ? & ? & ? & ? & ? & ? & ? & 1 & 1 & 0 & 1 & 1 & 0 & 1 \\ 0 & 0 & 1 & 1 & 0 & 1 & 0 & 0 & 0 & 0 & 0 & 0 & 1 & 0 & 1 & 1 & 1 & 2 & 0 & 1 & 1 & 1 & ? & ? & 0 \\ 1 & 0 & 1 & 0 & 0 & 0 & ? & 0 & ? & 1 & 0 & 0 & 0 & 1 & 1 & 1 & 1 & 0 & 0 & 2 & 1 & 1 & 1 & 2 & 0 \\ 1 & 0 & 0 & 1 & 0 & 0 & 0 & 0 & 0 & 1 & 0 & 0 & ? & 1 & 1 & 1 & 1 & 0 & 0 & 1 & 0 & 0 & 0 & 0 & 0 \\ 1 & 1 & 1 & 0 & 1 & 0 & 0 & 0 & 1 & 1 & 0 & 0 & 1 & 1 & 0 & 0 & 1 & 0 & 0 & 0 & 1 & 1 & 0 & 0 & 0 \\ 1 & 1 & 0 & 0 & 1 & 0 & 0 & 0 & 0 & 0 & 0 & 3 & 1 & 0 & 2 & 1 & 0 & 1 & 1 & 1 & 0 & 0 & 1 & 2 & 0 \\ 1 & 1 & 0 & 0 & 0 & 1 & 1 & 1 & 0 & 0 & 1 & 1 & 1 & 0 & ? & 0 & 0 & 1 & 0 & 0 & 1 & 1 & 0 & 0 & 0 \\ 0 & 0 & 0 & 1 & 3 & 0 & 1 & 1 & 1 & 0 & 0 & 0 & 0 & 0 & 0 & 0 & & & & & & & & & \end{array}$

Micromomyidae

$\begin{array}{lllllllllllllllllllllllll}0 & 0 & 1 & 0 & 0 & 0 & 0 & 1 & 0 & 0 & 1 & 0 & 0 & 0 & 0 & 1 & 0 & 1 & 0 & 0 & 1 & 1 & 1 & 0 & 1\end{array}$ $\begin{array}{lllllllllllllllllllllllll}1 & 0 & 0 & 0 & 2 & ? & 0 & 1 & 0 & 0 & 0 & 0 & 0 & 0 & 0 & 0 & 1 & 0 & 0 & 2 & 0 & 0 & 1 & 0 & 2\end{array}$ $\begin{array}{lllllllllllllllllllllllll}1 & 0 & 0 & 0 & 0 & 0 & 0 & ? & 0 & 0 & 1 & 0 & 2 & ? & ? & ? & 1 & 0 & 0 & ? & ? & 1 & 0 & 0 & \text { ? }\end{array}$ $\begin{array}{lllllllllllllllllllllllll}0 & 2 & \text { ? } & \text { ? } & \text { ? } & \text { ? } & ? & \text { ? } & \text { ? } & \text { ? } & \text { ? } & \text { ? } & \text { ? } & 1 & \text { ? } & \text { ? } & \text { ? } & 2 & 1 & \text { ? } & 1 & 1 & 0 & 1 & \text { ? }\end{array}$ $\begin{array}{lllllllllllllllllllllllll}? & ? & 0 & 0 & 2 & ? & 1 & ? & ? & 0 & ? & 0 & 1 & 1 & 1 & 2 & 0 & 0 & 2 & 1 & 1 & 1 & 2 & 0 & 0\end{array}$ $\begin{array}{lllllllllllllllllllllllll}2 & 1 & 1 & 0 & 0 & 0 & 0 & 0 & 2 & 0 & 0 & 0 & 1 & 0 & 1 & 1 & 0 & 0 & 0 & 0 & 0 & 1 & 0 & 0 & 0\end{array}$ $\begin{array}{lllllllllllllllllllllllll}0 & 0 & 0 & 1 & 0 & 0 & 0 & 0 & 0 & 0 & 0 & 0 & 0 & 0 & 0 & 1 & 0 & 0 & 0 & 0 & 0 & 0 & 0 & 0 & 0\end{array}$ $\begin{array}{lllllllllllllllllllllllll}1 & 0 & 0 & 1 & 0 & 0 & 0 & 0 & 0 & 0 & 1 & 1 & 0 & 2 & 1 & 0 & 1 & 1 & 0 & 0 & 0 & 1 & 2 & 2 & 3\end{array}$ $\begin{array}{llllllllllllllllllllll}0 & 0 & 0 & 0 & 1 \& 3 & 0 \& 1 & 1 & 0 & 0 & 1 & 0 & 1 & 0 & 0 & 0 & 0 & 1 & 0 \& 1 & 0 & 1 & 1 & 0\end{array}$ $\begin{array}{llllllllllllllllll}1 & 0 & 0 & 1 & 0 & 1 & 3 & 0 & 0 & 1 & 1 & 0 & 0 \& 1 & 0 & 0 & 0 & 0 & 0\end{array}$ 
Altanius orlovi

$\begin{array}{lllllllllllllllllllllllll}? & ? & ? & ? & ? & ? & ? & ? & ? & ? & ? & ? & ? & ? & ? & ? & ? & ? & ? & ? & ? & ? & ? & ? & ? \\ ? & ? & ? & ? & ? & ? & ? & ? & ? & ? & ? & ? & ? & ? & ? & ? & ? & ? & ? & ? & ? & ? & ? & ? & ? \\ ? & ? & ? & ? & ? & ? & ? & ? & ? & ? & ? & ? & ? & ? & ? & ? & ? & ? & ? & ? & ? & ? & ? & ? & ? \\ ? & ? & ? & ? & ? & ? & ? & ? & ? & ? & ? & ? & ? & ? & ? & ? & ? & ? & ? & ? & ? & ? & ? & ? & ? \\ ? & ? & ? & ? & ? & ? & ? & ? & ? & ? & ? & ? & ? & ? & ? & ? & ? & ? & ? & ? & 0 & 0 & 2 & ? & 0 \\ 2 & 1 & 0 & 0 & 0 & 0 & 1 & 0 & 2 & 0 & 0 & 0 & ? & 0 & 1 & 1 & 0 & 0 & 1 & 0 & 0 & 0 & 1 & 1 & 1 \\ ? & 0 & 0 & 1 & 0 & 0 & 0 & 1 & 1 & 1 & 0 & 1 & 0 & 0 & 0 & 0 & 0 & 1 & 0 & 1 & 1 & 1 & 2 & 0 & 1 \\ 0 & 0 & 0 & 1 & 0 & 0 & ? & ? & 0 & 1 & ? & 0 & ? & 1 & 1 & 0 & 0 & 0 & 0 & 0 & 0 & 1 & 2 & 0 & 0 \\ 1 & 0 & 0 & 0 & 1 & 0 & 1 & 0 & 1 & 0 & 1 & 0 & 0 & 1 & 1 & 0 & 1 & 1 & 0 & 0 & 0 & 0 & 0 & 0 & 0 \\ 1 & 1 & 2 & 1 & 0 & 2 & 0 & 1 & 0 & 2 & 0 & 0 & 0 & 0 & 0 & & & & & & & & & & \end{array}$

Adapidae

$$
\begin{array}{rllllllllllllllllllllllll}
? & 0 & 1 & 0 & 0 & 0 & 0 & 1 & 1 & 0 & 1 & 1 & 0 & 0 & 0 & 0 & 0 & 0 & 0 & 0 & 2 & 1 & 2 & 1 & 1 \\
2 & 2 & ? & 0 & 2 & 0 & 1 & 0 & 0 & 0 & 0 & 0 & 0 & 0 & 0 & 0 & 0 & 0 & 0 & 2 & 0 & 0 & 1 & 0 & 2 \\
1 & 1 & 0 & 1 & 1 & 1 & 1 & 0 & 0 & 1 & 1 & 0 & 0 & 0 & 0 & ? & 1 & 0 & 2 & 1 & 2 & 2 & 0 & 0 & 0 \\
1 & 1 & 1 & 0 & 2 & 1 & 0 & 0 & 0 & 0 & 0 & 0 & 0 & 1 & 1 & 0 & 0 & 2 & 1 & 1 & 0 & 1 & 0 & 1 & 1 \\
1 & 1 & 1 & 1 & 1 & 1 & 1 & 0 & 1 & 0 & ? & 0 & 1 & 0 & 0 & 0 & 0 & 0 & 1 \& 2 & 1 & 0 & 0 & 2 & 0 \\
0 & 0 & 1 & 0 & 0 & 1 & 0 & 1 & 0 & 2 & 1 & 0 & 0 & 1 & 0 & 1 & 1 & 0 & 1 & 1 & 0 & 0 & 0 & 0 & 1 \\
1 & 1 & 0 & 0 & 1 & 0 & 0 \& 1 & 0 & 1 & 1 & 0 & 0 & 1 & 0 & 1 & 0 & 0 & 0 & 0 & 0 & 0 & 1 & 1 & 1 \\
2 & 0 & 1 & 0 & 0 & 0 & 1 & 0 & 0 & 0 & 0 & 0 & 1 & 0 & 0 & 0 & 1 & 1 & 0 & 0 & 0 & 0 & 0 & 0 & 1 \\
2 & 0 & 0 \& 1 & 1 & 0 \& 1 & 0 & 0 & 1 & 0 \& 1 & 3 & 1 & 1 & 0 & 1 & 0 & 1 & 0 & 0 & 1 & 1 & 0 & 1 & 0 \\
0 & 0 & 0 & 1 & 0 & 0 & 0 & 1 & 0 & 1 & 1 & 0 & 2 & 0 & 1 & 0 & 0 \& 2 & 0 & 0 & 0 & 0 & 0 & 0 &
\end{array}
$$

Omomyidae

$$
\begin{array}{lllllllllllllllllllllllll}
? & 0 & 1 & 1 & 0 & 0 & 0 & 1 & 1 & ? & 1 & 1 & 0 & 0 & 0 & ? & ? & ? & ? & ? & ? & ? & ? & ? & ? \\
? & 1 & 1 & 1 & 2 & 1 & 1 & 1 & 0 & 0 & 0 & 0 & 0 & 0 & 0 & 0 & 1 & 0 & 0 & 2 & 2 & 0 & 0 & 0 & 2 \\
1 & 1 & 0 & 1 & ? & ? & 1 & ? & ? & 1 & ? & ? & ? & ? & ? & ? & ? & ? & 2 & ? & 2 & 2 & 0 & ? & 0 \\
1 & 2 & 1 & 0 & 2 & 1 & ? & 0 & 0 & 0 & ? & 0 & 1 & 1 & ? & ? & 0 & 2 & 1 & 1 & 0 & 1 & ? & 1 & 1 \\
1 & 1 & 1 & 1 & 1 & ? & 1 & 0 & ? & 0 & ? & 0 & ? & 0 \& 1 & 0 \& 1 & 1 & 0 & 0 & 1 \& \& & 1 & 0 & 0 \\
1 & 0 & 0 & 1 & 1 & 1 & 0 & 0 & 0 & 1 & 0 & 2 & 1 & 0 & 0 & 0 & 0 & 1 & 1 & 0 \& 1 & 0 & 1 & 1 & 0 \\
0 & 0 & 0 & 1 & 1 & 1 & 0 & 0 & 1 & 0 & 0 & 0 & 1 & 1 & 0 & 0 & 1 & 0 & 0 & 0 & 0 \& 1 & 0 & 1 & 0 \\
0 \& 1 & 1 & 1 & 2 & 0 & 0 \& 1 & 0 & 0 & 0 & 1 & 0 & 0 & 0 & 0 & 0 & 1 & 0 \& 1 & 0 & 0 & 1 & 1 & 0 \\
0 & 0 & 1 & 0 & 0 & 1 & 2 & 0 & 0 & 1 & 0 & 0 & 0 & 1 & 1 & 1 & 0 & 1 & 0 & 1 & 0 & 0 & 1 & 0 & 0 \\
0 & 1 & 0 & 0 & 0 & 0 & 0 & 0 & 0 & 0 & 1 & 0 & 1 \& 2 & 3 & 0 & 2 & 0 \& 1 & 1 & 0 & 2 & 0 & 0 & 0 \\
0 & 0 & & & & & & & & & & & & & & & & & & & & &
\end{array}
$$




\section{References}

Asher, R.J., McKenna, M.C., Emry, R.J., Tabrum, A.R., Kron, D.G., 2002. Morphology and relationships of Apternodus and other extinct zalambdodont, placental mammals. Bull. Am. Mus. Nat. Hist. 273, 1-117.

Bajpai, S., Kay, R.F., Williams, B.A., Das, D.P., Kapur, V.V., Tiwari, B.N., 2008. The oldest Asian record of Anthropoidea. Proc. Natl. Acad. Sci. 105, 11093-11098.

Beard, K.C., 1989. Postcranial anatomy, locomotor adaptations, and paleoecology of Early Cenozoic Plesiadapidae, Paromomyidae, and Micromomyidae (Eutheria, Dermoptera). Ph.D. Dissertation, Johns Hopkins University School of Medicine.

Beard, K.C., 1990. Gliding behavior and palaecology of the alleged primate family Paromomyidae (Mammalia, Dermoptera). Nature 345, 340-341.

Beard, K.C., 1991. Vertical postures and climbing in the morphotype of Primatomorpha: Implications for locomotor evidence in primate history. In: Coppens, Y., Senut, B. (Eds.), Origines de la Bipedie chex les Hominides. Editions du CNRS (Cahiers de Paleoanthropologie), Paris, pp. 79-87.

Beard, K.C., 1993a. Phylogenetic systematics of the Primatomorpha, with special reference to Dermoptera. In: Szalay, F.S., McKenna, M.C., Novacek, M.J. (Eds.), Mammal Phylogeny: Placentals. Springer-Verlag, New York, pp. 129-150.

Beard, K.C., 1993b. Origin and evolution of gliding in Early Cenozoic Dermoptera (Mammalia, Primatomorpha). In: MacPhee, R.D.E. (Ed.), Primates and their Relatives in Phylogenetic Perspective. Plenum Press, New York, pp. 63-90. 
Beard, K.C., 2006. The Hunt for the Dawn Monkey: Unearthing the Origins of Monkeys, Apes, and Humans. University of California Press, Berkeley.

Beard, K.C., 2008. The oldest North American primate and mammalian biogeography during the Paleocene-Eocene Thermal Maximum. Proc. Natl. Acad. Sci. 105, 3815-3818.

Beard, K.C., Houde, P., 1989. An unusual assemblage of diminutive "plesiadapiforms" (Mammalia, ?Primates) from the early Eocene of the Clark's Fork Basin, Wyoming. J. Vert. Paleontol. 9, 388-399.

Beard, K.C., MacPhee, R.D.E., 1994. Cranial anatomy of Shoshonius and the antiquity of Anthropoidea. In: Fleagle, J.G., Kay, R.F. (Eds.), Anthropoid Origins. Plenum Press, New York, pp. 55-97.

Beard, K.C., Wang, J.W., 1995. The first Asian plesiadapoids. Ann. Carnegie Mus. 64, 1-33.

Beard, K.C., Krishtalka, L., Stucky, R.K., 1991. First skulls of the early Eocene primate Shoshonius cooperi and the anthropoid-tarsier dichotomy. Nature 349, 64-67.

Bloch, J.I., 2001. Mammalian paleontology of freshwater limestones from the Paleocene-Eocene of the Clarks Fork Basin, Wyoming. Ph.D. Dissertation, University of Michigan.

Bloch, J.I., Bowen, G.J., 2001. Paleocene-Eocene microvertebrates in freshwater limestones of the Clarks Fork Basin, Wyoming. In: Gunnell, G.F. (Ed.), Eocene Biodiversity: Unusual Occurrences and Rarely Sampled Habitats. Plenum Publishing Corporation, New York, pp. 94-129. 
Bloch, J.I., Boyer, D.M., 2001. Taphonomy of small mammals in freshwater limestones from the Paleocene of the Clarks Fork Basin. In: Gingerich, P.D. (Ed.), Paleocene-Eocene Stratigraphy and Biotic Change in the Bighorn and Clarks Fork Basins, Wyoming. Univ. Mich. Pap. Paleontol. 33, 185-198.

Bloch J.I., Boyer D.M., 2002. Grasping primate origins. Science 298, 1606-1610.

Bloch, J.I., Boyer, D.M., 2007. New skeletons of Paleocene-Eocene Plesiadapiformes: a diversity of arboreal positional behaviors in early primates. In: Ravosa, M.J., Dagosto, M. (Eds.), Primate Origins: Adaptations and Evolution. Springer, New York, pp. 535-581.

Bloch, J.I., Gingerich, P.D., 1998. Carpolestes simpsoni, new species (Mammalia, Proprimates) from the late Paleocene of the Clarks Fork Basin, Wyoming. Contrib. Mus. Paleontol. Univ. Mich. 30, 131-162.

Bloch, J.I., Silcox, M.T., 2001. New basicrania of Paleocene-Eocene Ignacius: re-evaluation of the plesiadapiform-dermopteran link. Am. J. Phys. Anthropol. 166, 184-198.

Bloch, J.I., Silcox, M.T., 2006. Cranial anatomy of Paleocene plesiadapiform Carpolestes simpsoni (Mammalia, Primates) using ultra high-resolution X-ray computed tomography, and the relationships of "plesiadapiforms" to Euprimates. J. Hum. Evol. 50, 1-35.

Bloch, J.I., Secord, R., Gingerich, P.D., 2004. Systematics and phylogeny of late Paleocene and early Eocene Palaeoryctinae (Mammalia, Insectivora) from the Clarks Fork and Bighorn Basins, Wyoming. Contrib. Mus. Paleontol. Univ. Mich. 31, 119-154. 
Bloch, J.I., Silcox, M.T., Boyer, D.M., Sargis, E.J., 2007. New Paleocene skeletons and the relationship of "plesiadapiforms" to crown-clade primates. Proc. Natl. Acad. Sci. 104, 11591164.

Bowen, G.J. and Bloch, J.I., 2002. Petrography and geochemistry of floodplain limestones from the Clarks Fork Basin, Wyoming, USA: carbonate deposition and fossil accumulation on a Paleocene-Eocene floodplain. J. Sediment. Res. 72, 50-62.

Bown, T.M., Rose, K.D., 1976. New early Tertiary primates and a reappraisal of some Plesiadapiformes. Folia Primatol. 26, 109-138.

Boyer, D.M., 2009. New cranial and postcranial remains of late Paleocene Plesiadapidae ("Plesiadapiforms," Mammalia) from North America and Europe: Description and evolutionary implications. Ph. D. Dissertation, Stony Brook University.

Boyer, D.M., Bloch, J.I., 2008. Evaluating the mitten-gliding hypothesis for Paromomyidae and Micromomyidae (Mammalia, "Plesiadapiformes") using comparative functional morphology of new Paleogene skeletons. In: Dagosto, M.J., Sargis, E.J. (Eds.), Mammalian Evolutionary Morphology: A Tribute to Frederick S. Szalay. Springer-Verlag, New York, pp. 231-279.

Boyer, D.M., Scott, C.S., Fox, R.C., 2012. New craniodental material of Pronothodectes gaoi Fox (Mammalia, "Plesiadapiformes") and relationships among members of Plesiadapidae. Am. J. Phys. Anthropol. 147, 511-550.

Boyer, D.M., Kaufman, S., Gunnell, G.F., Rosenberger A.L., Delson, E., 2014. Managing 3D digital data sets of morphology: Morphosource is a new project-based data archiving and distribution tool. Am. J. Phys. Anthropol 153, 84. 
Cartmill, M., 1972. Arboreal adaptations and the origin of the order Primates. In: Tuttle, R. (Ed.), The Functional and Evolutionary Biology of Primates. Aldine, Chicago, pp. 97-122.

Cartmill, M., 1974. Rethinking primate origins. Science 184, 436-443.

Chester, S.G.B., 2013. Origin and early evolutionary history of Primates: systematics and paleobiology of primitive plesiadapiforms. Ph.D. Dissertation, Yale University.

Chester, S.G.B., Beard, K.C., 2012. New micromomyid plesiadapiforms (Mammalia, Euarchonta) from late Paleocene of Big Multi Quarry, Washakie Basin, Wyoming. Ann. Carnegie Mus. 80, 159-172.

Chester, S.G.B., Bloch, J. I., 2013. Systematics of Paleogene Micromomyidae (Euarchonta, Primates) from North America. J. Hum. Evol. 65, 109-142.

Chester, S.G.B., Bloch, J.I., Boyer, D.M., Clemens, W.A., 2015. Oldest known euarchontan postcrania and affinities of Paleocene Purgatorius to Primates. Proc. Natl. Acad. Sci. 112, 1487-1492.

Fox, R.C., 1984. The dentition and relationship of the Paleocene primate Micromomys Szalay, with description of a new species. Can. J. Earth Sci. 21, 1262-1267.

Gebo, D.L., 2009. A response to Sargis et al., (2007). J. Hum. Evol. 57, 810-814.

Gebo, D.L., Smith, T., Dagosto, M., 2012. New postcranial elements for the earliest Eocene fossil primate Teilhardina belgica. J. Hum. Evol. 63, 205-218.

Gebo, D.L., Smith, R., Dagosto, M., Smith, T., 2015. Additional postcranial elements of Teilhardina belgica : The oldest European primate. Am. J. Phys. Anthropol. 156, 388-406. 
Gheerbrant, E., Sudre, J., Sen, S., Abrial, C., Marandat, B., Sigé, B., Vianey-Liaud, M., 1998.

Nouvelles données sur les mammifères du Thanetien et de l'Ypresien du Bassin

d'Ouarzazate (Maroc) et leur contexte stratigraphique. Palaeovertebrata 27, 155-202.

Gingerich, P.D., 1976. Cranial anatomy and evolution of early Tertiary Plesiadapidae

(Mammalia, Primates). Univ. Mich. Pap. Paleontol. 15, 1-141.

Gingerich, P.D., 1980. Eocene Adapidae, paleobiogeography, and the origin of South American

Platyrrhini. In: Ciochon R. L. and Chiarelli A. B. (Eds.), Evolutionary Biology of the New World Monkeys and Continental Drift. Springer, New York, pp. 123-138.

Gingerich, P.D., 2001. Biostratigraphy of the continental Paleocene-Eocene boundary interval on Polecat Bench in the northern Bighorn Basin. In: Gingerich P.D. (Ed.), Paleocene-Eocene Stratigraphy and Biotic Change in the Bighorn and Clarks Fork Basins, Wyoming. Univ. Mich. Pap. Paleontol. 33, 37-71.

Gingerich, P.D., Gunnell, G.F., 2005. Brain of Plesiadapis cookei (Mammalia, Proprimates): surface morphology and encephalization compared to those of Primates and Dermoptera. Univ. Mich. Pap. Paleontol. 31, 185-195.

Goloboff, P.A., Farris J.S., Nixon K.C., 2008. TNT, a free program for phylogenetic analysis. Cladistics, 24:774-786.

Godinot, M., 2007. Primate origins: A reappraisal of historical data favoring tupaiid affinities. In: Ravosa, M.J., Dagosto, M. (Eds.), Primate Origins: Adaptations and Evolution. Springer, New York, pp. 83-142. 
Gregory, W.K., 1920. On the structure and relationships of Notharctus, an American Eocene primate. Mem. Am. Mus. Nat. Hist. 3, 49-243.

Gunnell, G.F., 1989. Evolutionary history of Microsyopoidea (Mammalia, ?Primates) and the relationship between plesiadapiforms and primates. Univ. Mich. Pap. Paleontol. 27, 1-157.

Hooker, J.J., Russell, D.E., Phélizon. A., 1999. A new family of Plesiadapiformes (Mammalia) from the Old World lower Paleogene. Palaeontology 42, 377-407.

Hunt, R. M., Korth W.W., 1980. The auditory region of Dermoptera: morphology and function relative to other living mammals. J. Morphol. 164, 167-211.

Jepsen, G.L., 1930. Stratigraphy and paleontology of the Paleocene of northeastern Park County, Wyoming. Proc. Am. Phil. Soc. 69, 463-528.

Kay, R.F., Cartmill, M., 1977. Cranial morphology and adaptations of Palaechthon nacimienti and other Paromomyidae (Plesiadapoidea, ?Primates), with a description of a new genus and species. J. Hum. Evol. 6, 19-53.

Kay, R.F., Thorington R.W., Jr., Houde, P., 1990. Eocene plesiadapiform shows affinities with flying lemurs not primates. Nature 345, 342-344.

Kay, R.F., Thewissen, J.G.M., Yoder, A.D., 1992. Cranial anatomy of Ignacius graybullianus and the affinities of the Plesiadapiformes. Am. J. Phys. Anthrop. 89, 477-498.

Kay, R.F., Ross, C., Williams, B.A., 1997. Anthropoid origins. Science 275, 797-804.

Krause, D.W., 1978. Paleocene primates from western Canada. Can. J. Earth Sci. 15, 1250-1271. 
MacPhee, R.D.E., 1981. Auditory regions of primates and eutherian insectivores. Contrib.

Primatol. 18, 1-282.

MacPhee, R.D.E., Cartmill, M., 1986. Basicranial structures and primate systematics. In:

Swisher, D.R., Erwin, J. (Eds.), Comparative Primate Biology, Volume 1: Systematics, Evolution, and Anatomy. Alan R. Liss, New York, pp. 219-275.

MacPhee, R.D.E, Cartmill, M., Gingerich, P.D., 1983. New Paleogene primate basicrania and the definition of the order Primates. Nature 301, 509-511.

MacPhee, R.D.E., Novacek M.J., Storch, G., 1988. Basicranial morphology of early Tertiary erinaceomorphs and the origin of Primates. Am. Mus. Novit. 2921, 1-42.

MacPhee, R.D.E., Cartmill, M., Rose, K.D., 1989. Craniodental morphology and relationships of the supposed Eocene dermopteran Plagiomene (Mammalia). J. Vert. Paleontol. 9, 329-349.

MacPhee, R.D.E., Beard, K.C., Flemming, C., Houde, P., 1995. Petrosal morphology of Tinimomys graybulliensis is plesiadapoid not microsyopoid. J. Vert. Paleontol. 15, 42A.

Manz, C.L., Bloch, J.I., 2015. Systematics and phylogeny of Paleocene-Eocene Nyctitheriidae (Mammalia, Eulipotyphla?) with description of a new species from the Late Paleocene of the Clarks Fork Basin, Wyoming, USA. J. Mamm. Evol. 22, 307-342.

Manz, C.L., Chester, S.G.B., Bloch, J.I., Silcox, M.T., Sargis, E.J., 2015. New partial skeletons of Palaeocene Nyctitheriidae and evaluation of proposed euarchontan affinities. Biol. Lett. 11, 20140911.

Martin, R.D., 1968. Towards a new definition of Primates. Man 3, 377-401. 
Martin, R.D., 1972. Adaptive radiation and behavior of the Malagasy lemurs. Philos. T. Roy. Soc. B 264, 295-352.

McDowell, S.B. Jr., 1958. The Greater Antillean insectivores. Bull. Am. Mus. Nat. Hist. 115, $117-214$.

Meng J., Hu Y., Li C.-K., 2003. The osteology of Rhombomylus (Mammalia, Glires): implications for phylogeny and evolution of Glires. Bull. Am. Mus. Nat. Hist. 275, 1-247.

Miller, M.E., 1964. Anatomy of the Dog. W.B. Saunders, Philadelphia.

Muchlinski, M.N., 2008a. The relationship between the infraorbital foramen, infraorbital nerve, and maxillary mechanoreception: implications for interpreting the paleoecology of fossil mammals based on infraorbital foramen size. Anat. Rec. 291, 1221-1226.

Muchlinski, M.N., 2008b. Ecological and morphological correlates of infraorbital foramen size and its paleoecological implications. Ph.D. Dissertation, University of Texas at Austin.

Muchlinski, M.N., 2010. A comparative analysis of vibrissa count and infraorbital foramen area in primates and other mammals. J. Hum. Evol. 58, 447-473.

Ni, X., Wang, Y., Hu, Y., Li, C., 2004. A euprimate skull from the early Eocene of China. Nature 427, 65-68.

Ni, X., Meng, J., Beard, K.C., Gebo, D.L., Wang, Y., Li, C., 2009. A new tarkadectine primate from the Eocene of Inner Mongolia, China: phylogenetic and biogeographic implications. Proc. R. Soc. B. 277, 247-256. 
Ni, X., Gebo, D.L., Dagosto, M., Meng, J., Tafforeau, P., Flynn, J. J., Beard, K.C., 2013. The oldest known primate skeleton and early haplorhine evolution. Nature 498, 60-64.

Novacek, M.J., 1986. The skull of leptictid insectivorans and the higher-level classification of eutherian mammals. Bull. Am. Mus. Nat. Hist. 183, 1-112.

O'Leary, M.A., Kaufman S.G., 2012. MorphoBank 3.0: Web application for morphological phylogenetics and taxonomy. http://www.morphobank.org.

O'Leary, M.A., Bloch, J.I., Flynn, J.J., Gaudin, T.J., Giallombardo, A., Giannini, N.P., Goldberg, S.L., Kraatz, B.P., Luo, Z., Meng, J., Ni, X., Novacek, M.J., Perini, F.A., Randall, Z.S., Rougier, G.W., Sargis, E.J., Silcox, M.T., Simmons, N.B., Spaulding, M., Velazco, P.M., Weksler, M., Wible, J.R., Cirranello, A.L., 2013. The placental mammal ancestor and the post-K-Pg radiation of placentals. Science 339, 662-667.

Orliac, M.J., Ladevèze, S., Gingerich, P.D., Lebrun, R., Smith, T., 2014. Endocranial morphology of Palaeocene Plesiadapis tricuspidens and evolution of the early primate brain. Proc. R. Soc. B., 281, 20132792.

Rasband, W.S., 1997-2007. ImageJ, U. S. National Institutes of Health, Bethesda, Maryland, USA, http://rsb.info.nih.gov/ij/

Rose, K.D., 1975. The Carpolestidae: early Tertiary primates from North America. Bull. Mus. Comp. Zool. 147, 1-74.

Rose, K.D., 1981. The Clarkforkian land-mammal age and mammalian faunal composition across the Paleocene-Eocene boundary. Univ. Mich. Pap. Paleontol. 26, 1-197. 
Rose, K.D., Beard K.C., Houde, P., 1993. Exceptional new dentitions of the diminutive "plesiadapiforms" Tinimomys and Niptomomys (Mammalia), with comments on the upper incisors of Plesiadapiformes. Ann. Carnegie Mus. 62, 351-361.

Rose, K.D., Chester, S.G.B., Dunn, R.H., Boyer, D.M., Bloch, J.I., 2011. New fossils of the oldest North American euprimate Teilhardina brandti (Omomyidae) from the PaleoceneEocene Thermal Maximum. Am. J. Phys. Anthropol. 146, 281-305.

Rose, K. D., Chew, A. E., Dunn, R. H., Kraus, M. J., Fricke, H. C., Zack, S. P., 2012. Earliest Eocene mammalian fauna from the Paleocene-Eocene Thermal Maximum at Sand Creek Divide, southern Bighorn Basin, Wyoming. Univ. Mich. Pap. Paleontol. 36, 1-122.

Rowe, T., Carlson, W., Bottorff, W., 1995. Thrinaxodon: Digital Atlas of the Skull. (CD-ROM) 2nd ed. University of Texas Press, Austin.

Rowe T.B., Eiting T.P., Macrini T.E., Ketcham R.A., 2005. Organization of the olfactory and respiratory skeleton in the nose of the gray short-tailed opossum Monodelphis domestica. J. Mamm. Evol. 12, 303-336.

Russell D.E., 1959. Le crâne de Plesiadapis. Bull. Soc. Géol. Fr. 4, 312-314.

Russell, D.E., 1964. Les mammifères Paléocène d'Europe. Mém. Mus. Hist. Nat. Ser. C 13, 1324.

Scion Corporation, 2002. Scion Image Beta 4.02 for Windows. Available at http://scionimage.software.informer.com/ 
Secord, R., 2008. The Tiffanian land-mammal age (middle and late Paleocene) in the northern Bighorn Basin, Wyoming. Univ. Mich. Pap. Paleontol. 35, 1-192.

Seiffert, E.R., Simons, E.L., Clyde, W.C., Rossie, J.B., Attia, Y., Bown, T.M., Mathison, M.E., 2005. Basal anthropoids from Egypt and the antiquity of Africa's higher primate radiation. Science, 310, 300-304.

Seiffert, E.R., Perry, J.M.G., Simons, E.L., Boyer, D.M., 2009. Convergent evolution of anthropoid-like adaptations in Eocene adapiform primates. Nature 461, 1118-1121.

Sigé, B., Jaeger, J.-J., Sudre, J., Vianey-Liaud, M., 1990. Altiatlasius koulchii n. gen et sp., primate omomyidé du paléocène supérieur du Maroc, et les origines des euprimates. Palaeontographica 212, 1-24.

Silcox, M.T., 2001. A phylogenetic analysis of Plesiadapiformes and their relationship to Euprimates and other archontans. Ph.D. Dissertation, Johns Hopkins University School of Medicine.

Silcox, M.T., 2003. New discoveries on the middle ear anatomy of Ignacius graybullianus (Paromomyidae, Primates) from ultra high resolution X-ray computed tomography. J. Hum. Evol. 44, 73-86.

Silcox, M.T., 2008. The biogeographic origins of Primates and Euprimates: east, west, north, or south of Eden? In: Dagosto, M.J., Sargis, E.J. (Eds.), Mammalian Evolutionary Morphology: A Tribute to Frederick S. Szalay. Springer-Verlag, New York, pp. 199-231. 
Silcox, M.T., Gunnell, G.F., 2008. Plesiadapiformes. In: Janis, C.M., Gunnell, G.F., Uhen, M.D. (Eds.), Evolution of Tertiary Mammals of North America Vol. 2: Small Mammals, Xenarthrans, and Marine Mammals. Cambridge University Press, Cambridge, pp. 207-238.

Silcox, M.T., Dalmyn, C.K., Bloch, J.I., 2009. Virtual endocast of Ignacius graybullianus (Paromomyidae, Primates) and brain evolution in early primates. Proc. Natl. Acad. Sci. 106, 10987-10992.

Silcox, M.T., Benham, A.E., Bloch, J.I., 2010a. Endocasts of Microsyops (Microsyopidae, Primates) and the evolution of the brain in primitive primates. J. Hum. Evol. 58, 505-521.

Silcox, M.T., Bloch, J.I., Boyer, D.M., Houde, P., 2010b. Cranial anatomy of Paleocene and Eocene Labidolemur kayi (Mammalia: Apatotheria), and the relationships of the Apatemyidae to other mammals. Zoo. J. Linn. Soc. 160, 773-825.

Smith, T., Rose, K.D., Gingerich, P.D., 2006. Rapid Asia-Europe-North America geographic dispersal of earliest Eocene primate Teilhardina during the Paleocene-Eocene thermal maximum. Proc. Natl. Acad. Sci. 103, 11223-11227.

Soligo, C., Martin, R.D., 2007. The first primates: a reply to Silcox et al. (2007). J. Hum. Evol. $53,325-328$.

Szalay, F.S., 1969. Mixodectidae, Microsyopidae, and the insectivore-primate transition. Bull. Am. Mus. Nat. Hist. 140, 195-330.

Szalay, F.S., 1972. Cranial morphology of the early Tertiary Phenacolemur and its bearing on primate phylogeny. Am. J. Phys. Anthrop. 361, 59-76. 
Szalay, F.S., 1974. A new species and genus of early Eocene primate from North America. Folia Primatol. 22, 243-250.

Szalay, F.S., Rosenberger, A.L., Dagosto, M., 1987. Diagnosis and differentiation of the order Primates. Yearb. Phys. Anthropol. 30, 75-105.

Wible, J.R., 1993. Cranial circulation and relationships of the colugo Cynocephalus (Dermoptera, Mammalia). Am. Mus. Novit. 3072,1-27.

Wible, J.R., 2008. On the cranial osteology of the Hispaniolan solenodon, Solenodon paradoxus Brandt, 1833 (Mammalia, Lipotyphla, Solenodontidae). Ann. Carnegie Mus. 77, 321-402.

Wible, J.R., 2011. On the treeshrew skull (Mammalia, Placentalia, Scandentia). Ann. Carnegie Mus. 79, 149-230.

Wible, J.R., Covert, H.H., 1987. Primates: cladistic diagnosis and relationships. J. Hum. Evol. $16,1-22$.

Wible, J.R., Zeller U., 1994. Cranial circulation of the pen-tailed tree shrew Ptilocercus lowii and relationships of Scandentia. J. Mamm. Evol. 2, 209-230.

Wible J.R., Rougier G.W., Novacek M.J., Asher R.J., 2009. The eutherian mammal Maelestes gobiensis from the Late Cretaceous of Mongolia and the phylogeny of Cretaceous Eutheria. Bull. Am. Mus. Nat. Hist. 327, 1-123.

Zachos, J.C., Wara, M.W., Bohaty, S., Delaney, M.L., Petrizzo, M.R., Brill, A., Premoli-Silva, I., 2003. A transient rise in tropical sea surface temperature during the Paleocene-Eocene thermal maximum. Science 302, 1551-1554. 
Figure 1

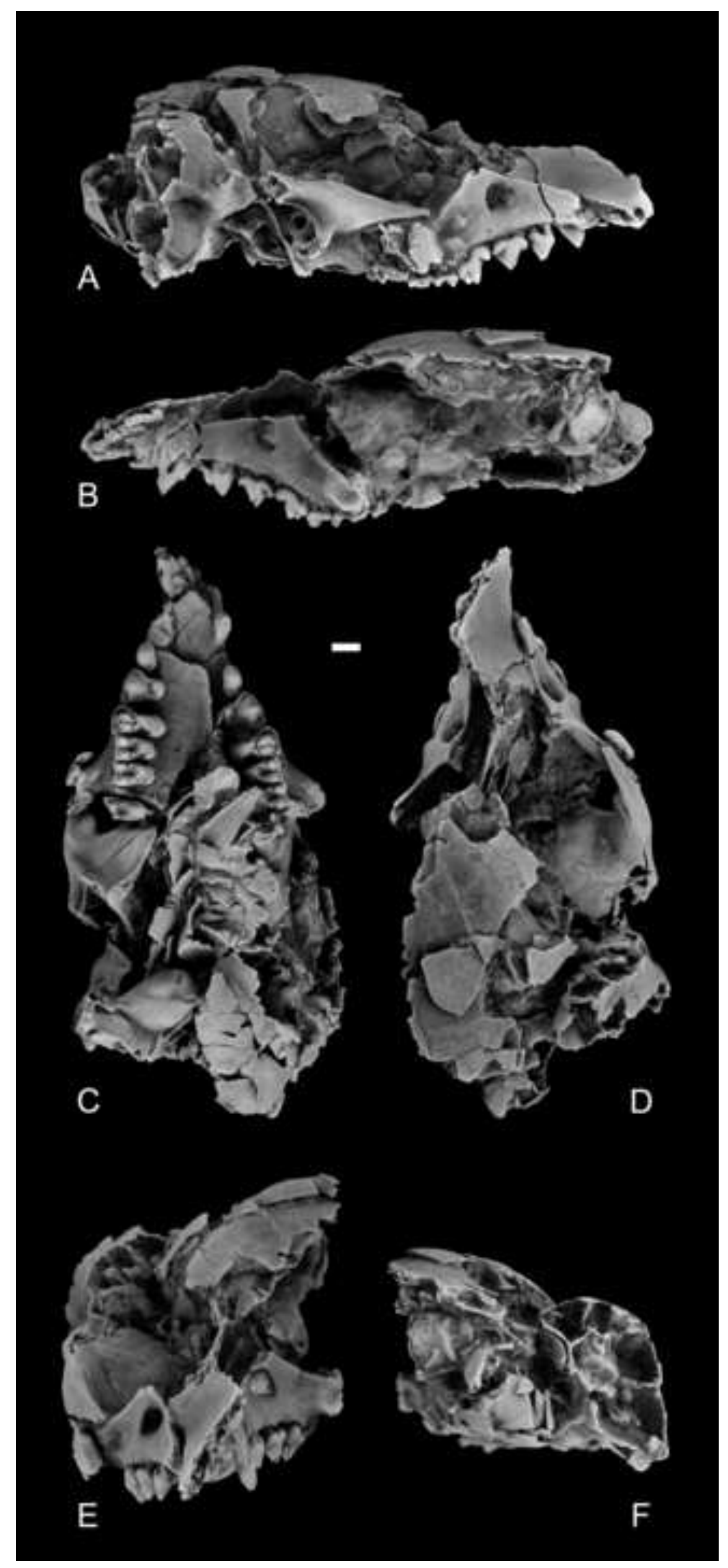



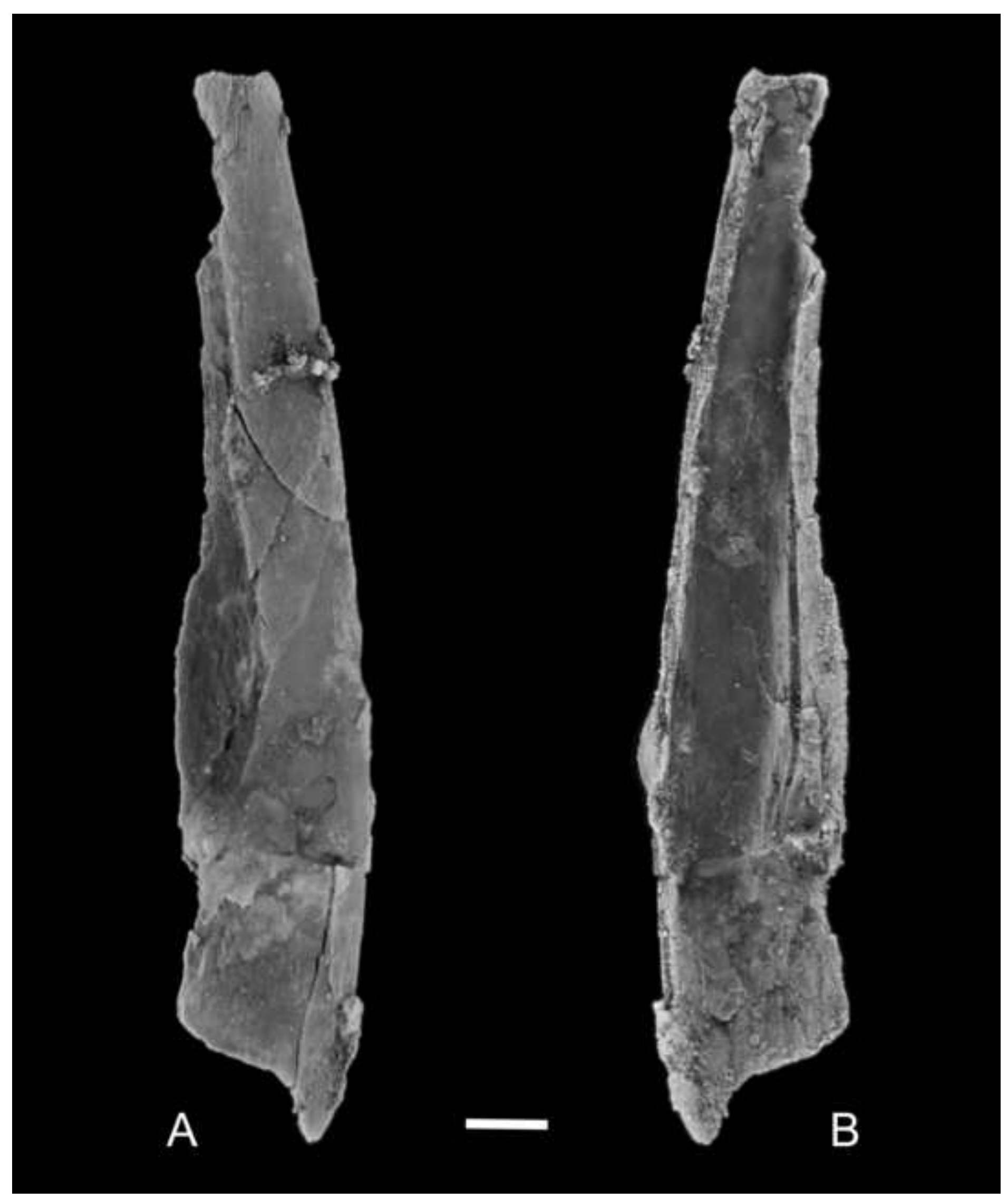

B 
Figure 4

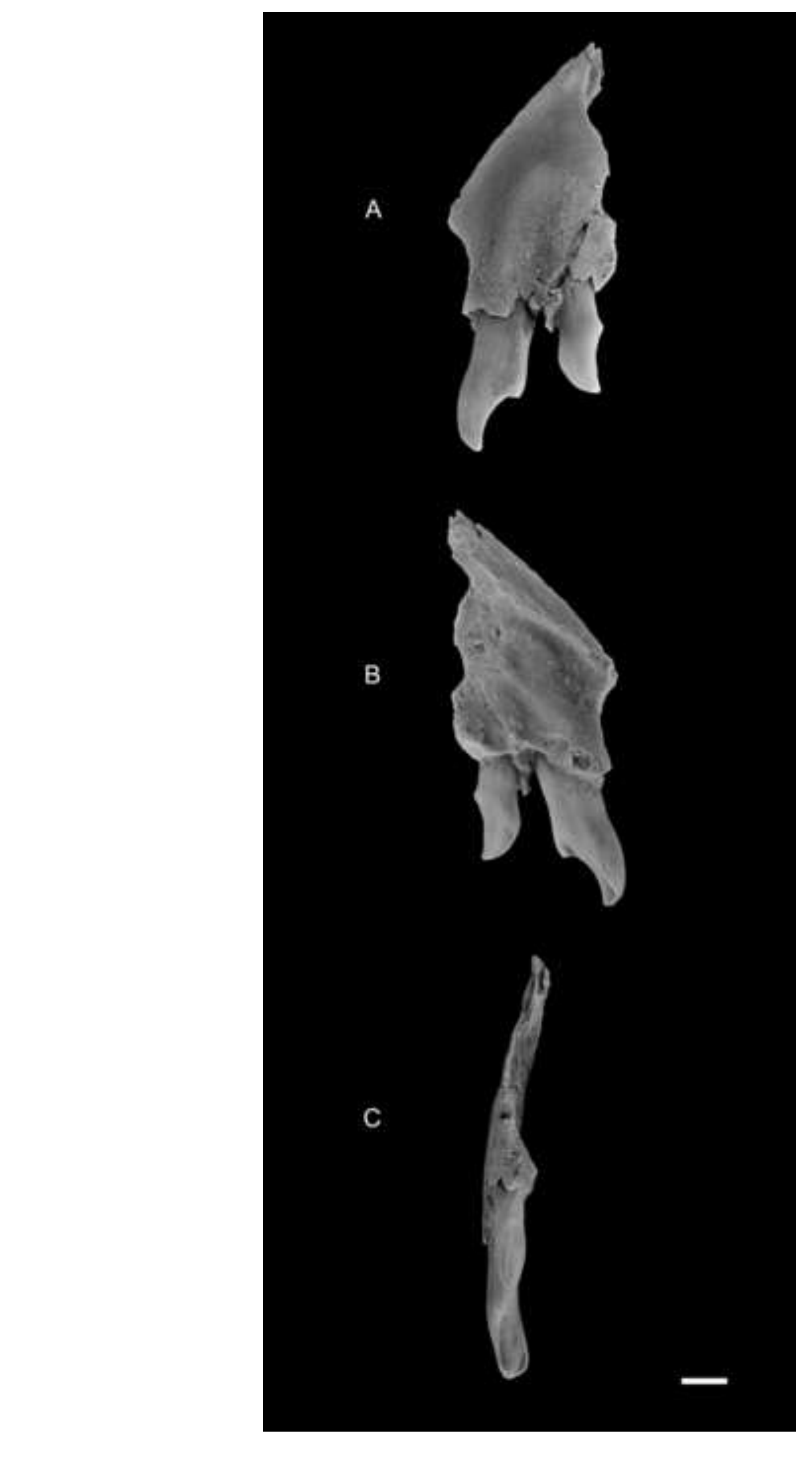

B

4
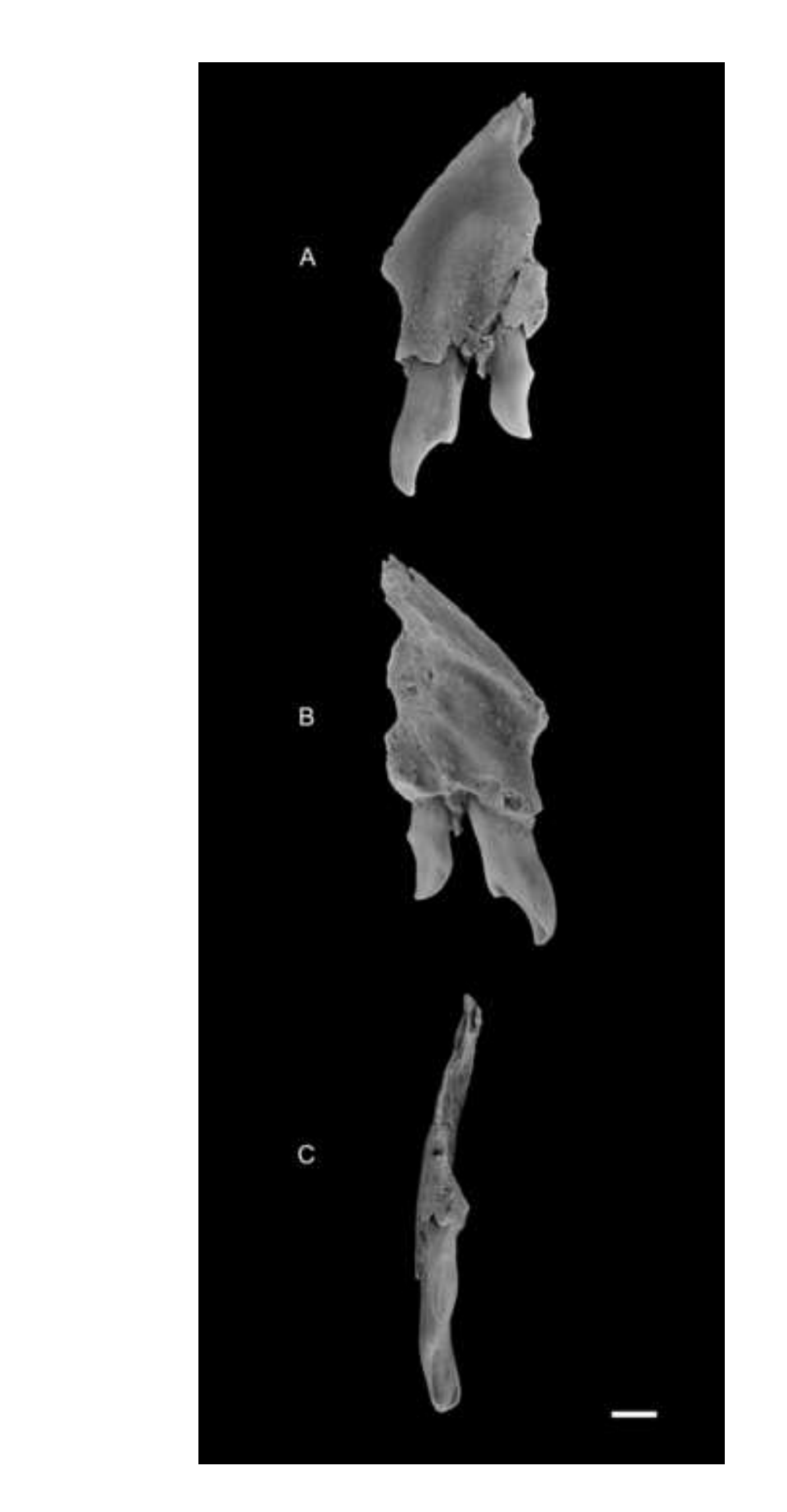

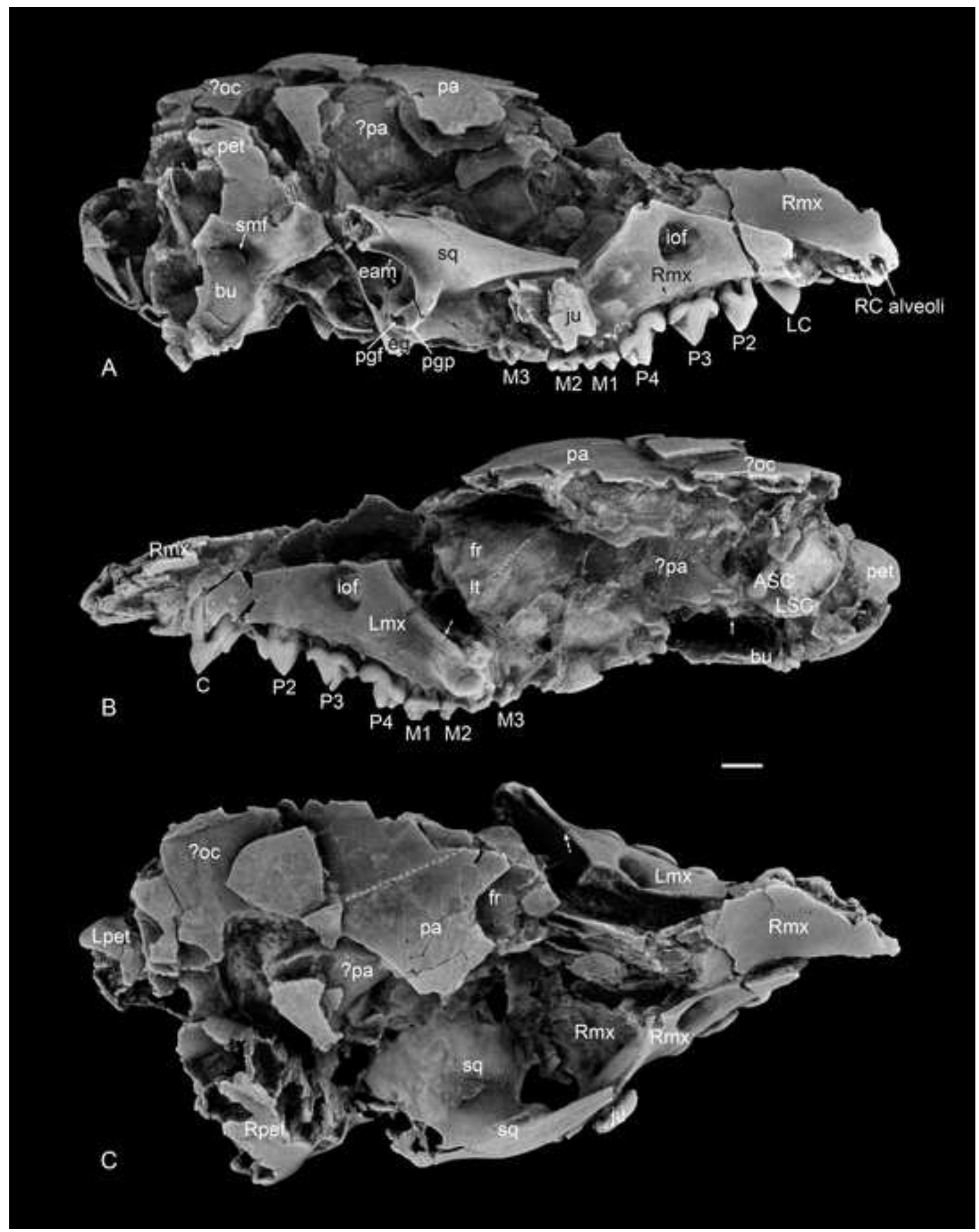

Figure 5 


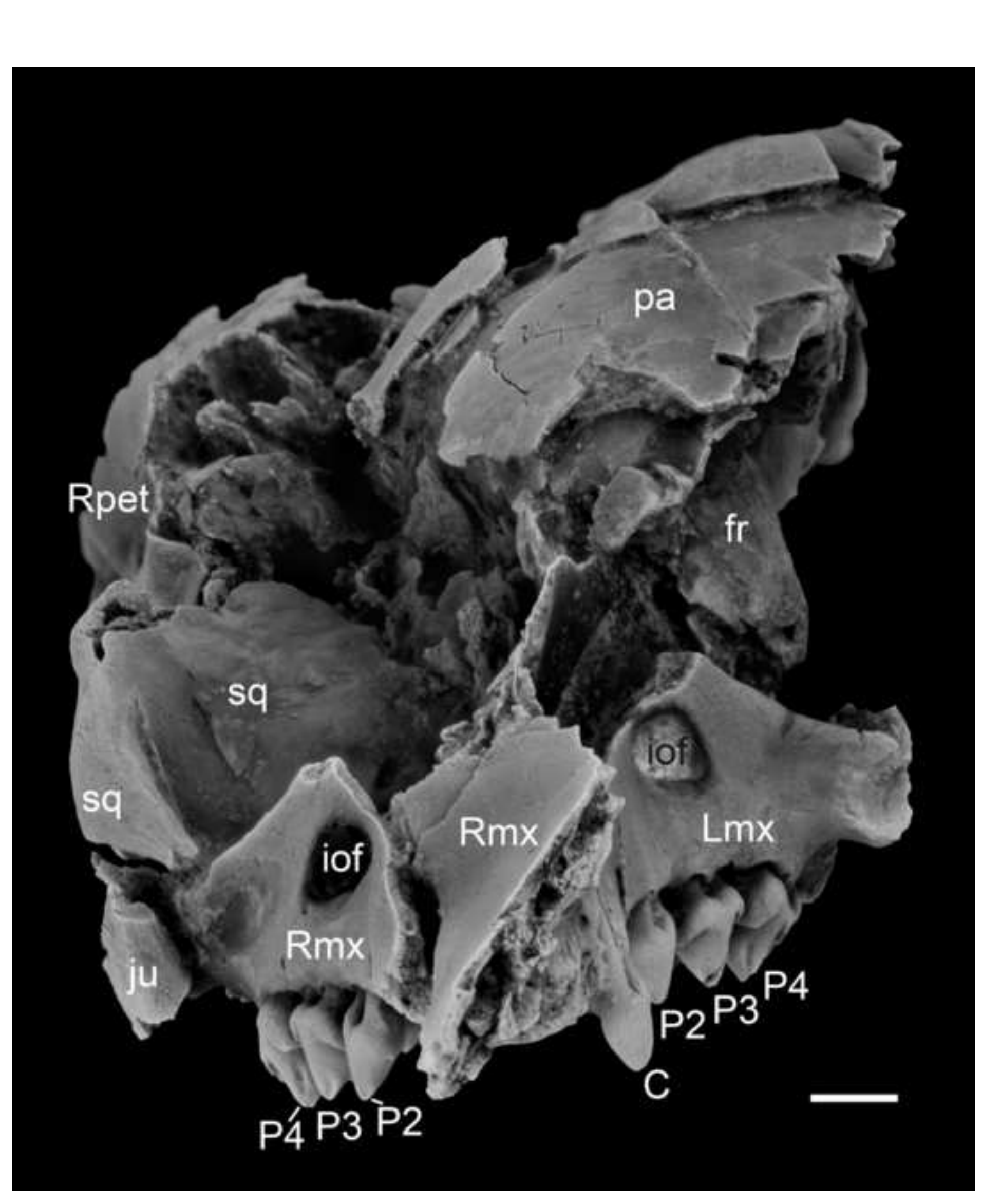

Figure 6

\section{6}

\section{Figure 6}
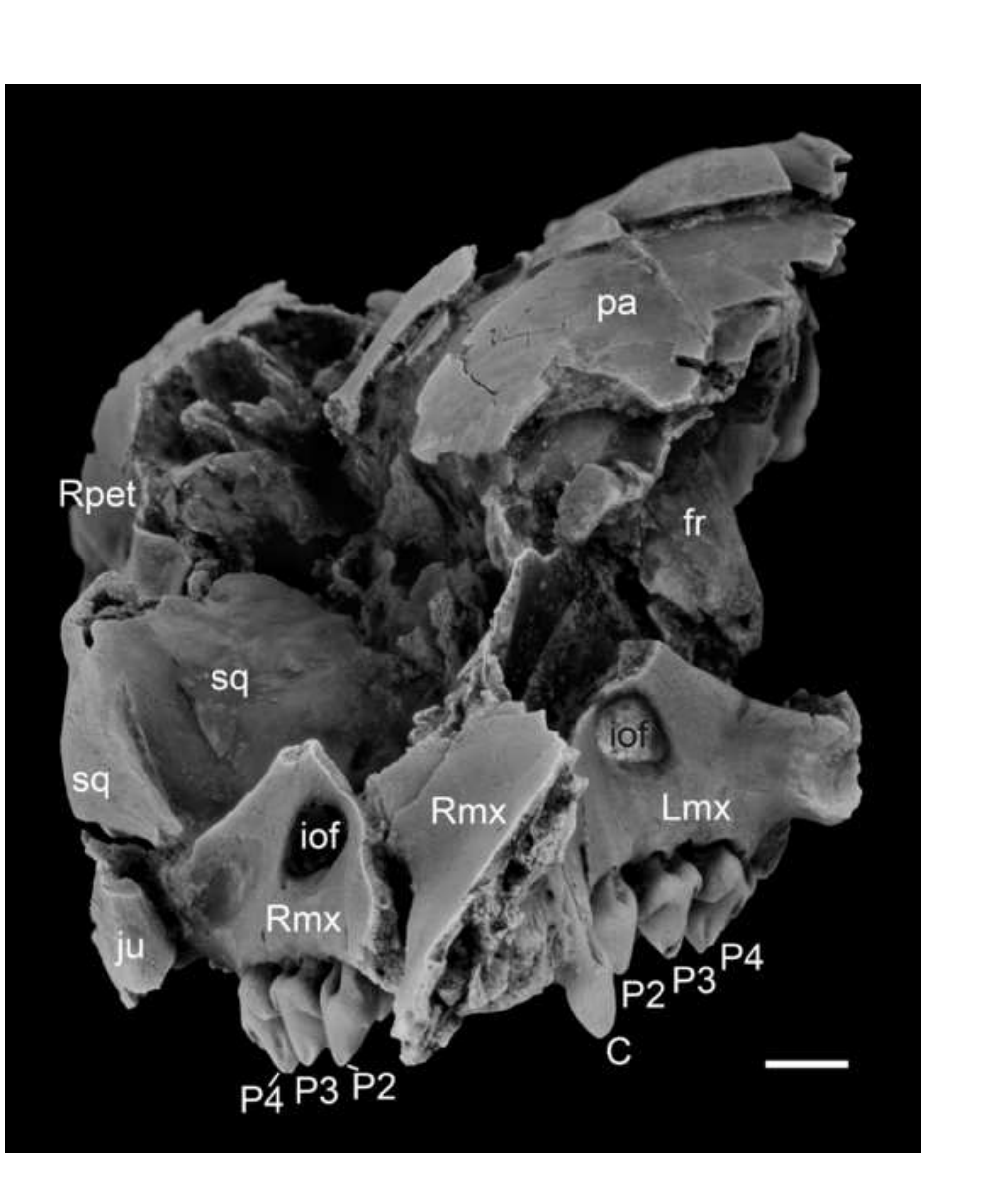

-
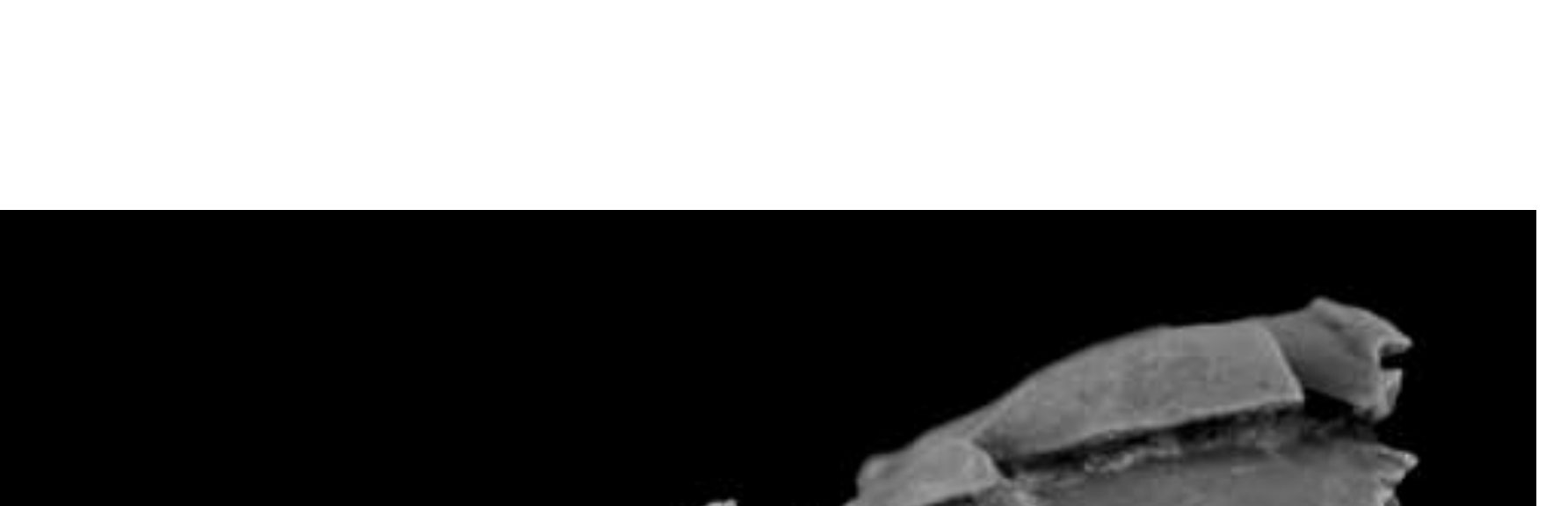

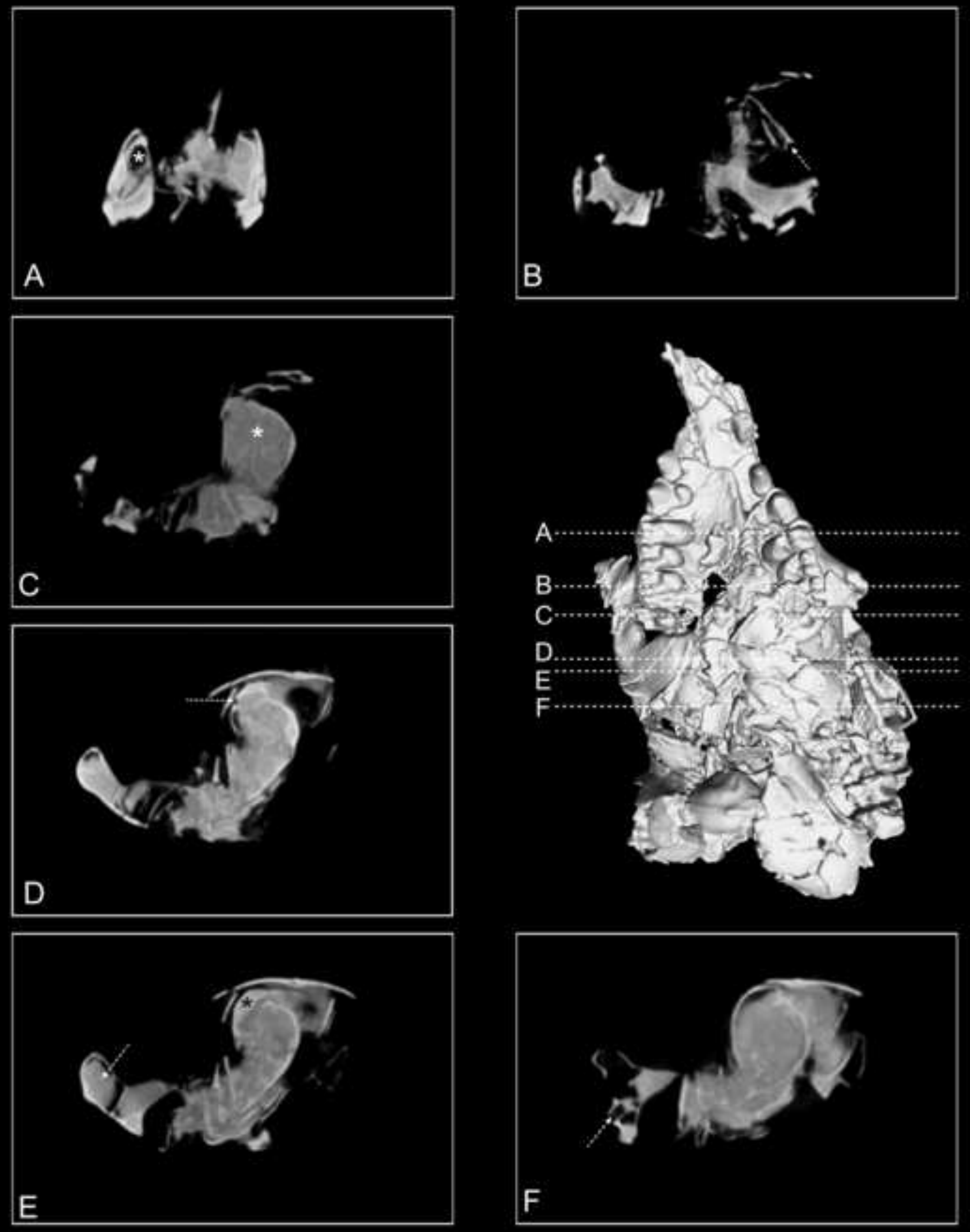

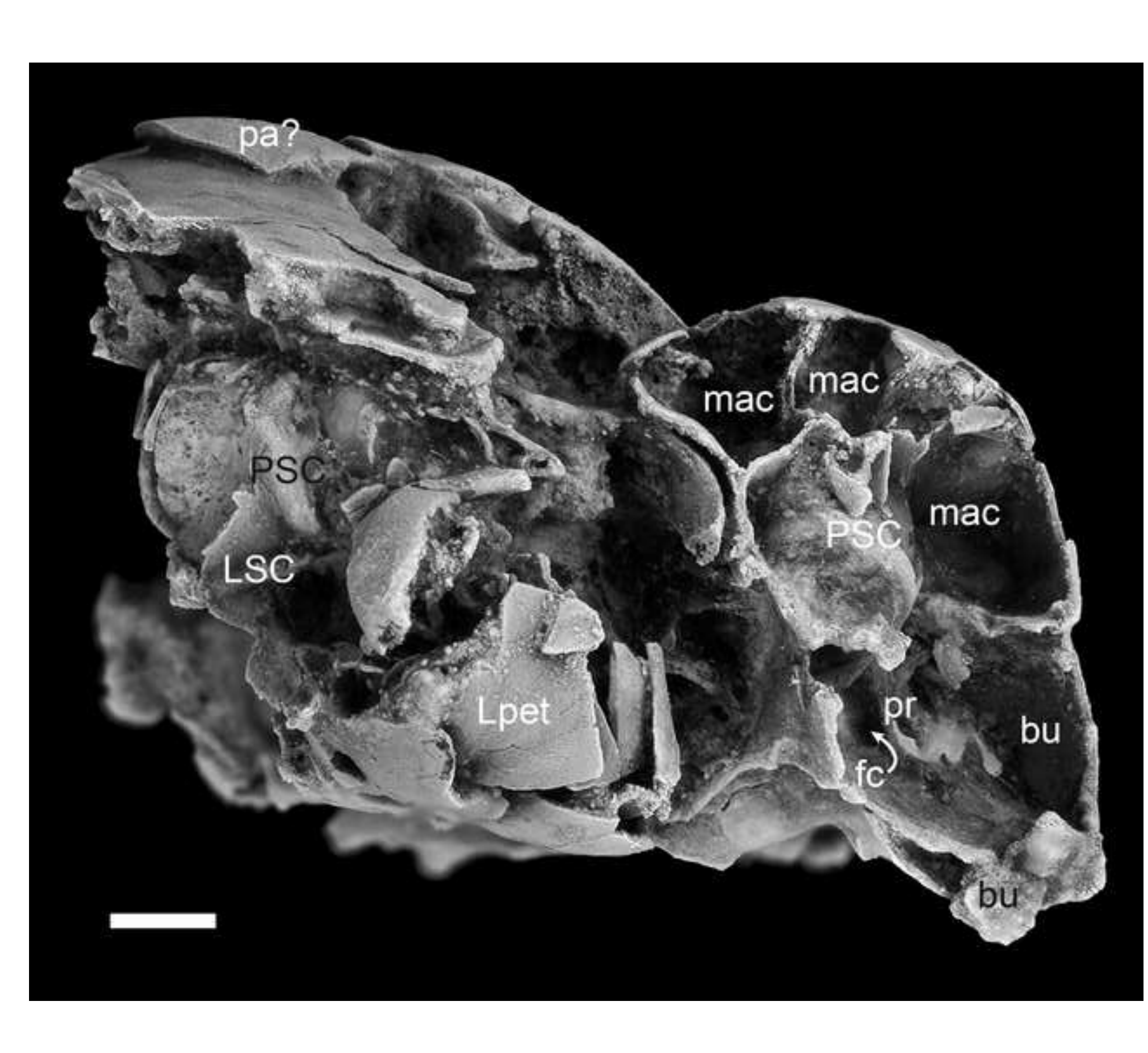

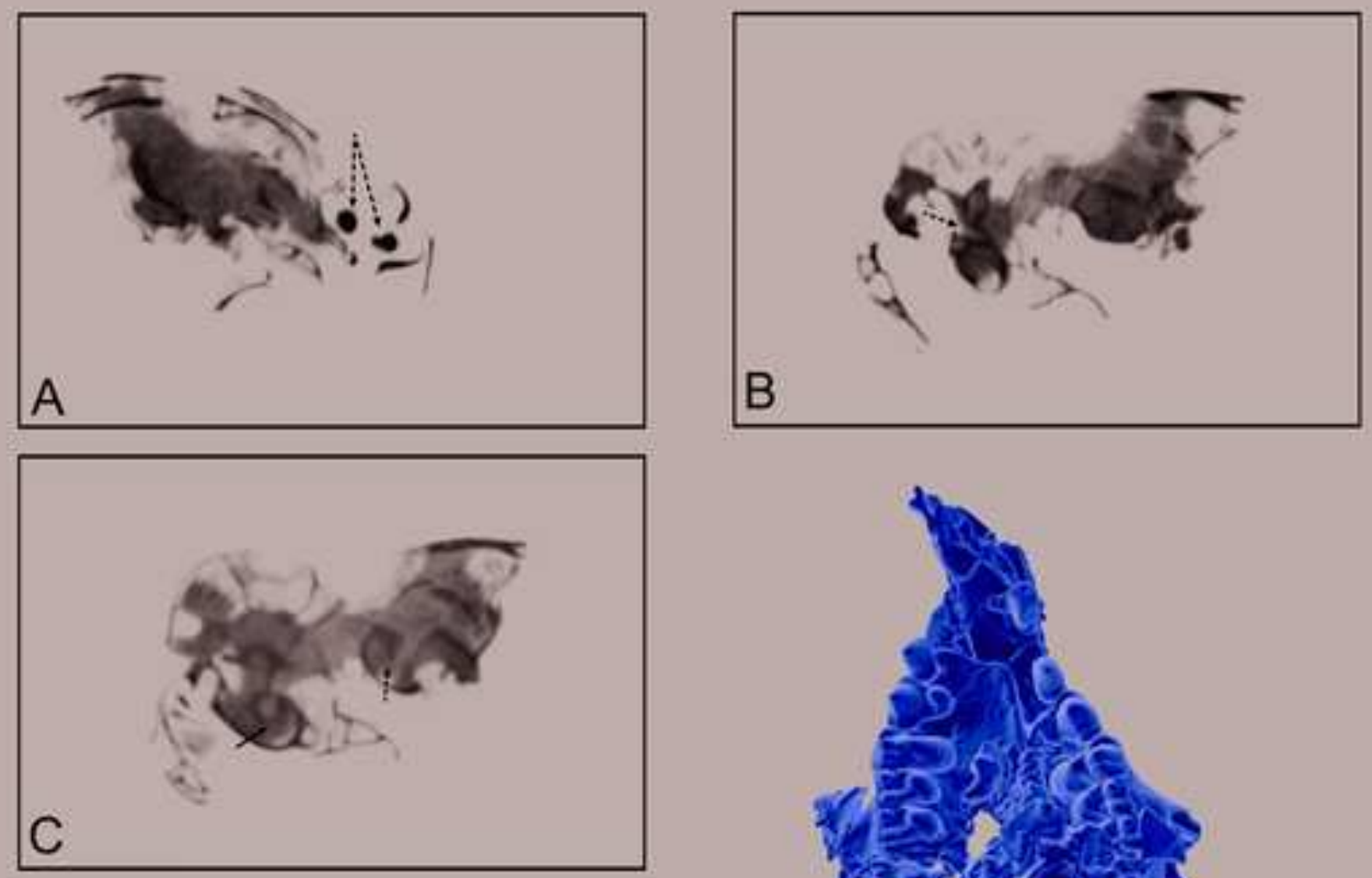

D
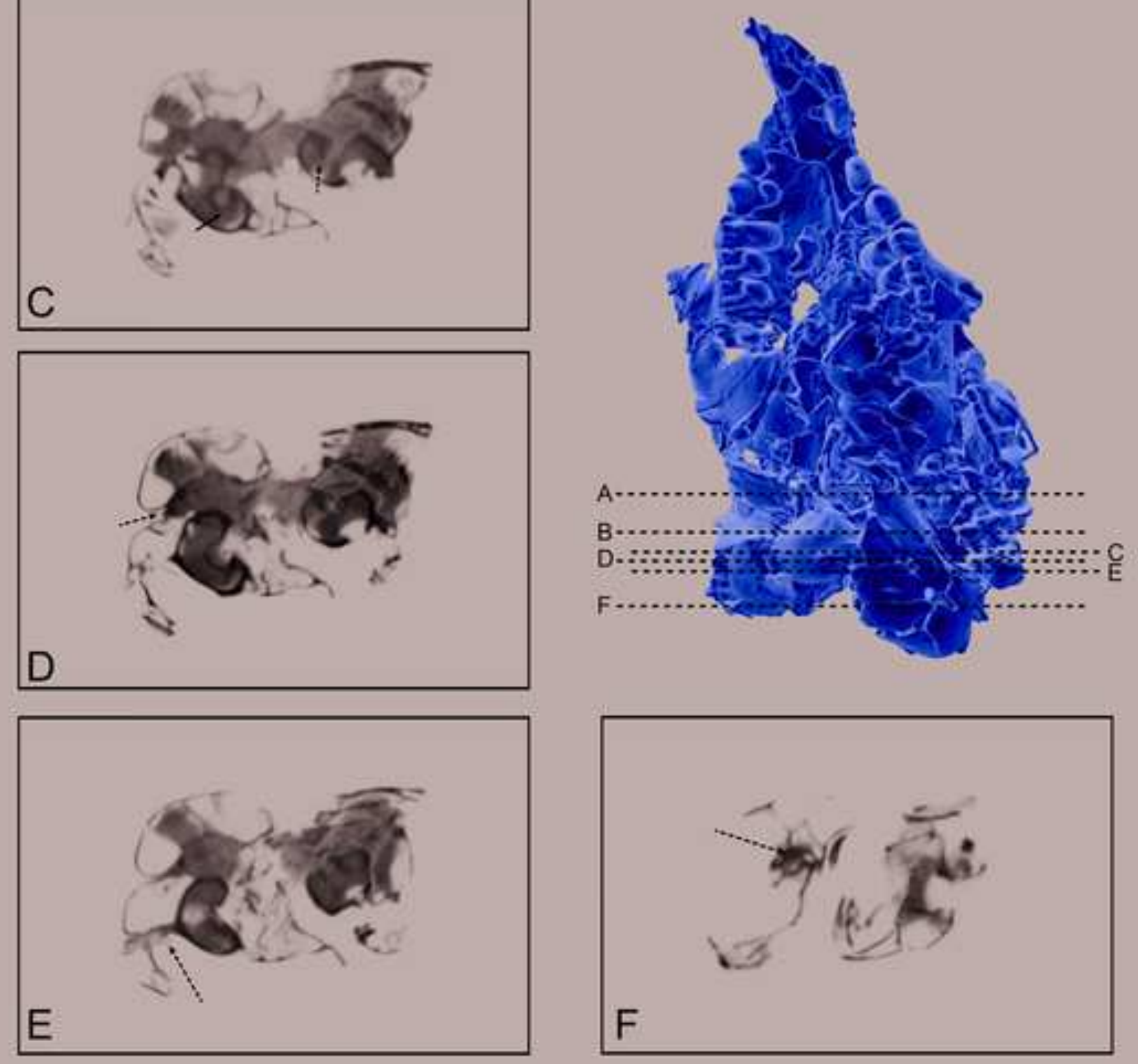


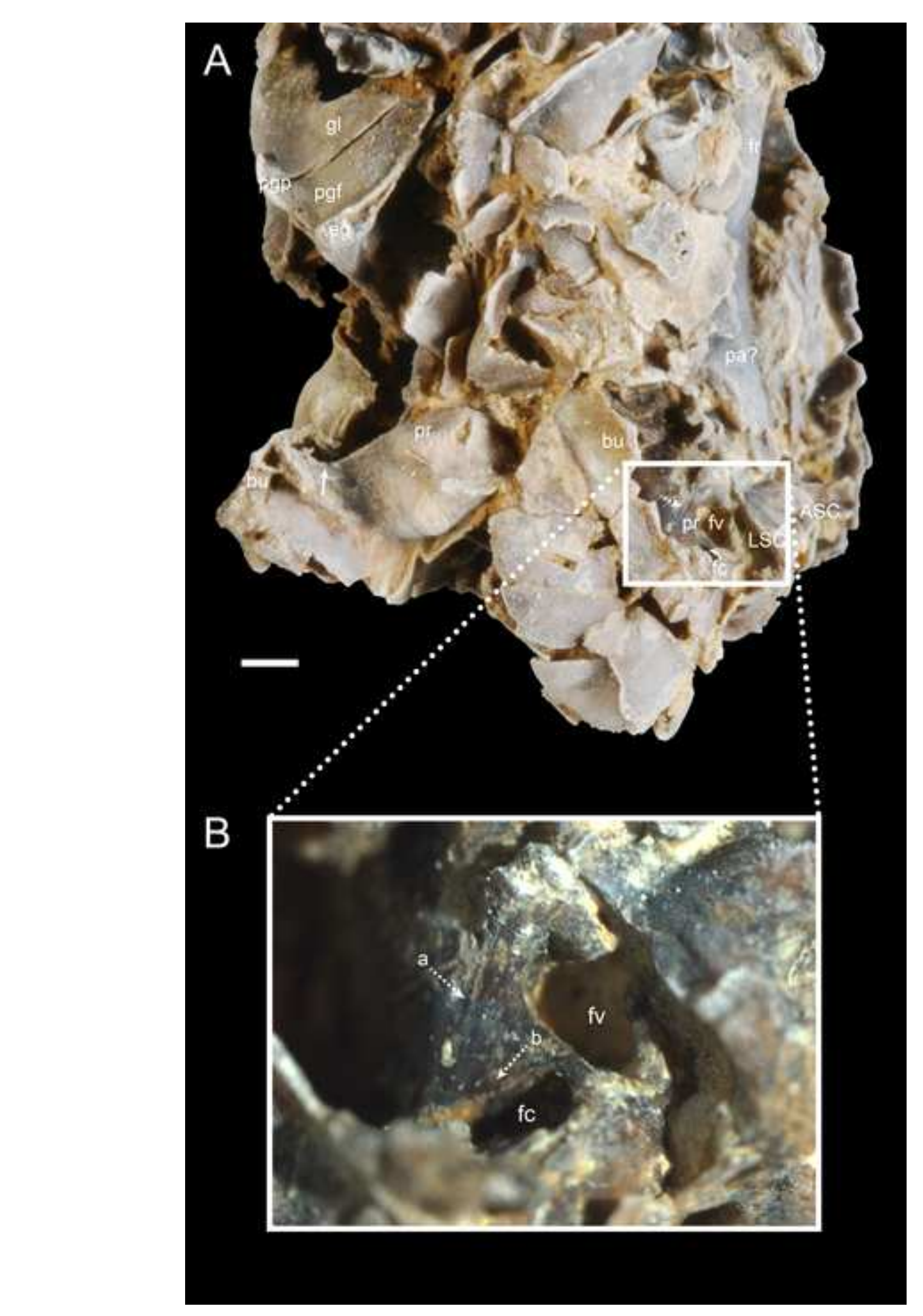

Figure 13

Fure 13
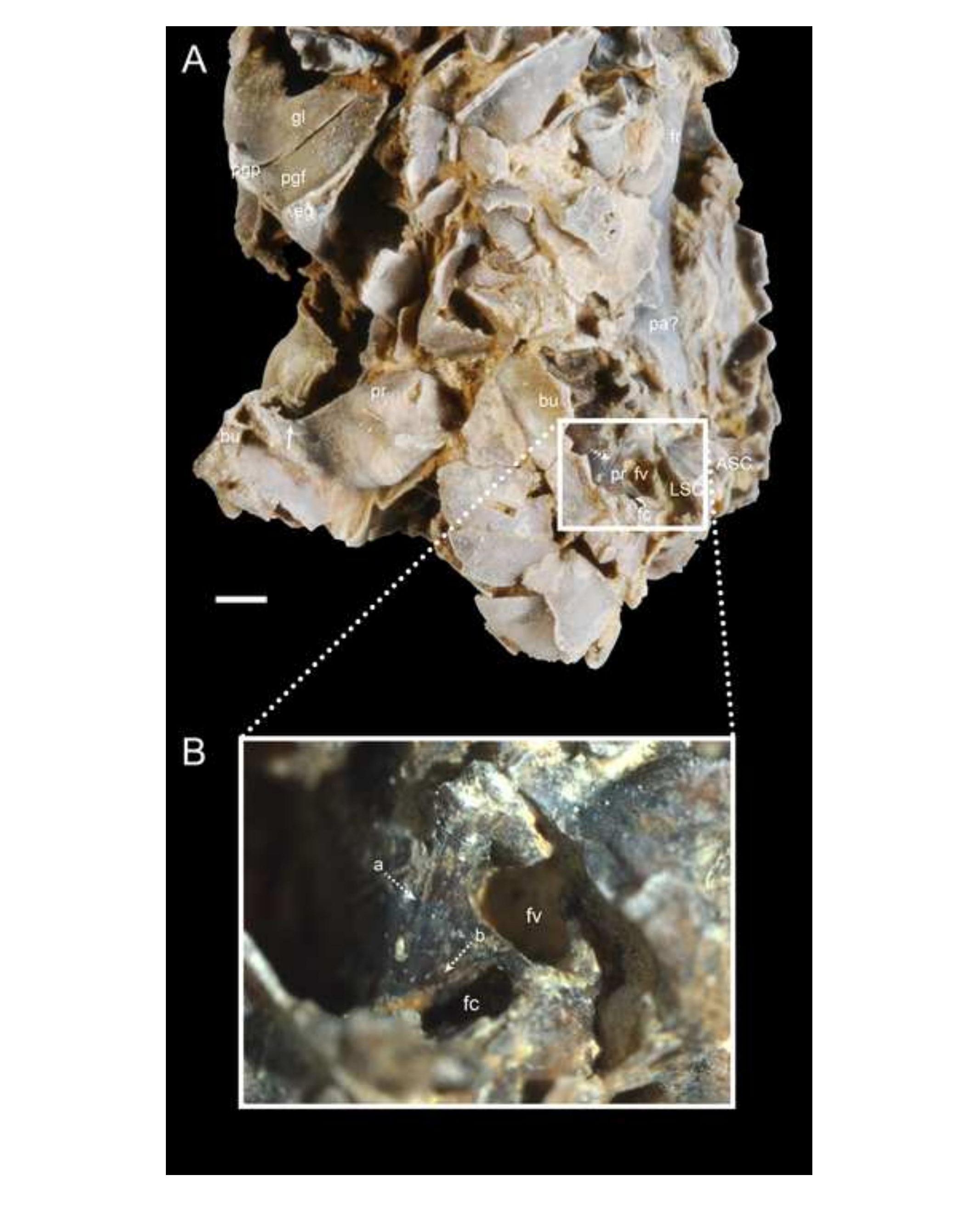

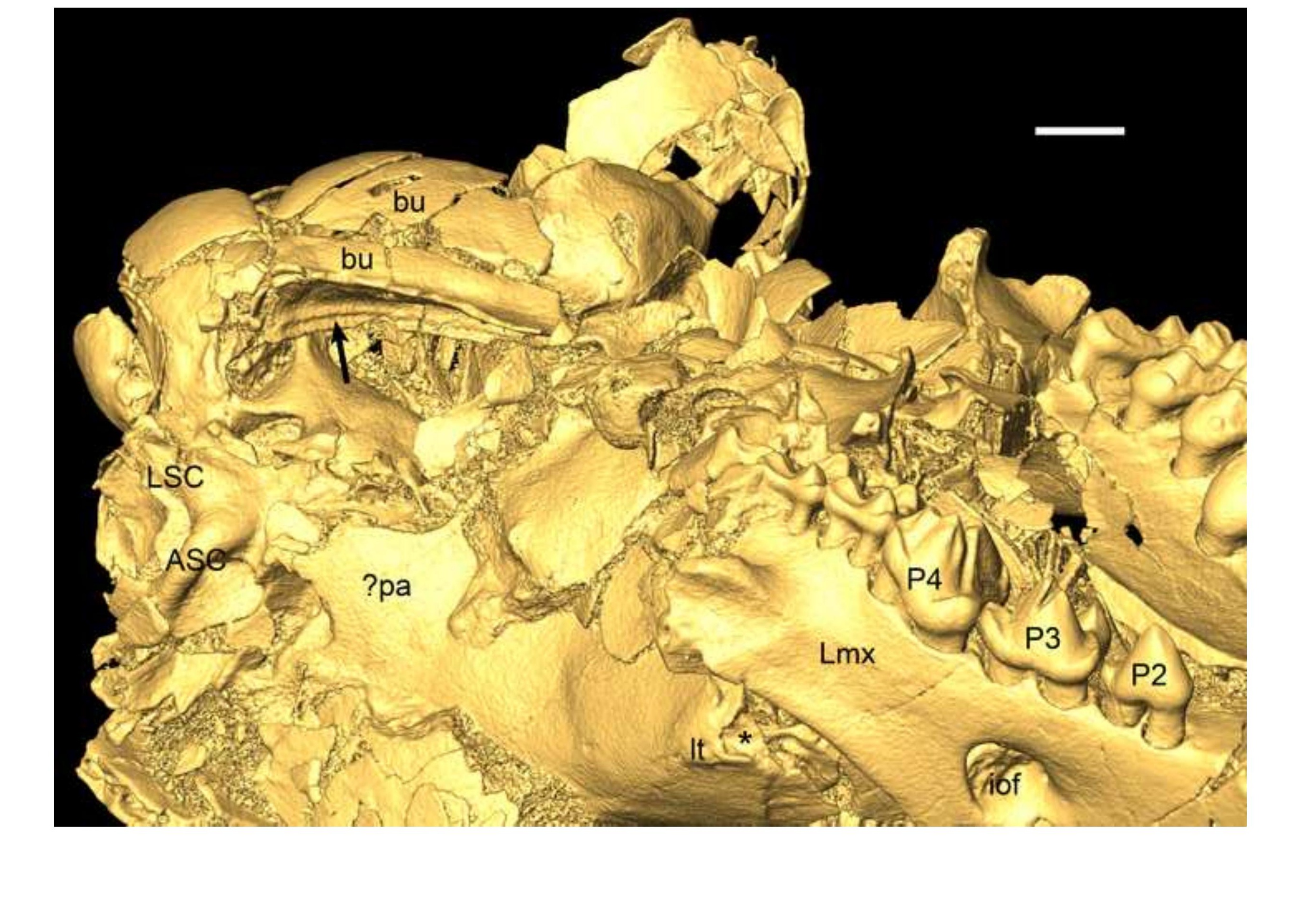

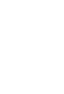

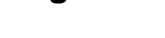

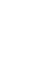



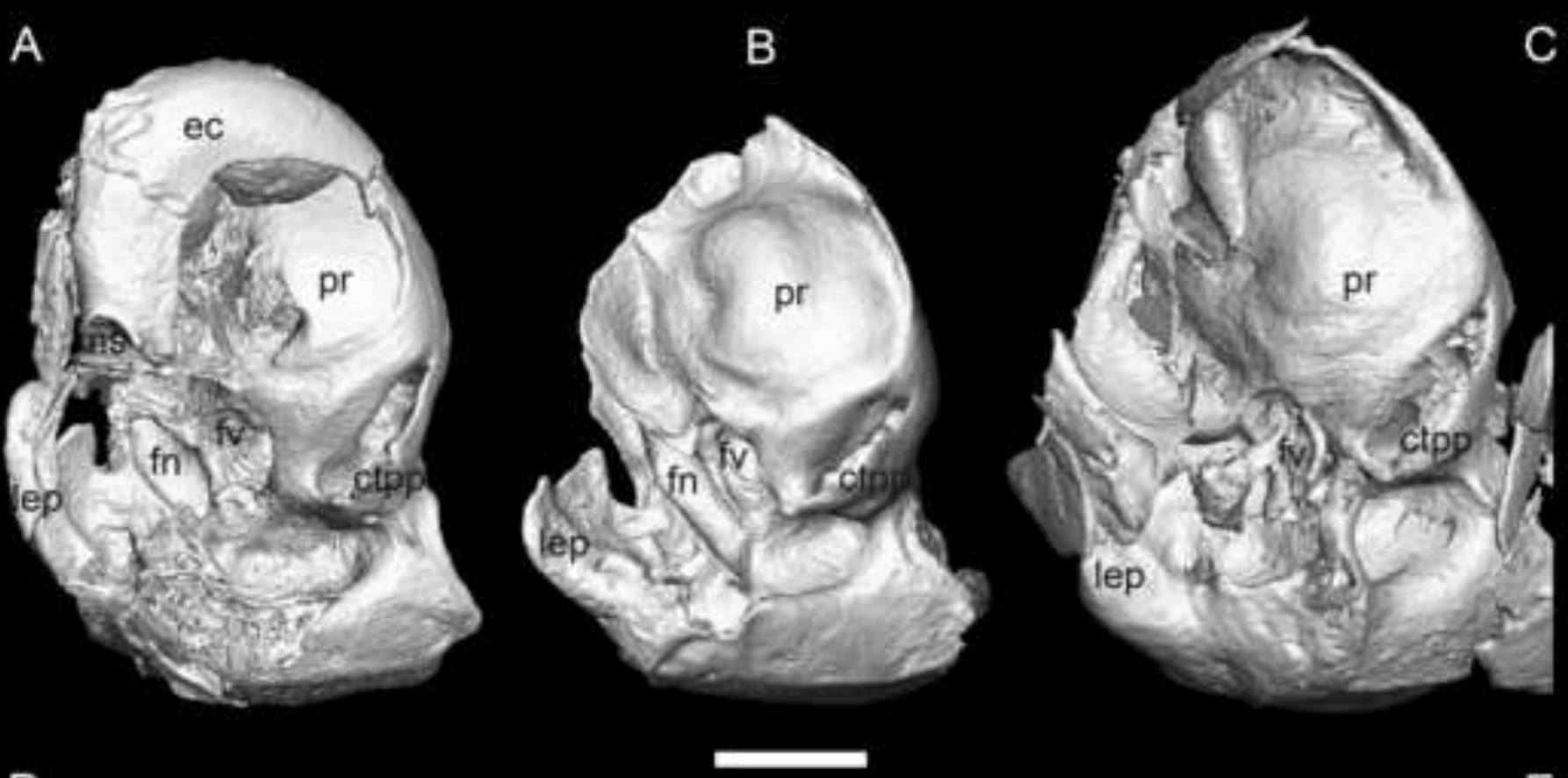

D
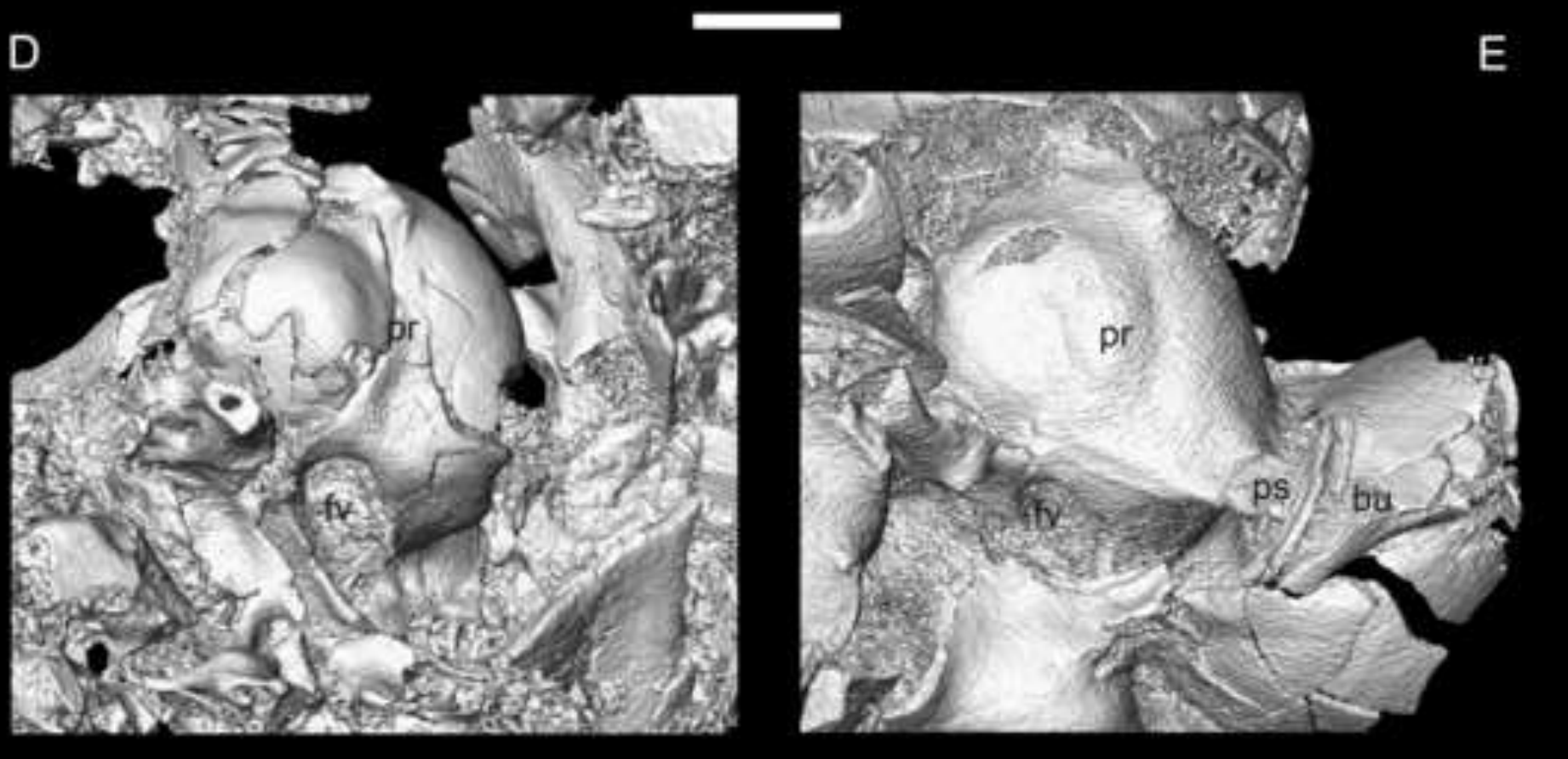

C 
Figure 16
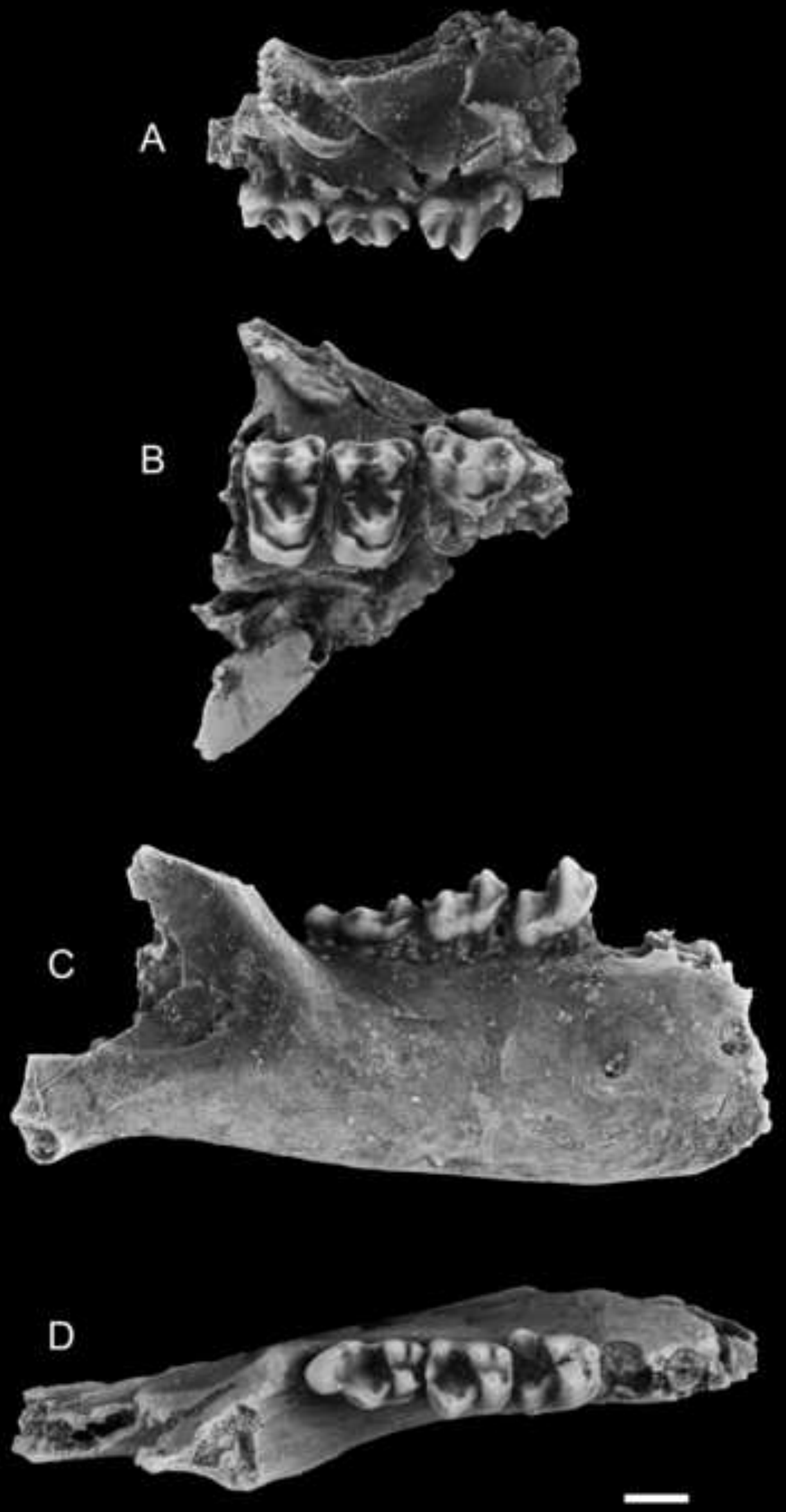
A

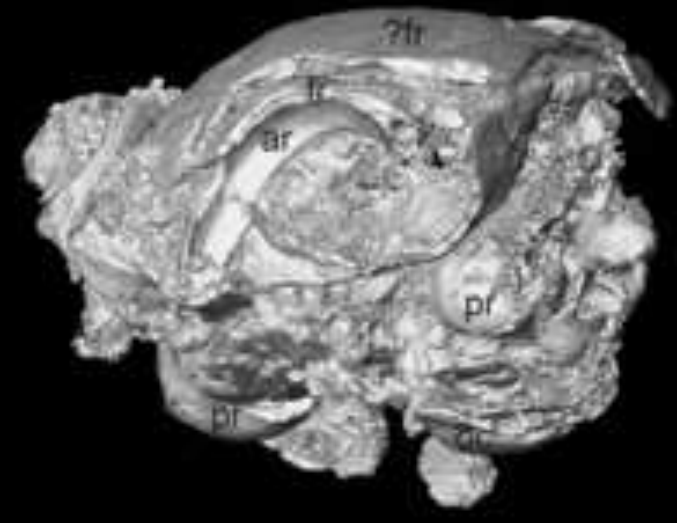

C

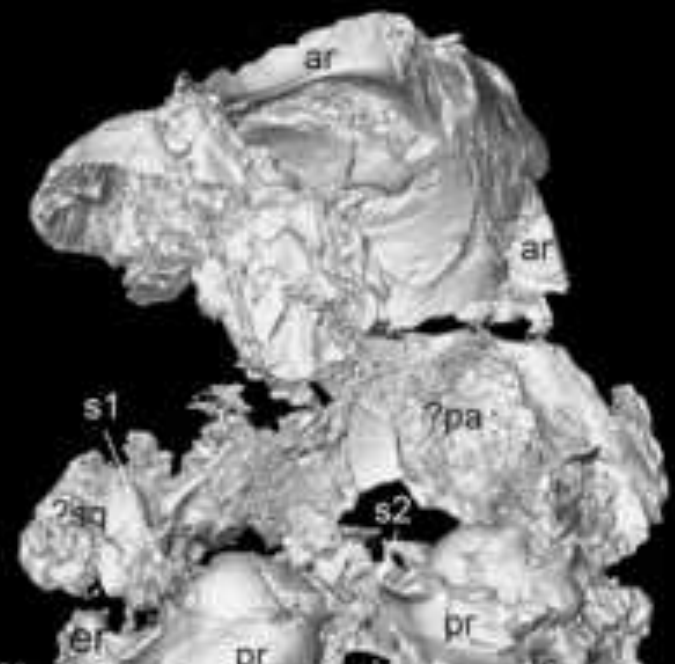

sulcus for facial nerve

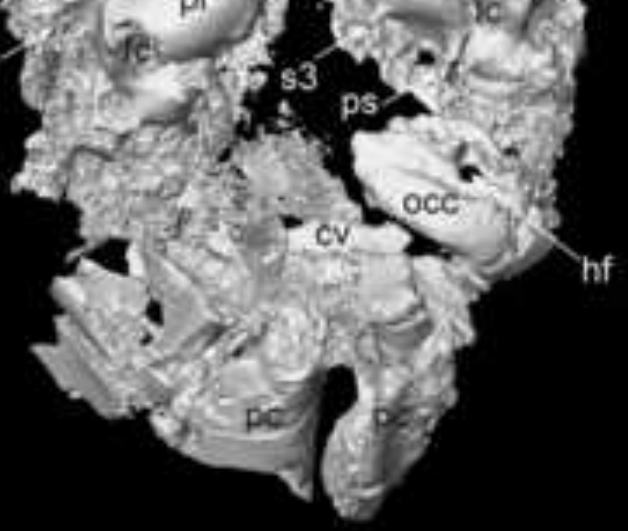

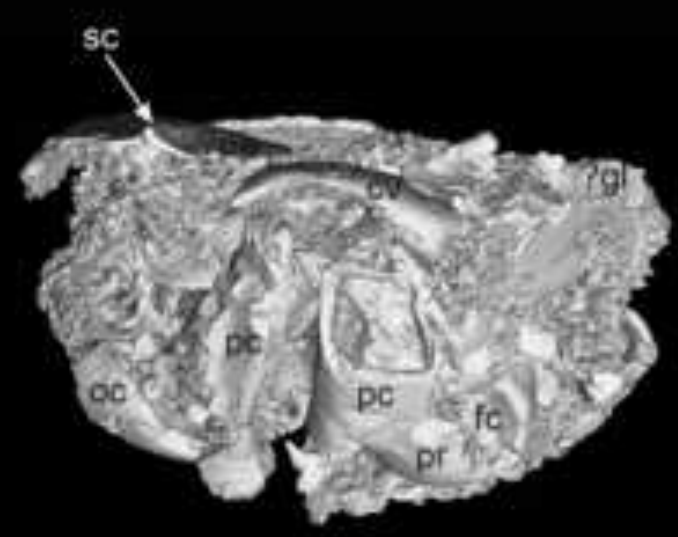
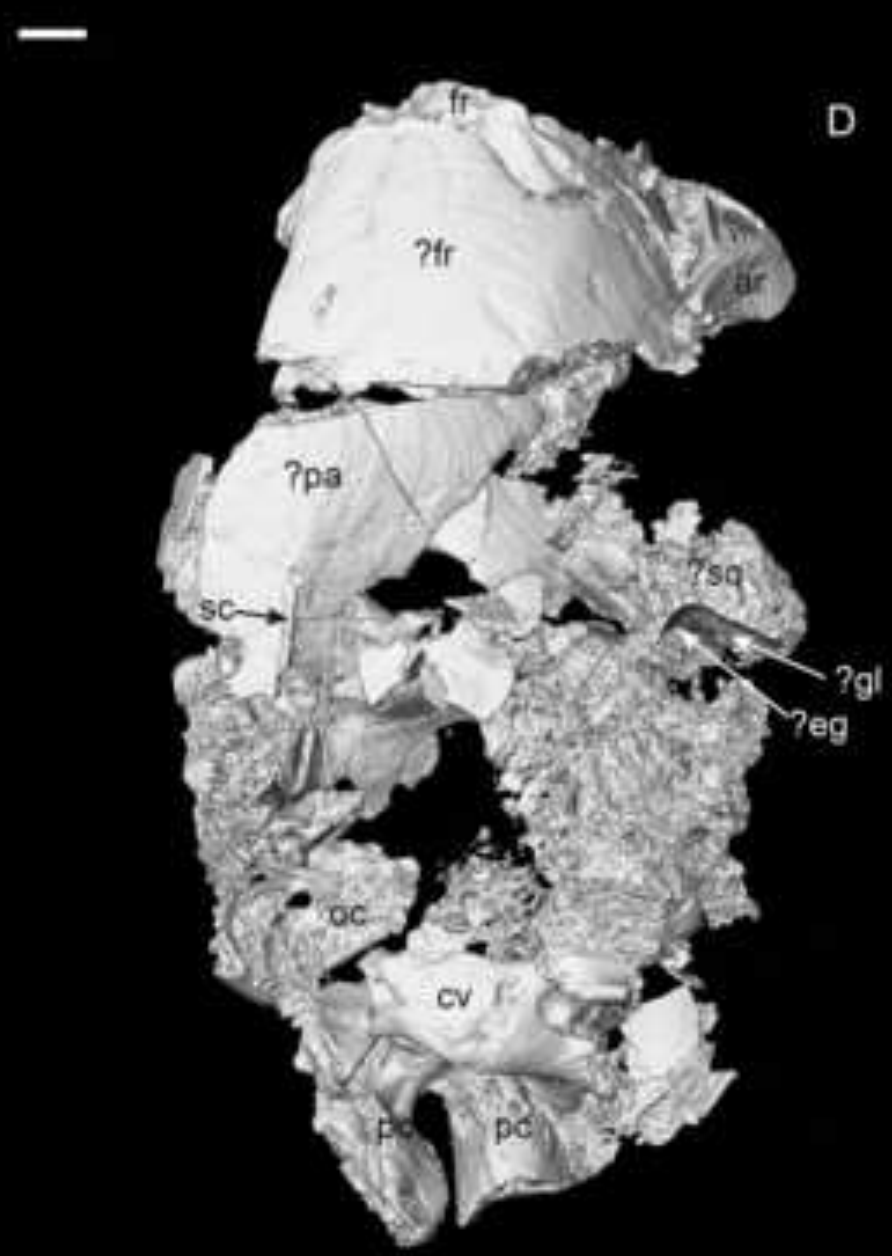
A

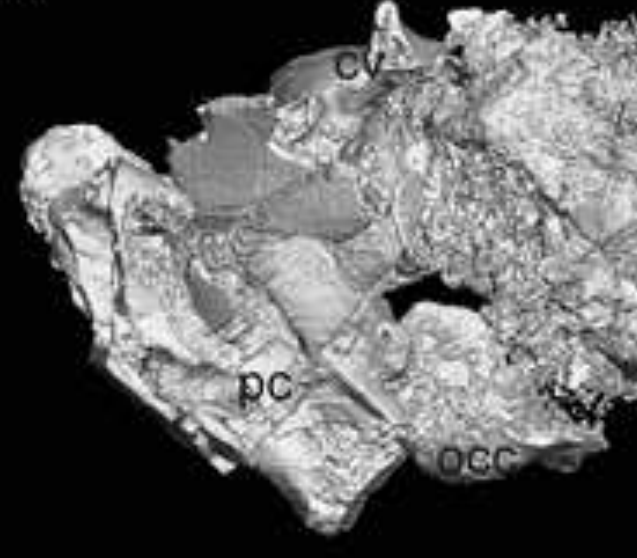

\section{$\downarrow$}

$2 p a$ 6. ?fr $39.75 q$ of 1 asr

B
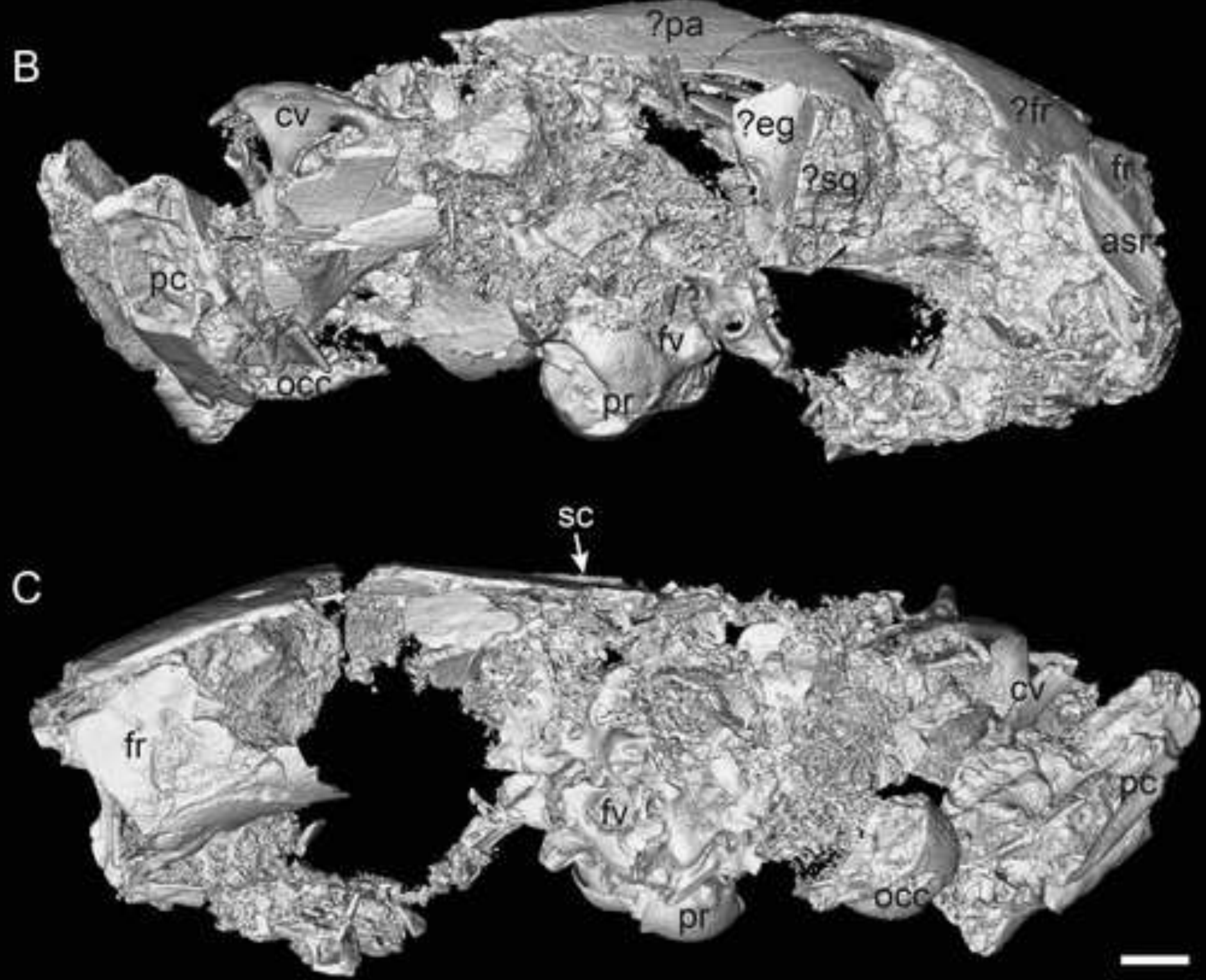

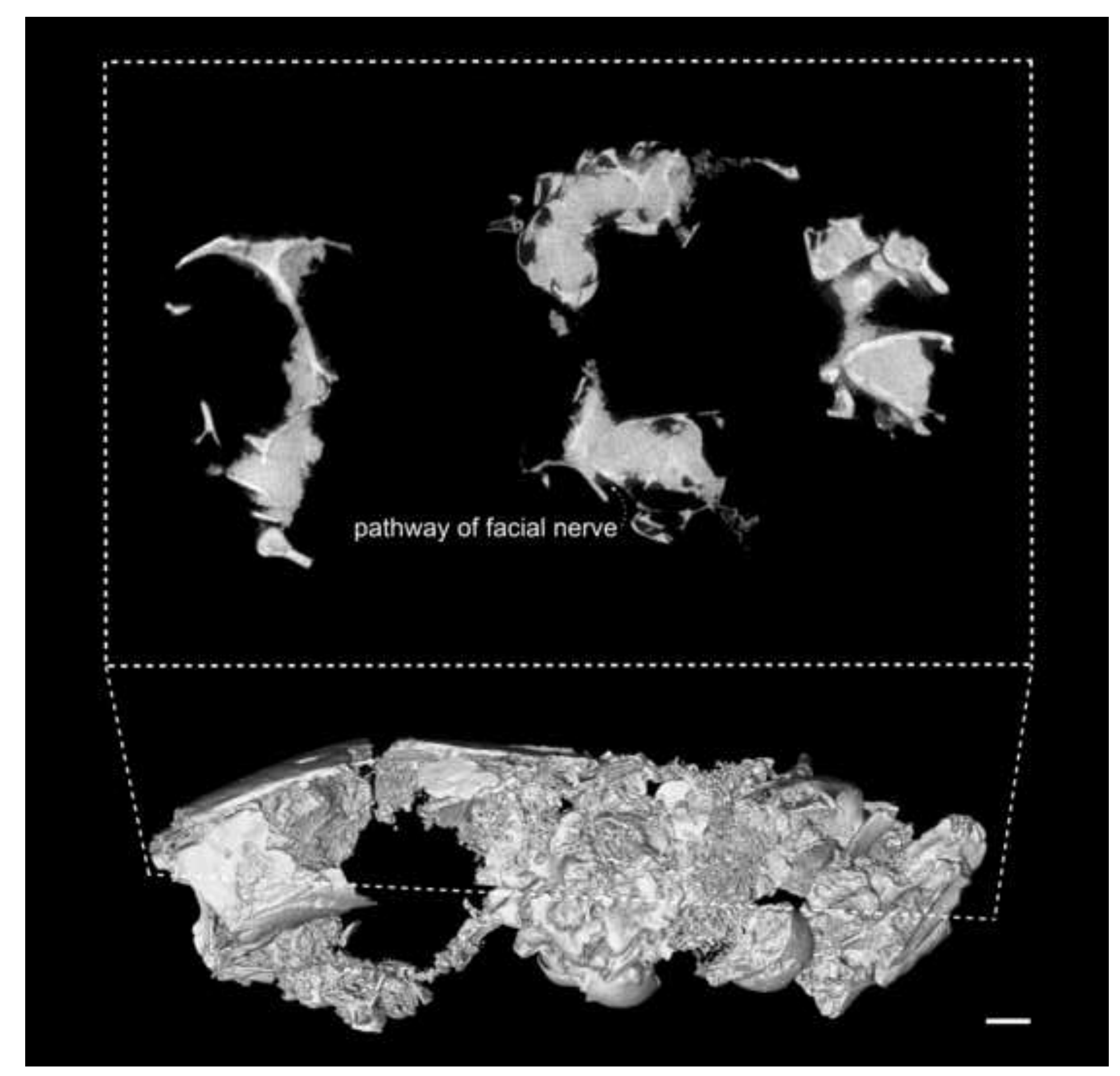

pathway of facial nerve

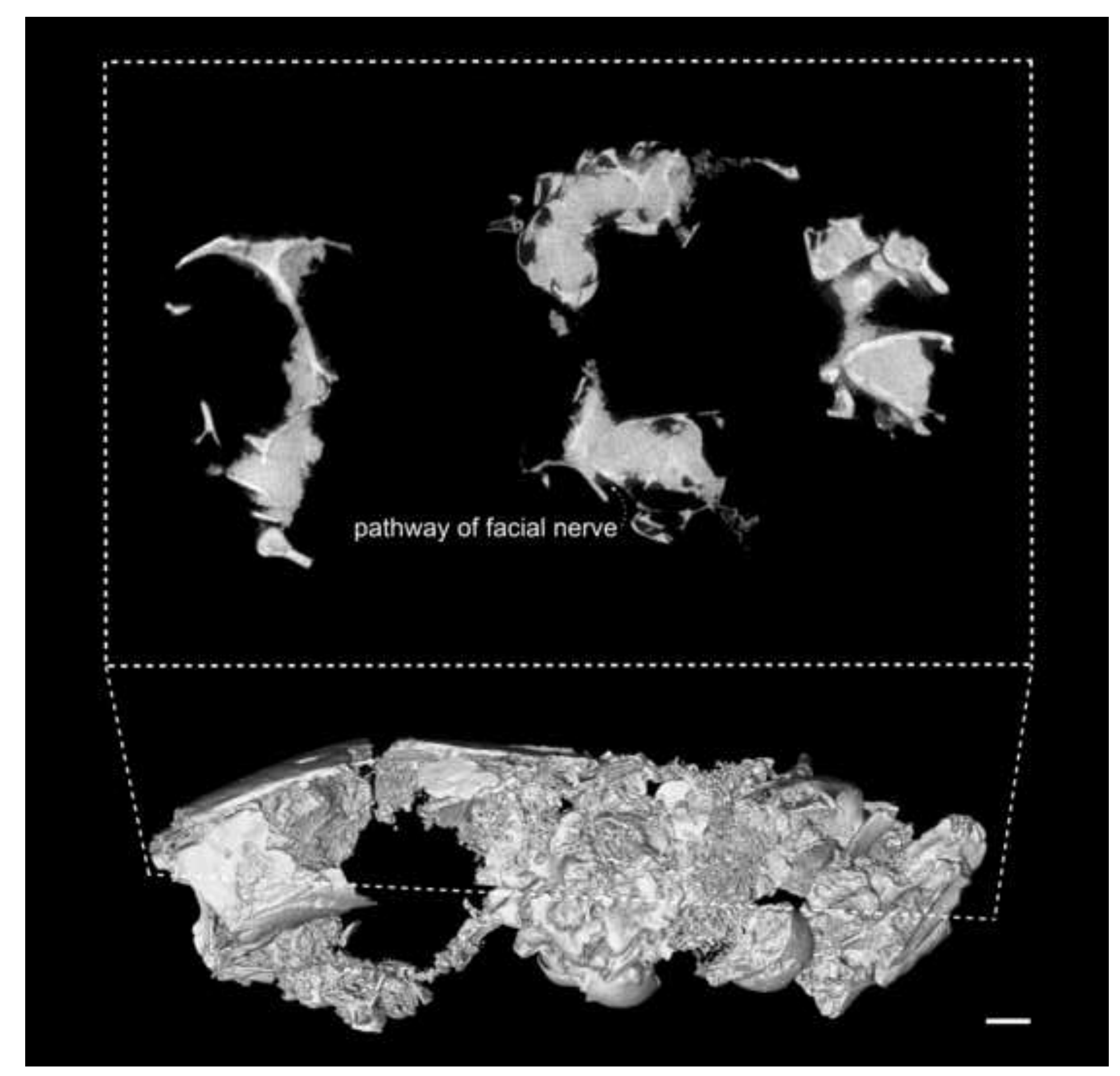



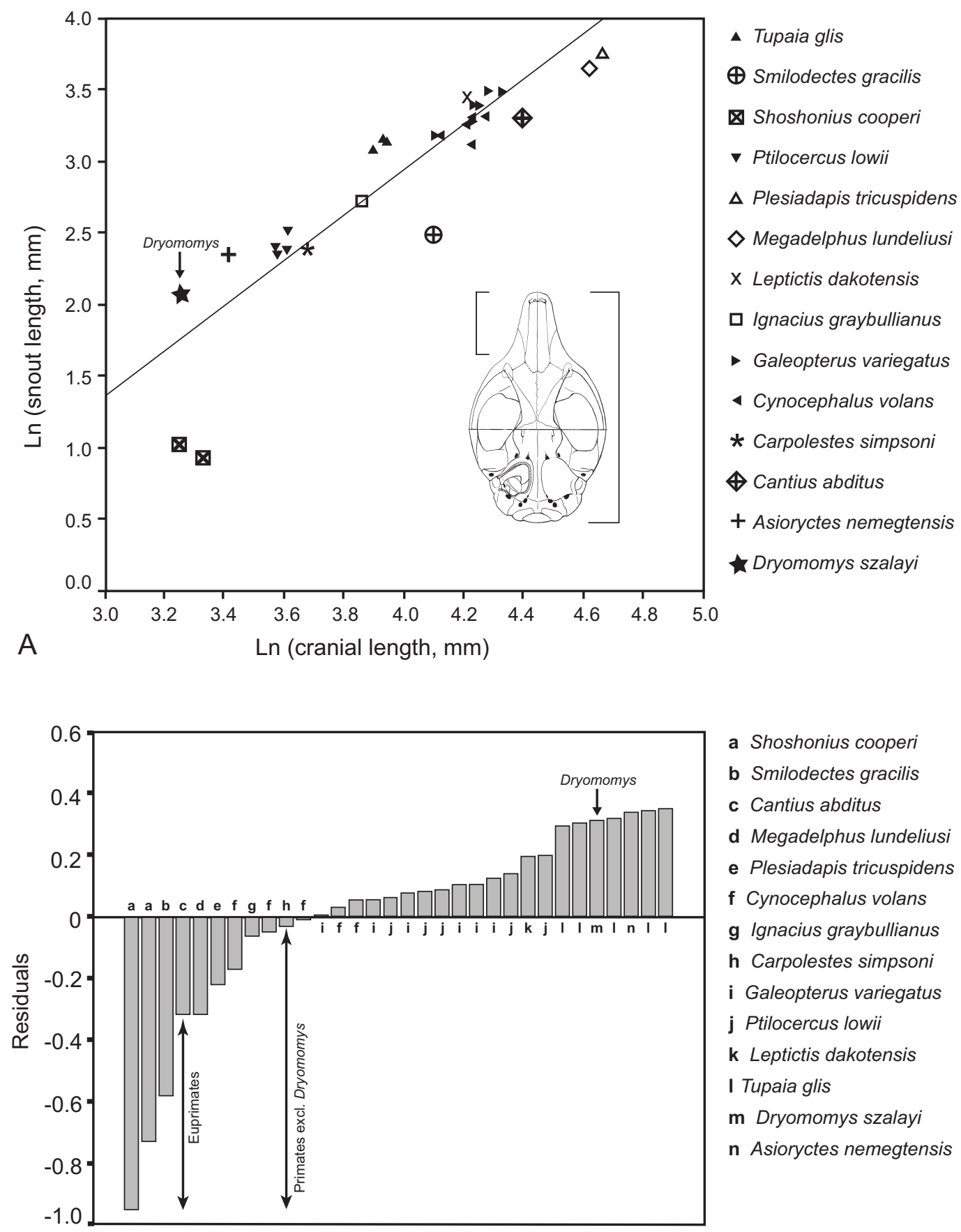

a Shoshonius cooperi

b Smilodectes gracilis

c Cantius abditus

d Megadelphus lundeliusi

e Plesiadapis tricuspidens

f Cynocephalus volans

g Ignacius graybullianus

h Carpolestes simpsoni

i Galeopterus variegatus

j Ptilocercus lowii

k Leptictis dakotensis

I Tupaia glis

m Dryomomys szalayi

n Asioryctes nemegtensis

B 


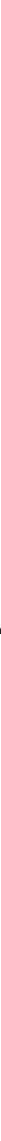


Figure 22

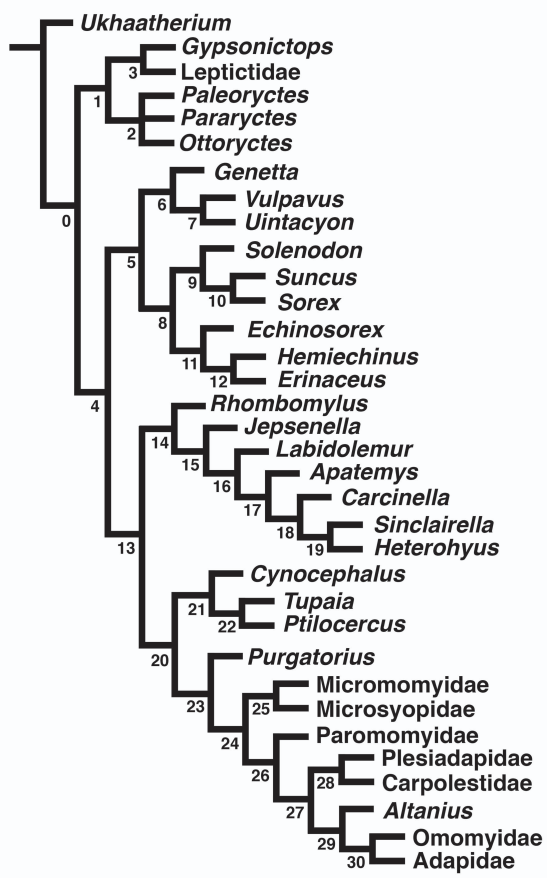

